\title{
Der Durchfluß des Wassers durch Röhren und Gräben insbesondere durch Werkgräben großer Abmessungen
}

von

\author{
Dr. Philipp Forchlieimer \\ Ilofrat, Professor, korr. Mritglied der Akademie \\ der Wigsenschaften in Wien
}

Mit 20 Textabbildungen

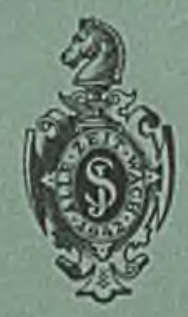

Berlin

Verlag vou Julius Springer

1923 


\title{
Der Durchfluß des Wassers durch
}

\section{Röhren und Gräben insbesondere}

durch Werkgräben großer

\section{Abmessungen}

\author{
von \\ Dr. Philipp Forchheimer \\ Hofrat, Professor, korr. Mitglied der Akndemie \\ der Wissenschaften in Wien
}

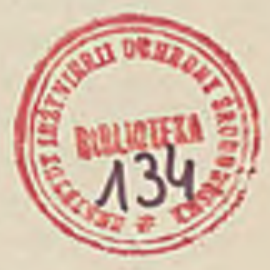

Mit 20 Textabbildungen

$$
\begin{aligned}
& s-g \\
& s-0
\end{aligned}
$$
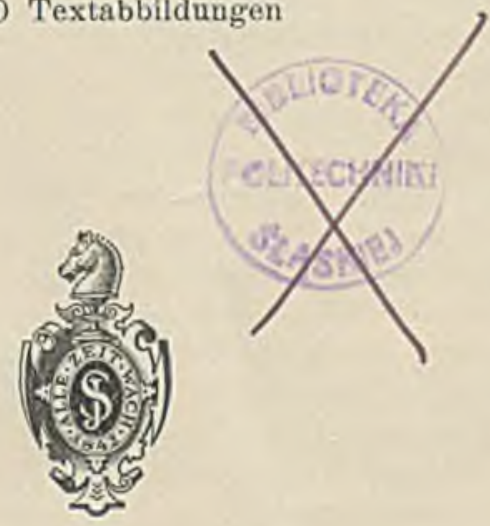

Berlin

Verlag von Julius Springer

1923 
Alle Rechte, insbesondere das der Ubersetzung in fremde Sprachen, vorbehalten.

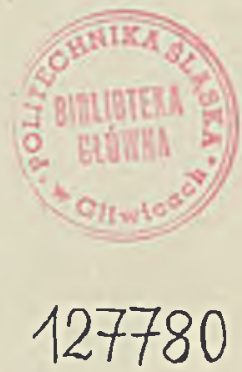




\section{Vorwort.}

Den Anstoß za der vorliegenden Untersuchung bot ein in der "Wusserkraft" voin 15. April 1920 veröffentlichter und zu gleicher Zeit an Fachleute, Unternehmungen und Industriefirmen verschickter "Aufruf zu Beiträgen für Modellversuche und sonstige hydraulische Untersuchungen an großen Kanälen". Fir trug die Unterschrift von Professor Dr.-Ing. Camerer, Prolessor Dantscher, Dr.-Ing. h. c. Ministerialrat v. Hensel, dem Staatskommissar für den Ausbau der Mittleren Isur, Regierungs- und Baurat Krieger, Regierungsbaumeister a. D. Dr. Kümelin, dem Direktol der Landesstelle für Gewässerkunde Oberregierungsrat Sommer' und Geh. Holrat Universitätsprofessor. Dr. Sommerfeld. Ein tragisches Geschick wollte es, daß dieselbe Zeitschrift innerhalb zweier Jahre den Tod von drei Unterzeichnern -.. Dr. Rümelin, Prolessor Camerer und Ministerialrat v. Hensel - beklagen mußte. Ihrer sei hier dankend gedaclut.

Der Aufruf hatte den Erfolg, daß schon im Sommer 1920 mit den Arbeiten begonnen werden konnte. Mir wurde die Aufgabe ubertragen, mich mit der Strömung in großen Kanälen zu befassen, oder enger umschrieben, das Gefälle anzugeben, das für die Förderung einer gegebenen Wassermenge durch ein Gerinne von großen Abmessungen erforderlich ist. Dic Beantwortung dieser Frage bildet daher den Hauptinhalt der nachstehenden Schrift. Ferner befasse ich mich in ihr, weil hierüber der deutschen Fachwelt zur Zeit keine gesammelten Daten vorliegen, mit dem Durchfluß durch Betonröhren, sowie auch mit dem Fließen im allgemeinen.

Zur Vornalıme eigener Messungen wurden mir die nötigen Mitte] zur Verfugung gestellt; auch wurde ich in meinen Arbeiten von verschiedenen Seitell gefördert, wie dies aus der Schrift selbst hervorgeht. Insbesondere stand mir die bayerische Iaandesstelle für Gewässerkunde lilfreich bei. Spender und Förderer hatten vor allem die Sicherung und Verbesserung der hydraulischen Grundlagen für den Entwurf von Wasserkraltwerken im Auge. Demselben praktischen Ziel trachtete ich bei dieser meiner Arbeit näher zu kommen.

Wien, im Oktober 1922.

Ph. Forchheimer. 


\section{Inhaltsverzeichnis.}

. Bemerkungen uber die bisherigen Messungen ...... 1

2. Zur Bauweise der Fließformeln . . . . . . . . . . 5

3. Beziehung zwischen geschlossenen und offenen Gerinnen . 7

4. Der Exponent $\nu$ des Gefälles bei Fließen in Rohren . . . 8

5 . Die Exponenten $\nu$ und $\mu$ und der Koeffizient $\lambda$ für das Fließen in Betonröhren . . . . . . . . . . . . . . . 11

6. Der Exponent $v$ des Gefäles bei Fließen in festen offenen Gerinnen . . . . . . . . . . . . . . . 15

7. Der Exponent $v$ des Gefälles bei Fließen in Erdbetten . . 19

8. Der Exponent $\mu$ des Profilradius bei Fließen in festen offenen Gerinnen . . . . . . . . . . . . . . 20

9. Der Koeffizient $\lambda$ für Gerinne mit fester Wandung . , , 26

10. Der Exponent $\mu$ des Profilradius bei Fließen in Erd- und Kiesbetten . . . . . . . . . . . . . . . 37

11. Der Koeffizient $\lambda$ für Erd- und Kiesbetten . . . . . . 43

12. Die Beziehung $\mathrm{z} w$ ischen $\lambda$ und $n$. . . . . . . . 50 


\section{Bemerkungen über die bisherigen Messungen.}

Soweit es sich um die Bewegung des Wassers in künstlichen Gerinnen handelt, sind heute noch die wichtigsten Beobachtungen jene, die Darcy einleitete, dann Bazin durchführte und mit noch einigen fremden 1865 unter dem Namen Recherches experimentales sur l'écoulement de l'cau dans les canaux découverts ${ }^{1}$ ) veröffentlichte. Im ganzen sind es 50 mit Nummern bezeichnete Versuchsreihen, von welchen die Nummern 1 bis 17,19 bis 27 und 32 bis 35 für die erwähnte Frage von Bedeutung sind ${ }^{2}$ ), während bei 18 anscheinend Fehler unterliefen, 28 bis 31 sich auf Profilradien von nur 1 bis $3 \mathrm{~cm}$ beziehen und die zumeist in Erdstrecken veranstalteten Serien 36 bis $50 \mathrm{zu}$ große Unregelmäßigkeiten ${ }^{3}$ ) aufweisen, um in Betracht zu kommen. Der bleibende Wert der Arbcit Bazins beruht darauf, daß er mit Genauigkeit vorging, regelmäßige Gerinne von vorgeschriebenen Querschnitten und Oberflächen herstellen ließ, für gleichmäßigen Durchfluß sorgte, das Gefälle durch Messung der Tiefenlage des Wasserspiegels unter Querlatten bekannter Höhenlage feststellte und Längenprofile des Spiegels aufnahm. Nicht ausreichend in Anbetracht der Bedürfnisse der heutigen Technik waren die Querschnittsabmessungen seiner Kunstgerinne, denn deren größte Tiefe betrug bei dreieckigem Querschnitt und der tiefsten Stelle in der Mitte $0,995 \mathrm{~m}$, bei Halbkreisquerschnitt 0,720 , welche Tiefen aber nur Ausnahmen bildeten. Bazin faßte seine Ergebnisse in einer Fließformel (seiner älteren) zusammen, die, wenn $J$ das Spiegelgefälle, $R$ den Profilradius in $\mathrm{m}, U$ dic Geschwindigkeit in $m / \mathrm{sec}$ bedeutet,

$$
\frac{R J}{U^{2}}=0,00015\left(1+\frac{0,03}{R}\right) \text { bis } 0,00028\left(1+\frac{1,25}{R}\right)
$$

oder

lautet.

$$
U=\frac{81,65}{\sqrt{1+\frac{0,03}{R}}} \sqrt{R J} \text { bis } \frac{59,8}{\sqrt{1+\frac{1.25}{R}}} \sqrt{R J}
$$

1) Paris, Mémoires présentés par divers sarants à l'académie des sciences, 59 (1865).

7) Vgl. Abb. 6, S. 22. 3) Vgl. Abb. 7, S. 23.

Forchheimer, Durchfluß des Wassers. 
Bald nach den Recherches wurden in Europa Humphreys und A b bots Mississippi-Messungen bekannt, welche damals für genau galten. Sie bewogen die Schweizer Ingenieure Ganguillet und Kutter ${ }^{1}$, ihren bekannten Ausdruck

$$
U=\frac{23+\frac{1}{n}+\frac{0,00155}{J}}{1+\left(23+\frac{0.00155}{J}\right) \frac{n}{\sqrt{R}}} \sqrt{R \cdot J}
$$

aufzustellen, der sich wesentlich dadurch kennzeichnet, daß nach ihm, je nachdem der Profilradius $R \geqslant 1 \mathrm{~m}$ ist, die de Chézysche Zahl $c$ des Ausdruckes $U=c \sqrt{R J}$ mit wachsendem Gefälle $J$ ab-oder zunimmt. Trotz ihrer Umständlichkeit und dem Mißstande, daß die Rauheit $n$ im Zähler als unbenannte Zahl und im Nenner als Längenwurzel erscheint, hat in Deutschland, England und Amerika Gl. (2) ihre große Verbreitung gefunden, so daß die Rauheiten $n$ den meisten mit Wasserbauentwürfen beschäftigten Ingenicuren geläufig sind. Dabei stand das Beobachtungsmaterial, welches Ganguillet und Kutter dem Bazinschen linzufügen konnten, an Güte beträchtlich hinter diesem zurück. Die alten Mississippi-Messungen, die nur mit Doppelschwimmern vorgenommen worden waren, sind seitdem als ungenau erkannt worden ${ }^{2}$ ) und die eigenen Schwimmermessungen Kutters waren als solche mit einer gewissen Unsicherheit behaftet. Einen wesentlichen Vorzug der Bazinschen Versuche hatte ferner, soweit sie Gerinne betrafen, ihre Vornahme in ganzen Serien gebildet, während der neve Stoff fast ganz aus Einzelbestimmungen bestand. Dagegen schien eine bessere Eignung für natürliche Gewässer ein Vorzug der Schweizer Formel zu sein.

Genaue tiefreichende Aufnahmen in großen Flüssen mit Hilfe von Woltmannflügeln nahmen ein Jahrzehnt später ihren Anfang mit denen Harlachers in Böhmen. Andere Länder folgten schrittweise nach, und so wurden die Durchflüsse mehr und mehr bekannt. Diese wollto man in erster Linie erfahren und höchstens nebenbei den Zusammenhang zwischen Geschwindigkeit, Profilradius und Gefälle aufhellen, welch letzteres daher häufig gar nicht erhoben wurde. Zudem ging man bei der Gefällsbestimmung meist unzweckmäßig vor. Während das Wasser eines Stromes, wie unbeirrt durch örtliche Störung, gleichmäßig dahinfließt, ist das Gefälle örtlich und zeitlich beständigem Wechsel unterworfen. Einen Beleg hicrfür bieten z. B. die Messungen, die in der

1) 7. österr. Ing.- 1. Arch.-Ver. 21 (1869), S. 6, 46.

2) E. Beyerhaus bemängelt besonders die Gefällebestimmung, Zentralbl. Bauy. 41 (1921), S. 168. Er betont mit Recht, daß3 überhaupt das Gefälle der Energielinie, welche die Anderung der Geschwindigkeitshöhe bcrücksichtigt, vom Spiegelgefälle oft stark abweicht. Über dic Mängel der Doplelschwimmer 5. H. Bazin, Ann. Ponts Chauss. (6) $7^{1}$, S. 554, 1884 . 
Donau an der Kaiser-Tranz-Joseph-Brücke bei Wien 1898 und in Stein 1897 stattfanden, und mit Einführung des örtlichen Gefälles als Gefälle $J$ für die Geschwindigkeit zu den Ausdrücken ${ }^{1}$ )

$$
U=20 \pm R^{0,39}, J^{0,67} \mathrm{bzw} .1,37 R^{0,71}, J^{0,09}
$$

führten. Dieses Gefälle $J$, welches damals in Wien zwischen 0,000439 und 0,000576 und in Stein zwischen 0,00045 und 0,0013 schwankte, kann offenbar nicht als das für eine gleichförnige Bewegung zutreffende gelten. Den schlagenden

Nachweis, daß dem auf liurzer Strecke herrschenden Gefälle nur eine geringfügige Bedeutung für dic mittlere Geschwindigkeit zukommt, lieferte Ende 1919 Ministerialrat von Hensel durch Ver-
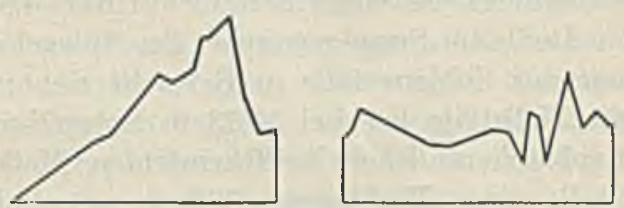

Abb. 1. Wasserstand und Gelälle in Firgental. anstaltung von Messungen mit dem - dic augenblicklichen Gefälle lehrenden - Albrechtschen Gefällsmesser. Insbesondere sei auf zwei Messungen ${ }^{2}$ ) im Trostberger Kanal hingewiesen, wo trotz fast gleichem Querschnitt, Durchfluß und Wandzustand in Firgental im Mittel $J=0,00012$ und bei der Mußenmühle $=0,000437$ be. stimmt wurde, wobei allerdings bemerkt werden muß, daß die schwankende Turbinenbelastung in Werkgräben besonders starke Gefällswechsel verursachen kann.

Dic Figuren links geben die Wasserstände, die Figuren rechts die Gefälle während der Messung an. Jeder mm länge
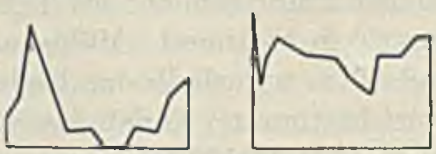

Abb. 2. Wasserstand und Gefälle in Firgental.

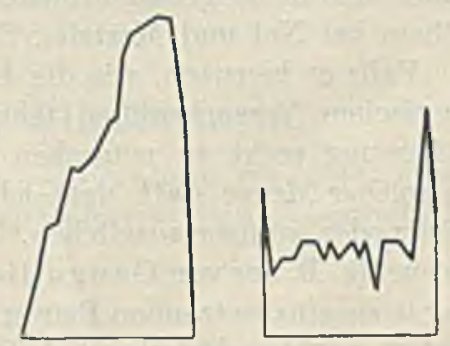

Abb. 3. Wasserstand und Gefälle an der MuBenmiihle. stellt $1 / 3$ Minuten dar. Links sind die Höhen in $3 / 4$ der wirklichen Größe aufgetragen, rechts bedeutet $1 \mathrm{~mm}$ Höhe $0,0133 \%$ Gefällc. Es war in Firgental am 2. XII. 1919 (Abb. 1) der Querschnitt $F=41,4 \mathrm{~m}^{2}$, der Profilradius $R=2,17 \mathrm{~m}$, der Durchflu $\beta Q=48,4 \mathrm{~m}^{3} / \mathrm{sec}$, am 3. XII. (Abb. 2) $F=41.4 \mathrm{~m}^{2}, R=2,17 \mathrm{~m}, Q= \pm 7 \mathrm{~m}^{3} / \mathrm{sec}$, !an der MuBenmühle $\mathrm{am}$ 3. XII. 1919 (Abb. 3) $F=42 \mathrm{~m}^{2}, R=2,17 \mathrm{~m}, Q=49,3 \mathrm{~m}^{3} / \mathrm{scc}$.

Ursprünglich glaubte man aber, wie gesagt, daß das Gefülle auf recht kurzer Strecke zu erheben sei. So wurde es in Österreich Vorschrift, bei kleinen Wasserläufen das Gefälle einer Strecke von der Länge gleich

1) Hydrographischer Dienst in Österreich, Jahrb. d. hydrograph. Zentralbureaus $6=1898$ (Wien 1900), Donaugebiet S. 304, 308, 311 .

$\left.{ }^{2}\right)$ Unveröffentlicht. S. auch Wasserkraft. Heft 18, 1919. 
der dreifachen Flußbreite zu messen $\left.{ }^{1}\right) ; 2 / 8$ der Strecke sei vom Meßquerschnitt stromauf, $1 / 3$ stromab zu nehmen, obwohl doch in Flüssen nach Boussinesq der Abflußvorgang von unten beherrscht wird.

Heute ist man bedacht, gleichförmige Flußstrecken aufzusuchen. Früher war das weniger der Fall. So mag es zur Kennzeichnung der Wandlung unserer Ansichten von Interesse sein, die 1907 veröffentlichten Angaben der schweizerischen Behörde ${ }^{2}$ ) aufzuzählen und anzudeuten, warum sie trotz sorgfältiger Erhebungen des Durchflusses nur ausnahmsweise einen Schluß auf das Widerstandsgesetz zulassen:

Dohle in Simplontunnel: der Spiegel war so wellig, daß der Bericht nur das Sohlengefälle in Betracht zieht; Zuleitungskanal Rheinfelden: die Meßstelle lag bei $55,73 \mathrm{~m}$ Spiegelbreite nur $190 \mathrm{~m}$ unterhalb des Grobrechens; Rhein bei Rheinfelden: MLßquerschnitt an etwas verengter Stelle eines Flußbogens $300 \mathrm{~m}$ unterhalb der Untergrabenmündung; Tavernbach: unregelmäßiger Bach; Rhone bei Zenhäusern: unregelmäßiger Fluß; Simme: bei 17,6 m Spiegelbreite wurde das Gefälle nur längs $20 \mathrm{~m}$ bestimmt. Mühlebach in Burgdorf: Meßquerschnitt anscheinend $10 \mathrm{~m}$ unterhalb der Radstube, Spiegelbreite $3,7 \mathrm{~m}$, Gefälle längs $20 \mathrm{~m}$ bestimmt; Kanal des Elektrizitätswerkes Aarau: Gefälle längs $200 \mathrm{~m}$ zu 0,000120 bestimmt, brauchbar; Impianto idraulico di S. Giovanni Lupatoto: der Bericht sagt, daß wegen Schwankungen das Gefälle sich nicht genau ermitteln ließ; Sitter-Tunnel: wertvolle Serie; Rhein bei Nol und Mastrils: Schwimmermessungen.

Falls es hiernach, wie die Beispiele zweier Länder zeigen, an systematischen Versuchsreihen fehlte und die Genauigkeit der Gefällsbestimmung recht zu wünschen ließ, so fanden dafür Einzelmessungen in solcher Menge statt, daß sich bei deren Zusammenfassung die Fehler mehr oder weniger ausglichen. So war es möglich, bei Wahl einer Fließformel (z. B. der von Ganguillet und Kutter) diese durch Bestimmung der in sie einzusetzenden Beiwerte (in diesem Falle die Rauheit $n$ ) brauchbar zu machen. Deren willkürliche Wahl hörte auf, als man für die Flüsse mit beweglichem Bett zu den Formeln ohne Rauhigkeitsziffer vorschritt. Wieder war es neben der kritischen Auswahl der Beobachtungen in erster Linie das Heranziehen solcher in großer Zahl - zu vielen Hun. derten - durch welches man zur Lösung zu kommen trachtete. Die Ausdrücke ohne Rauhigkeitsziffer - meistens Exponentialmonome bilden also die rechnerische Zusammenfassung der zahlreichen in offenen natürlichen Läufen ausgeführten Durchflußbestimmungen. Stellt man statt dessen die Messungen zusammen, die an ein und derselben Flußstelle gemacht worden sind, wofür unter anderem die Jahrbücher des österreichischen hydrographischen Zentralbureaus viele Beispiele bieten,

1) Vgl. z. B. R. Siedek, Z. östert. Ing.- u. Arch.-Ver. Bd. 55 (1903), S. 104.

\%) Die Entwicklung der Hydrometrie in der Schweiz. Bern 1907. 
so kommt man immer wieder auf Unstimmigkeiten, die in der Unregelmäßigkeit des Bettes, der Ungleichförmigkeit des Fließens (also dem Vorhandensein einer Beschleunigung oder Verzögerung) oder der ungenauen Gefällsermittlung ihren Grund haben mögen.

Während die Literatur, wie gesagt, von zahlreichen MLessungen in natürlichen Läufen aller Art vom Riesel bis zum Strom berichtet, fehlen solche in regelmäßigen künstlichen Gerinnen großer Abmessungen. Um den in ihnen auftretenden Reibungswiderstand zu erfahren, waren daher neue Messungen nötig. Wie aus dem Nachfolgenden hervorgehen wird, hat der Verfasser mit Unterstützung der Bayerischen Landesstelle für Gewässcrkunde, sowie der "Mittleren Isar" solche in 8 Strecken der Werkkanäle von Deutsch-Treistritz-Peggau, Trostberg-Tacherting, Garching-Neukirchen und des Uppenbornwerkes nördlich München vorgenommen, welchen Messungen die genannte Landesstelle noch solche am Werkgraben der Lechwerke bei Stettenhofen beifügte. Außerdem stellte ihm das österreichische hydrographische Zentralbureau unveröffentlichte Messungen zur Verfügung, dic an 7 Stellen des Betongerinnes des Wienflusses in Wien vorgenommen worden waren, und der ehemalige Bauleiter der Wasserkraftanlage der Bayerischen Stickstoffwerke in Trostberg und Tacherting, der damalige Regierungsbaumeister a. D. Dr. Th. Rümelin, die nach Fertigstellung des Baues von ihm daselbst angeordneten Erhebungen. Auf die Einzclheiten wird im Laufe der Abhandlung eingegangen werden.

\section{Zur Banweise der F'ließformeln.}

Oben sind bereits zwei Fließformeln - die ältere von Bazin und die von Ganguillet und Kutter - angegeben worden. Letztere, die sich für

Zu

$$
\frac{1}{n}+\frac{0,00155}{J}=77
$$

$$
U=\frac{100 \sqrt{R}}{(100 n-1)+\sqrt{R}} \sqrt{R J}=\frac{100}{1+\frac{100 n-1}{\sqrt{R}} \sqrt{R J}}
$$

vereinfacht, bewog Bazin, seinen äIteren Ausdruck durch

$$
U=\frac{87}{1+\frac{\gamma}{\sqrt{R}}} \sqrt{R \cdot J}
$$

zu ersetzen ${ }^{1}$ ), worin $\gamma$ für Holz, Quader, Ziegel $=0,16$, für Pflaster und regelmäßiges Erdbett $=0,85$ und für Erdkanäle üblichen Zustandes

1) Ann. Ponts Chauss. (7), 74, (1897), S. 55. 
$=1,30$ zu setzen sei. Die Fließformel (4) ist heute, wenn auch kaum mit Recht, viclleicht dic beliebteste. In Bayern insbesondere stark in Gcbrauch ist jedoch die von $\mathrm{Biel}$, die für nicht allzu kleine Abmessungen und Geschwindigkeiten

oder

$$
1000 J=\frac{U^{2}}{R}\left(0.12+\frac{f}{\sqrt{R}}\right)
$$

$$
C=\frac{\sqrt{1000}}{\sqrt{0.12+\frac{f}{\sqrt{R}}}} \sqrt{R J}=\frac{91.29 R^{2 / 4}}{\sqrt{\sqrt{R+8.33} j}} \gamma^{/ J}
$$

lautet, worin man für älteren Beton $f=0,12$, für Erde $f=0,45$ zu nehmen pflegt ${ }^{1}$ ), so daß man

$$
U=\frac{91.29 R^{3 \%}}{\sqrt{\sqrt{R}+1}} \sqrt{J} \text { bzw }=\frac{91.29 R^{3 / 4}}{\sqrt{\sqrt{R}+3.75}} \sqrt{J}
$$

hat.

Die angegebenen GI. (1) bis (5) deuten bercits die Verschiedenartigkeit der für die Fließ3formeln gewählten Bauweisen an. Fast seit Beginn der einschlägigen Forschung nahm ein Teil der Fachleute keinen Anstand. mehr oder weniger verwickelte Ausdrücke aufzustellen, vorausgesetzt. da $\beta$ diese nur erste und zweite Potenzen und Wurzeln enthielten, während andere Forscher als Geschwindigkeits- oder Gefälleausdruck ein Monom verlangten und dafür gebrochene Exponenten zuließen. Formeln wie die Biels mit dritten oder vierten Wurzeln bildeten gewissermaßen den Übergang zwischen beiden Gruppen ${ }^{2}$ ). Der erste, der cine Exponentialgleichung. und zwar für Röhren, gab, war Woltmann ${ }^{3}$ ) 1791, dem später Eytelwein 1796, de Saint-Venant 1851 und Hagen 1854. dieser mit dem Ausdruck ${ }^{4}$ )

$$
J=\text { konst. } \frac{U^{1.75}}{R^{1,25}}
$$

folgten. Der Unterschied der beiden Bauweisen ist übrigens mehr ein formaler als ein sachlicher, da im allgemeinen keine Ableitung aus einem Grundgeset\% versucht wurde. Denkt man sich nun nach einer Fließformel der erstgenannten Gruppe, falls man sie für genau halten sollte, die Profilradien und Gefälle, also $R$ und $J$, als zueinander rechtwinklige Koordinaten aufgetragen und die Geschwindigkeiten $U$ als senkrechte Koordinaten, so erhält man cine Fläche. Es ist damn immer

1) Nitteilungen über Forschungsarbeiten, Heft 44. Berlin 1907. Bicl selbst gibt allerdings für so große Rauhigkeit hier keinc Zahlen.

2) Niheres s. Forchheimer, Hydraulik. Leipzig 1914. S. 37. 62.

3) Woltmann, Beitrïge zur hydraulischen Architektur 1. Göttingen 1791.

2) Utber den Einfluß der Temperatur auf die Bewegung des Wassers. Abhandlungen der Akademie der Wissenschaften. Berlin $185 \tilde{4}$. 
möglich, innerhalb eines beschränkten Gebietes sich dieser Fläche mit. ciner neuen

$$
U=\lambda \cdot R^{\prime \prime} \cdot{ }^{*}
$$

durch passende Wahl der Zahlen $\lambda, \mu$ und $\nu$ so zu nähern, daß die eine Fläche praktisch durch die andere ersetzt werden kann. Wo die beiden Flächen merklich voneinander abweichen würden, kann man durch Einführung neuer Werte von $i, \mu$ und $\nu$ dann abermals genügende U'bereinstimmung erlangen. Hier sei nur betont, daß die Annäherung an die Wirklichkeit bei Gebrauch der Bauweise (7) eine enge ist, für ganz glatte Röhren, sogar innerhalb der Genauigkeitsgrenzen unserer Beobachtungen liegt. In offenen Gerinnen steht andererseits die Pro. portionalität der Geschwindigkeit $U$ mit einer Potenz $R^{\mu}$ innerhalb weiter Grenzen fest, liefert doch z. B. die Auftragung von $\log R$ und $\log U$ nach Bazins Versuchen als Koordinaten in über 30 Fällen gerade. in weniger als 20 Fällen unregelmäßig gebrochene (also bedeutungslose) und nur in 1 oder 2 Fällen solche Punktfolgen, die man als Punkte gesetzmäßig verlaufender Kurven auffassen könnte. So sind denn in den Vereinigten Staaten die Hydrauliker schon seit einigen Jahren dazu übergegangen, die Form (7) den mehr oder weniger willkürlichen sonstigen Bauarten vorzuziehen, wovon man sich beim Durchblättern der Lehrbücher von $F$. C. Lea ${ }^{1}$ ), H. J. Hughes und A. T. Safford ${ }^{2}$ ) oder E. A. Moritz ${ }^{3}$ ) überzeugen kann.

\section{Bezielnung zwischen geschlossenen und offenen Gerinnen.}

Die experimentelle Bestimmung von $\mu$ und $\gamma$ böte keine besondere Schwierigkeit, wenn man wüßte, daß in Röhren und offenen Gerinnen ein und dasselbe Gesetz gilt, denn in Röhren kann man unschwer das Gefälle $J$ (also das Verhältnis des Druckhöhenverlustes zur Rohrlänge): in offenen Läufen die Füllung und hiermit den Profilradius $R$ verändern, ohne daß sich rlabei in den Pöhren $R$, in den Offenläufen $J$ ändern. Leider liegen als Beleg für das übereinstimmende Verhalten der beiden Gerinnearten nur zwei Versuche von Bazin mit Kastenleitungen von $0,8 \mathrm{~m}$ Weite auf $0,5 \mathrm{~m}$ Höhe bzw. $0,48 \mathrm{~m}$ Weite auf $0,3 \mathrm{~m}$ Höhe vor ${ }^{4}$ ), die man später durch Abtragen der oberen Hälften in offene

1) Hydraulics. New-Iork und London. Vorrede von 1907.

7) A Treatise on Hydraulies. New York 1911.

3) Working Data for Irrigation Engineers. New York und London 1915.

4) Mémoires présentés par divers savants 19 (1865), Serie 19 und 20, S. 176. Ein Versuch von Christen (Das Gesetz der Translation des Wassers, Leipzig 1903. S. 48) kommt schon deswegen nicht in Betracht, weil er sciner Röhre von $0,0406 \mathrm{~m}$ Durchmesser und 2,55 $\mathrm{m}$ Länge 0,010 und 0,0142 , seincr Halbröhre aber 0,038 Gefalle gab. 
Gerinne verwandelte. Bei gleichem Gefälle 0,0043 im einen, 0,006 im anderen Falle stellten sich in beiden Gerinnen gleiche mittlere Geschwindigkeiten ein. Dabei war die Geschwindigkeitsverteilung im späteren halben Gerinne eine andere wie früher in der Unterhälfte. Etwas besser glich die Verteilung in einer Halbkreisrinne der in einem vollen Rohr. Bazin drückt die Erscheinungen in den Worten aus, daß das Wasser durch die Luftreibung nicht merklich verzögert werde. Die Ubereinstimmung der mittleren Geschwindigkcit im geschlossenen Gerinne und scinen Hälften ist offenbar nur möglich, wenn der Profilradius in den beiden Bewegungsgesetzen dieselbe Rolle spielt, was mit der herrschenden Ansicht im Einklang steht. Neben der Länge des Profilradius zeigte sich aber auch die Querschnittsform von Belang, denn das Wasser nahm bei gleichem $R$ und $J$ in einer Halbkreisrinne eine etwa 1,1 mal so große mittlere Geschwindigkcit wie in einem rechteckigen oder trapezförmigen Gerinne an. Bazin ${ }^{1}$ ) schloß hieraus, daß es wesentlich die Ecken sind, welche bei polygonalem Querschnitt eine Geschwindigleitsabnahme verursachen. In der Tat zeigen z. B. auch die seitdem vorliegenden vielen Aufnahmen, daß in den Ecken nur ein unbedeutender Durchfluß ror sich geht. Die Bedeutung dieser Erscheinung für die Ubertragung eines Meßergebnisses von einem Geriune auf ein anderes, sowie für die praktische Wahl der Querschnittsform eines Werkgrabens liegt auf der Hand.

\section{Der Exponent $\nu$ des Gefälles bei Fließen in Röhren.}

Versuchsreihen, bei welchen man ein und dieselben Röhren mit verschiedenen Druckverlusten durchfließen ließ, liegen in beträchtlicher Ienge vor. Wenn man die Logarithmen der $J$ einer Reihe als Abszissen, die Logarithmen der $U$ als Ordinaten aufträgt, so erhält man, wie O. Reynolds gezeigt hat, Punkte, die in einer Geraden liegen, womit der Nachweis erbracht ist, daß $U$ der Potenz $J^{v}$ proportional ist, falls $v$ das Verhältnis der Lotrechten zu den Wagrechten bezeichnet. Auf Grund eigener Versuche, sowie solcher von Reynolds, Saph und Schoder und Lang hat speziell für ganz glatte Röhren und Wasser von $15^{\circ} \mathrm{C}$ Blasius ${ }^{2}$ ) gezeigt, daß

$$
J=0,00009334 \frac{U^{\top / 4}}{R^{T /}}
$$

oder die größtmögliche Geschwindigkeit bei gleichförmiger Bewegung

$$
U=201 R^{s / 7} J^{1 / 7}=201 R^{0,71} J^{0,5 i}
$$

ist, womit hier $\nu=0,57$ wäre.

1) a. a. O. S. 17, 102 .

9) Z. V. d. I. 56 (1912), S. 639; Forchheimer, Hydraulik. Leipzig 1914. S. 54. 
Die Versuche, auf die sich Blasius stützte, waren mit engen Röhren und verschiedenen Metallen gemacht worden; dasselbe $v$ geben auch Holzrohre großen Durchmessers. So bestimmten in einem neuen Daubenrohr von $1841,5 \mathrm{~mm}$ Weite Marx, Wing und Hoskins ${ }^{1}$ ) für

$$
\begin{aligned}
& U=0,356 \quad 0,610 \quad 0,914 \quad 1,067 \mathrm{~m} / \mathrm{sec} \\
& 1000 J=0,0851 \quad 0,204 \quad 0,408 \quad 0,557
\end{aligned}
$$

womit sich unter der Voraussetzung, daß der Exponent $\mu=5 / 7$ sei

$$
\lambda=\begin{array}{llll}
131 & 136 & 137 & 134
\end{array}
$$

oder genügend genau

$$
U=135 R^{*} / J^{4 / s}=135 R^{0,71} J^{0,57}
$$

findet. Mit der Verrauhung der Innenleibung sank $v$, denn aus den Messungen, welche dieselben Ingenieure 2 Jahre später am gleichen Rohre vornahmen, berechneten Hughes und Safford ${ }^{2}$ ) für Fußmaß $1000 J=0,0473 v^{1,90}$ oder für metrisches Maß3

$$
U=49,06 J^{0,51}=85,4 R^{0,71} J^{0,51} \text {. }
$$

Das Ergebnis von 28 Versuchsreihen mit zusammen 286 Messungen, welche teils von ihm selbst, teils von anderen Beobachtern an Holzleitungen - fast durchweg Daubenröhren - gemacht worden waren, faßt Scobey ${ }^{3}$ ) in die Formel

$$
U=122 R^{0,65} J 0,550
$$

zusammen, in der $v=0,556$ erscheint. Daß die Rauheit eine Abnahme von $\nu$ bewirkt, geht auch aus nachstehender Zusammenstellung ${ }^{4}$ ) hervor:

\begin{tabular}{c|c|c}
\multicolumn{3}{c}{ Holzröhren } \\
\hline \hline Beobachter & $\begin{array}{c}\text { Durchm. } \\
\text { mua }\end{array}$ & $"$ \\
\hline Noble . . . . . & 1118 & 0,578 \\
" . . . . . . & 1372 & 0,571 \\
Marx, Wing u. Hoskins & 1841 & 0,581 \\
1841 & 0,518
\end{tabular}

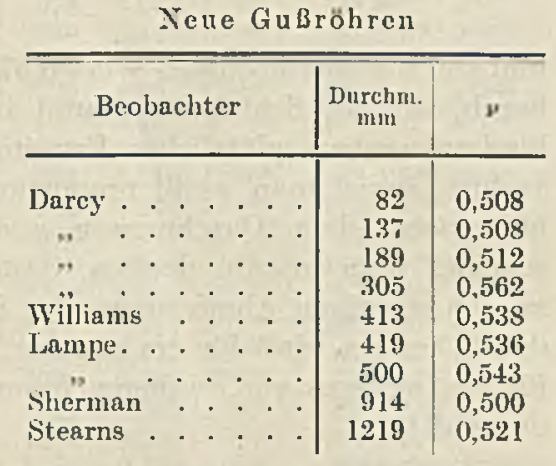

1) Transactions of the American Society of Civil Engineers 40 (1898), S. 512.

2) Ebenda 44 (1900), S. 48.

3) The Flow of Water in Wood-Stave Pipe by Fred. C. Scobey, United States Department of Agriculture. Bulletin 376 (besprochen in Wasserkraft 16 (1921), S. 341).

4) Entnommen aus L ea, Hydraulics S. 137 mit Fortlassung aller engen und einiger sonstiger Röhren. Versuche an liöhren bis höchstens 6 Zoll (1б2 mm) Durchmesse: machten Schoder und Gchring, Fng. Record 58 (1908), S. 241. 
Genictete Schmiedeeisenrohre

\begin{tabular}{|c|c|c|}
\hline Bcobachter & $\underset{\substack{\text { Durchm. } \\
\text { mm }}}{\text {. }}$ & 2 \\
\hline Giltner u. Ketchum. & 76 & 0,532 \\
\hline Ham. Smith . . . & 279 & 0,569 \\
\hline 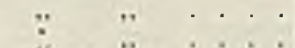 & 298 & 0,529 \\
\hline Kuichling & $\begin{array}{l}381 \\
965\end{array}$ & $\begin{array}{l}0.515 \\
0,500\end{array}$ \\
\hline Herschel. & 1067 & 0,518 \\
\hline$n \quad$. & 1219 & 0,500 \\
\hline Marx, Wing u. Hoskins & 11829 & 0,502 \\
\hline Herschel. . . . & $\begin{array}{r}1 \\
2616\end{array}$ & 0,481 \\
\hline
\end{tabular}

Gereinigte Gußrohre

\begin{tabular}{|c|c|c|}
\hline Beobachter & $\underset{\mathrm{mm}}{\text { Durchm. }}$ & $v$ \\
\hline Darcy & 306 & 0,500 \\
\hline $\begin{array}{c}\text { Fitrgerald } \\
\text {. }\end{array}$ & $\begin{array}{l}1255 \\
1255\end{array}$ & $\begin{array}{l}0,498 \\
0,515\end{array}$ \\
\hline
\end{tabular}

Alte GuBrohxe mit Ansät\%en

\begin{tabular}{|c|c|c|}
\hline Beobachter & $\underset{\substack{\text { Durchm. } \\
\mathrm{nIm}}}{\text {. }}$ & $v$ \\
\hline Darcy. . & 36 & 0,503 \\
\hline & 99 & 0,515 \\
\hline & 343 & 0.505 \\
\hline Sherman & 523 & $0, \tilde{5}$ \\
\hline Fitzgerald & 1255 & 0.490 \\
\hline ,. & 1255 & 0,500 \\
\hline
\end{tabular}

Hierṇach zeigten im Mittel

\begin{tabular}{|c|c|c|c|c|c|}
\hline $\begin{array}{l}\text { Glatte } \\
\text { Metallrohre }\end{array}$ & Holzrohre & $\begin{array}{l}\text { Neue } \\
\text { Gußrohre }\end{array}$ & $\begin{array}{l}\text { Genietete } \\
\text { Schmiede- } \\
\text { cisenrohre }\end{array}$ & $\begin{array}{l}\text { Gereinigte } \\
\text { GuBrolire }\end{array}$ & $\begin{array}{l}\text { Alte GuB } \\
\text { rohre mit } \\
\text { Ansätren }\end{array}$ \\
\hline$v=0,571$ & 0,562 & 0.528 & 0,519 & 0,504 & 0,502 \\
\hline
\end{tabular}

und sinkt $v$ vom höchsten Wert 0,571 mit zunehmender Rauheit auf 0,5 herab, welcher Schlußwert damit im Einklang steht, daß bei Einzelhindernissen wic plötzlichen Erweiterungen, Hähnen u. dgl. der Druckverlust, soviel man weiß, proportional $U^{2}$ ist. Auffallend ist es, daß bei wachsendem Durchmesser $v$ eher abzunchmen als zuzunehmen scheint. \[an könnte denken, daß clas VerhäItnis der Unebenhciten zu den sonstigen Abmessungen im Strëmungsgesetz dadurch zum Ausdruck kommt, daß für ein engeres, glatteres Rohr classelbe $\nu$ gilt wie für ein weiteres von rauherer Innenfläche. Das ist anscheinend nicht der Fall ${ }^{1}$ ).

1) H. Lan $\mathrm{g}$ fand nach der Hütte (22. Auf1., 1915, Bd. 1) bei großer Geschwindigkeit - sie stieg bis ät $\mathrm{m} / \mathrm{sec}-J$ proportional $U^{2}$. Nach freundlicher Mitteilung verwendete er Kupfer- und Messingrohre bis zu $11 \mathrm{~mm}$ bichtwcite. - C. Camichel [Fortschritte der Physik im Jahre 1918. 74. Jahrg., 1. Abt., S, 76 u, Beibl. 7. d. Ann. d. Physik 43 (1919), S. 758 nach Comptes Rendus Acad. des Sciences 167 (1918). S. 525$]$ fand für $U=25$ bis $80 \mathrm{~m} / \mathrm{sec} U$ proportional $J^{1,93}$ in eincm $3 \mathrm{~mm}$ weiten Rohr. - Fs fehlt an Messungen bei großer Geschwindigkeit und größeren Durchmessern. - 
Dic Exponenten $\nu$ u. $\mu$ u. d. Koeffizient $\lambda$ für das Fließen in Betonröhren. 11

\section{Die Exponenten $\nu$ and $\mu$ und der Koeffizient $\lambda$ für das Fließen in Betonröhren.}

Für den Vergleich der geschlossenen und offenen Gerinnen ist das Verhalten von Betonröhren belangreich: Erd-oder Pflasterflächen kommen ja in Röhren überhaupt nicht, Metallwände in offenen Lüufen nur ausnahmsweise vor, Betonwandungen gibt es hingegen sowohl in len einen wie in den anderen. Da sei denn zunächst bemerkt, daß das Verhalten von Betonsträngen von deren Herstellungsweise abhängig ist. Am glattesten sind fugenlose (monolithische) Stränge, deren Beton im Rohrgraben über geölte Eisenformen (oder mit Blech verkleidete Holzschalung) gestampft wird, am rauhesten aus Einzelrohren zusammengesetzte Leitungen, bei denen man es versäumt hat, den beim Zusammenschicben an den Fugen austretenden Mörtel zu entfernen. Auch bezüglich der Betonleitungen ist Scobey ${ }^{1}$ ) eine Zusammenstellung zu ver-

Betonröhren.

\begin{tabular}{|c|c|c|c|c|c|c|}
\hline \multirow{2}{*}{ 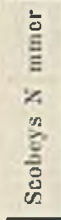 } & \multirow[b]{2}{*}{$\begin{array}{l}\text { Innen- } \\
\text { Dm. } \\
=4 K \\
\\
\text { mm }\end{array}$} & \multirow[b]{2}{*}{$\begin{array}{l}\text { Geschwin- } \\
\text { digkeit } \\
\mathrm{m} / \mathrm{sec}\end{array}$} & \multirow[b]{2}{*}{$\begin{array}{l}\text { Gefälle } \\
\text { in } \% \\
= \\
1000 \mathrm{~J}\end{array}$} & \multirow[b]{2}{*}{$\begin{array}{l}\text { Länge } \\
\text { der } \\
\text { Meß- } \\
\text { strecke }\end{array}$} & \multicolumn{2}{|c|}{ Reihengleichungen } \\
\hline & & & & & $\begin{array}{l}\text { Ausdruck } \\
\text { für } 1000 . J\end{array}$ & 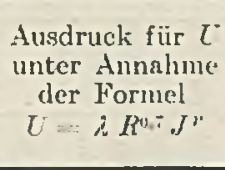 \\
\hline 5 & 305 & $0,46-1,14$ & $1,69-7,65$ & 56 & $U^{1,413}$ & $98,6 R^{1,7}, J^{11, \pi 2}$ \\
\hline 10 & 405 & $0,52-0,74$ & $1,00-2,09$ & 578 & $U^{\text {IUIN5 }}$ & $83,4 K^{u, i}, J^{\cup, 5 u-4}$ \\
\hline 16 & 500 & $0,11-0,45$ & $0,056-0,781$ & 339 & $U^{1,-03}$ & $91,4 K^{3,7} J^{0,53 i}$ \\
\hline 17 & 500 & $0,19-0,60$ & $0,102-0,946$ & 235 & $U^{1,\{* 41}$ & $8 \pi, 1 R^{n, \tau} J^{\prime 1,3 u=1}$ \\
\hline 18 & 506 & $0,27-0,77$ & $0,200-1,278$ & 639 & $U^{1, ! \text { +нH }}$ & $109,2 K^{11,7} J^{11,524}$ \\
\hline 19 & 509 & $0,29-1,23$ & $0,230-3,20$ & - & $U^{\text {1.\{nा:s }}$ & $108,3 R^{10.7}, J^{0.3}$ \\
\hline 21 & 610 & $0,19-0,40$ & $0,103-0,49 i$ & 319 & $U^{\text {Znata }}$ & $57.4 / R^{0.7}, J^{0,481}$ \\
\hline 22 & 759 & $0,20-0,57$ & $0,094-0,806$ & 701 & $U^{2, \text { nind }}$ & $57,9 R^{1,7} J^{11,447}$ \\
\hline 23 & 762 & $0,32-0,75$ & $0,150 \cdots 0,745$ & 208 & $U^{1,4 ; 02}$ & $114,6 K^{13,7} J^{11.537}$ \\
\hline $\left.26^{2}\right)$ & 774 & $1,49-1,76$ & $2,280-3,727$ & 694 & $0,647 \quad U^{3,1 \mathrm{H}}$ & $31,1 R^{10.7} J^{11,31-i}$ \\
\hline 27 & 799 & $0.91-2,01$ & $0,673-3,275$ & 40 & $0,844 \quad U^{1,4+1}$ & $111,9 I^{20,7} J^{0,317}$ \\
\hline 29 & 914 & $1,66-2,76$ & $2,072-5,30$ & 2220 & $0,652 U^{2,160}$ & $83,0 J^{21,7} \cdot J^{0,4 f 9}$ \\
\hline 30 & 1067 & $0,31-0,80$ & $0,076-0,530$ & 4,16 & $0,671 U^{1,45 ! 1}$ & 120,6 R R \\
\hline 31 & 1067 & $0,30-0,79$ & $0,042-0,429$ & $11 \tilde{5}$ & $0,777 \quad U^{2,432}$ & $47,4 R^{211} T \cdot J 0,411$ \\
\hline 32 & 1164 & $0.43-0,97$ & $0,096-0,544$ & 2979 & $0,598 U^{2.100}$ & $79,0 R^{21.7} J^{(1,+4) 2}$ \\
\hline 35 & 1612 & $0.98-1,95$ & $0,289-1,581$ & 347 & $1,363 \quad U^{2,4 / 3}$ & $29, \overline{5} l^{\prime \prime, \bar{i}} J^{0.417}$ \\
\hline 36 & 2201 & $0.44-1.24$ & $0,066-0,496$ & 1280 & $0,324 \quad U^{1,412}$ & $101,5 R^{0,7}, J^{0,323}$ \\
\hline 39 & 4419 & $0,48-1,42$ & $0,031-0,253$ & 2566 & $0,136 \quad U^{2.119}$ & $63,4 I^{n, 7} \cdot J^{0,4 \pi 4}$ \\
\hline 40 & 4419 & $0,48-1,42$ & $0,033-0,269$ & 4249 & $0,134 \quad U^{*, 102}$ & $75,6 I l^{2,7}, J^{0,403}$ \\
\hline 41 & 5486 & $1,22-6,10$ & $0,108-2,397$ & 1971 & $0,08] 2 U^{1,4: 3}$ & $105,9 K^{11, \pi} \cdot J^{0,514}$ \\
\hline
\end{tabular}

1) The Flow of Water in Conerete Pipe by Fred. C. Scobey, United States Department of Agriculture: Bulletin 852. Washington 1920 (besprochen in Wasserkraft Bd. 17 (1922), S. 1).

2) Das eigentümliche Verhalten $(v=0,315)$ dieses Stranges rermag Scobey nicht zu erklüren. 


\begin{tabular}{|c|c|c|c|c|c|c|c|c|c|c|c|c|c|c|}
\hline 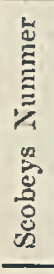 & $\begin{array}{l}\text { Leitung } \\
\text { oder } \\
\text { Leitungsnetz }\end{array}$ & 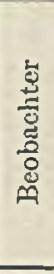 & $\begin{array}{c}\text { Innen- } \\
\text { durch- } \\
\text { messer } \\
D=4 K \\
\text { mm }\end{array}$ & Baujahr & $\begin{array}{l}\text { Alter } \\
\text { Jahre }\end{array}$ & $\begin{array}{l}\text { Bau- } \\
\text { weise }\end{array}$ & $\begin{array}{c}\text { Länge } \\
\text { der } \\
\text { Rohre } \\
\text { cm }\end{array}$ & $\begin{array}{c}\text { Geschwin- } \\
\text { dligkeiten } \\
U \\
\text { wälirend } \\
\text { d. Messungen } \\
\mathrm{m} / \mathrm{sec}\end{array}$ & $\begin{array}{c}\begin{array}{c}\text { Gefülle } \\
a b- \\
\text { gerundet }\end{array} \\
\% \%\end{array}$ & {$\left[\begin{array}{rr}1 & 10 \\
0 & 0 \\
11 & 11 \\
2 & 2\end{array}\right]$} & $\mid \begin{array}{cc}1 & 0 \\
0 & 0 \\
0 & 0 \\
\| & \| 1 \\
z & \vdots\end{array}$ & $\mid \begin{array}{cc}1 & 0 \\
0 & 1 \\
0 & 0 \\
11 & 0 \\
2 & 11 \\
2\end{array}$ & 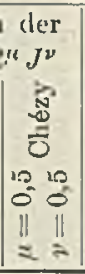 & 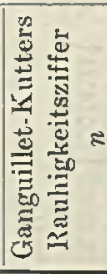 \\
\hline 1 & l'omona . . . & $S$ & 203 & 1885 & 30 & $Z B$ & - & $0,97-1,09$ & 10,8 & 84 & 92 & 73 & 46 & 0,0123 \\
\hline 2 & " $\quad$. & ," & 254 & 1888 & 27 & $"$, & - & $0,62-0,64$ & $3,1-3,4$ & 76 & 85 & 69 & 44 & 0,0134 \\
\hline 3 & Ontario ... & , & 254 & - & 10 & , , & - & $1,45-1,48$ & 15,9 & 80 & 87 & 71 & 46 & 0,0128 \\
\hline 8 & Oakdale ... & ," & 300 & - & - & $"$, & 61 & $0,39-0,47$ & $1,3-1,8$ & 68 & 77 & 63 & 40 & 0,0147 \\
\hline 4 & Pomona ... & $"$ & 305 & - & 30 & , , & - & 0,49 & 1,8 & 70 & 79 & 65 & 41 & 0,0146 \\
\hline 5 & , . . & $n$ & 305 & 1885 & 30 & ", , & - & $0,46-1,11$ & $1,7-7,6$ & 77 & 85 & 70 & 44 & 0,0138 \\
\hline 6 & Ontario $\ldots$ & $"$ & 305 & 1911 & 4 & $"$, & - & 1,78 & 14,8 & 89 & 97 & 80 & 53 & 0,0120 \\
\hline 7 & , $\quad .$. & , & 305 & 1900 & 15 & $"$, & - & $0,59-0,61$ & $1,4-1,5$ & 95 & 108 & 90 & 57 & 0,0113 \\
\hline 9 & Pomona & , & 406 & 1883 & 32 & ", & - & $0,30-0,43$ & $0,5-0,6$ & 69 & 80 & 67 & 44 & 0,0138 \\
\hline 10 & . . & ", & 406 & 1883 & 32 & $"$, & - & $0,52-0,74$ & $1-2$ & 80 & 91 & 77 & 52 & 0,0128 \\
\hline 11 & . . & ", & 406 & - & 32 & ", & - & 0,52 & 1 & 83 & 95 & 80 & 52 & 0,0127 \\
\hline 12 & Umatilla ... & $N$ & 406 & - & 2 & ", & 61 & $0,82-1,06$ & $3,8-4,5$ & 72 & 82 & 68 & 46 & 0,0144 \\
\hline 13 & . . . &, & 406 & - & 2 & ", , & - & 0,75 & 1,9 & 85 & 96 & 84 & 54 & 0,0125 \\
\hline 14 & Oakdale ... & $S$ & 457 & - & - & ," & - & $0,60-0,66$ & $1,6-1,9$ & 67 & 76 & 64 & 44 & 0,0149 \\
\hline 15 & , . . . & , & 457 & - & - & ,", & - & 0,29 & 0,3 & 74 & 87 & 74 & 50 & 0,0132 \\
\hline 16 & Kamloops ... & , & 457 & 1911 & 5 & ", & - & $0,11-0,45$ & $0,06-0,8$ & 70 & 81 & 68 & 44 & 0,0144 \\
\hline 17 & . . & , & 500 & 1911 & 5 & , , & - & $0,19-0,60$ & $0,1-0,9$ & 84 & 96 & 82 & 55 & 0,0125 \\
\hline 18 & Temescal . . . & $"$ & 506 & bfg. 1910 & 4 & $Z E$ & 91 & $0,27-0,77$ & $0,2-1,3$ & 92 & 105 & 90 & 61 & 0,0117 \\
\hline 19 & - & $F$ & 509 & vor 1880 & - & Verkl & - & $0,29-1,23$ & $0,2-3,2$ & 91 & 102 & 88 & 61 & 0,0117 \\
\hline 21 & Kamloops . . & $S$ & 587 & & 5 & $/ 2 B$ & - & $0,19-0,40$ & $0,1-0,5$ & 66 & 79 & 69 & 46 & 0,0148 \\
\hline
\end{tabular}

\begin{tabular}{|c|c|c|c|c|c|c|c|c|c|c|c|c|c|c|}
\hline 20 & Oakdale & $S$ & 602 & 1912 & 4 & $M I B$ & & $0,57-0,59$ & $0,4-0,5$ & 90 & 105 & 91 & 70 & 0,0117 \\
\hline 22 & Temescal & , & 762 & 1911 & 4 & $Z E$ & - & $0,20-0,57$ & $0,1-0,8$ & 65 & 74 & 55 & 47 & 0,0155 \\
\hline 23 & Unatilla & , & 762 & 1910 & 5 & $Z B$ & 122 & $0,32-0,75$ & $0,1-0,8$ & 85 & 100 & 88 & 61 & 0,0124 \\
\hline 24 & Dieselbe Strecke & $N$ & 762 & 1910 & neu &,, & 122 & $1,03-1,10$ & 1,1 & 104 & 120 & 106 & 75 & 0,0106 \\
\hline 25 & Umatilla ... & ., & 762 & - & 4 & ", , & - & 0,83 & 0,9 & 95 & 109 & 92 & 70 & 0,0119 \\
\hline 26 & Sunnyside ... & $S$ & 775 & 1911 & 5 & $Z E$ & 122 & $1,49-1,76$ & $2,2-3,7$ & 94 & 106 & 94 & 67 & 0,0117 \\
\hline 27 & Den & $B a$ & 800 & 1895 & neu & $M B$ & - & $0,90-2,00$ & $0,7-3,3$ & 108 & 121 & 113 & 73 & 0,0106 \\
\hline 28 & Oakdale & $S$ & 914 & 1912 & 4 & $M-$ & - & $0,55-0,59$ & $0,4-0,6$ & 73 & 85 & 76 & 56 & 0,0139 \\
\hline 29 & Boise . & , & 814 & 1912 & 3 & $Z E$ & 183 & 1,08 & 1,2 & 89 & 101 & 91 & 65 & 0,0123 \\
\hline $29 \mathrm{~b}$ & Dieselbe Strecke & ", & 914 & 1912 & 5 & $"$, & 183 & $1,66-2,76$ & $2-5,3$ & 103 & 115 & 103 & 76 & 0,0109 \\
\hline 30 & Victoria Aquädukt. & ,, & 1067 & 1914 & 2 & 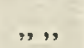 & - & $0,31-0,89$ & $0,08-0,5$ & .97 & 113 & 102 & 72 & 0,0112 \\
\hline 31 & , , & , & 1067 & 1914 & 2 & ",", & - & $0,30-0,79$ & $0,04-0,4$ & 103 & 119 & 106 & 79 & 0,0103 \\
\hline 32 & Umatilla. & , & 1168 & 1909 & 5 & & - & $0,43-0,97$ & $0,1-0,5$ & 98 & 118 & 108 & 78 & 0,0105 \\
\hline $33 \mathrm{a}$ & Dieselbo Strecke & $N$ & 1168 & 1909 & iib. 1 & & - & $0,24-0,31$ & $0,8-1$ & 96 & 111 & 101 & 76 & 0,0112 \\
\hline $33 \mathrm{~b}$ & Anderson-Cott. & $S$ & 1219 & vor 1910 & 4 & $Z E$ & - & 0,35 & 1,1 & 81 & 89 & 82 & 61 & 0,0137 \\
\hline 34 & Sunnyside . & , & 1372 & 1909 & 7 & - & - & 0,38 & 1,2 & 91 & 104 & 96 & 73 & 0,0118 \\
\hline 35 & Sun River. & $"$ & 1613 & $1907 / 8$ & 7 & $M E$ & - & $0,98-1,95$ & $0,3-1,6$ & 92 & 105 & 98 & 82 & 0,0108 \\
\hline 36 & Perlmoos . . & $B_{u}$ & 2200 & 1913 & neu & 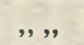 & - & $0,44-1,24$ & $0,1-0,5$ & 85 & 99 & 94 & 76 & 0,0120 \\
\hline 38 & Catskill Aquädukt. & $M$ & 2794 & vor 1915 & 3 & Verkl & - & $0,06-0,09$ & $0,2-0,3$ & 72 & 85 & 84 & 69 & 0,0139 \\
\hline 39 & , $\quad, \quad \ldots$ & $"$ & 4420 & , " & neu & ", & - & $0,48-1,42$ & $0,03-0,3$ & 83 & 99 & 99 & 82 & 0,0124 \\
\hline 18 & " & ," & 4420 & & ," & & - & $0,48-1,42$ & $0,03-0,3$ & 81 & 95 & 96 & 82 & 0,0124 \\
\hline 1 & Ontario-Kraftwerk. & $J$ & 5486 & vor 1913 & 4 & $M E$ & - & $1,22-6,10$ & $0,1-2,4$ & 100 & 113 & 116 & 84 & 0,0102 \\
\hline
\end{tabular}

Es bedeutet $S$ Scobey, $N$ Newell, $B a$ Bazin, $B u$ Budau, M Moore, $J$ Johnston, $Z$ Zusammensetzung aus Einzelröhren, $B$ Beton, $E$ Lisenbeton, $M$ M Monolith, Verkl verkleidetes Eisenrohr.

Wenn im gleichen Strang bei verschiedenen Gesehwindigkeiten gemessen wurde, entspricht jeder Messung cin anderes $\lambda$; dus Mittel dieser $\lambda$ ist in der 'Tabelle angegeben. 
danken, die seine vielen eigenen und alle ihm aus der Literatur zugänglichen Messungen umfaßt. Sie bestehen teils aus Einzelbeobachtungen, teils aus Reihen, nämlich aus Beobachtungen, die in größcrer Zahl an einer und derselben Strecke bei verschiedenem Gefälle gemacht worden sind. Die Logarithmen-Auftragung führte bei ihnen auf Potenzen . ${ }^{\prime \prime}$. deren Exponent $v$ freilich, wie dies auch bei den Holzröhren der Fall gewesen war, sich nicht bei allen Strängen derselben Gattung gleich groß zeigte: bisher unbekannte Ursachen können ihn also ändern. Das Ergebnis der Versuchsreihen bringt die crste der beiden vorstehenden Tabellen zum Ausdruck.

Auf Grund dieser Zahlen entschied sich Scobey für $v=0,5$; für $1=0,5$ und $v=0,52$ ergeben sich mit $\mu=0,7$ und 0,625 drei Spalten der zweiten Tabelle, zu denen bemerkt werde, daß der Strang 14 vermutlich Ablagerungen enthielt, 20 auf Holzschalung, 30, 31 und 36 bis $4 l$ auf geölte Eisenformen gestampft und 41 überdies sehr sorgfültig geschliffen wurde ${ }^{1}$ ).

Aus dieser Zahlentafel könnte man bei flüchtigem Utberblick folgern, claß $U$ einer höheren Potenz von $R$ als $R^{0,7}$ proportional wachse, weil clie für $\lambda$ gegebenen Spalten eine Zunahme von $\lambda$ mit dem Rohrdurchmesser aufweisen. Zum Teil kommt letztere aber daher, daß die engen Stränge zumeist aus einer Zeit stammten, in der man beim Verlegen wenig sorgsam verfuhr, und daß es überhaupt leichter ist, in weiten Strängen eine glatte Innenleibung herzustellen als in engen. Dazu kommt noch, daß Luftblasen und Ablagerungen den Durchflul3 in den engen Strängen mehr behindert haben werden als in den weiten. Die Zunahme von $\lambda$ ist also nur zum Teil auf eine hydraulische Ursache zurückzuführen. Immerhin erscheint es gerechtfertigt, von Scobey abzuweichen, der $\mu=0,625$ haben will und $\mu$ - wenn schon nicht größer als 0,7 - doch gleich $0,7 \mathrm{zu}$ setzen. Dann gilt für ${ }^{2}$ )

(9) alte mit wenig Sorgfalt aus Einzelröhren zusammengesetzte Stränge . . . . . $U=76 R^{0,7} J^{0,5}$

(9a) einige Jahre in Betrieb stehende aus Einzelröhren zusammengesetztc Stränge . . . . U $=85 R^{0,7} J^{(0,5}$

$(9 \mathrm{~b})$ monolithische über geölte Eisenformen gestampfte Strünge ......... $U=88 K^{0,7} J^{0,5}$

(9c) monolithische geschliffene Stränge größter erzielbarer Glätte ......... $U=100 R^{0, \pi} J 0,5$

1) G. Sasváry fand für $U=0,435$ bis $1,242 \mathrm{~m} / \mathrm{sec}$ in einem $2584 \mathrm{~m}$ langen, $1,2 \mathrm{~m}$ weiten Eisenbetonrohr $J \mathrm{im}$ Mittel $=77,2 \sqrt{R J}$, also $\lambda=98,2 \mathrm{~m}^{0.3} / \mathrm{sec}^{0.7}$. Die Herstellungsweise des Rohres ist nicht angegeben. Mrgyar Mernök és Epitési Egylet Közlönye 1916.

2) Da die folgenden Werte Mittelwerte darstellen, muß bei ihrer praktischen Anwendung noch ein Sicherheitszuschlag gemacht werden. 
Betonröhren verhalten sich hiernach ähnlich wie Eisenröhren, denn für gebrauchte bzw. neue Gußröhren fand Flamant, gestützt auf Messungen von über 20 Vorgängern,

$$
U=148 \text { bzw. } 166 R^{4 / 2} J^{*}=148 \text { bzw. } 166 R^{0,71 \pm} J^{0,571}
$$

oder für ein Gefälle $J$ von ungefähr 0,001 wie oben

$$
U=90 \text { bzw. } 101 R^{0,714} \cdot J^{0,5}
$$

Bei sehr kleinem Gefälle wird die Abweichung der Gleichungen (9b) his $(9 \mathrm{c})$ von der Flamantschen Formel übrigens größer, denn für $J=$ 0,0001 ergibt letztere z. B. $U=76$ bzw. $85 R^{0,714} J^{0,5}$. Freilich kann seine Formel, deren Exponent $v$ gemäß der Zusammenstellung auf Seite 10 nur für ganz glatte Rohre zutrifft, bloß als angenähert richtig gelten.

\section{Der Exponent $\nu$ des Gefälles bei Fließen in festen offenen Gerinnen.}

Trotz der erwähnten Schwierigkeit der Ermittlung von $v$ in offenen Gerinnen geben die eingangs genannten Versuche Bazins einigen Aufschluß, so die Reihen 6, 7, 8, welche er in Strecken verschiedenen Gefälles desselben aus ungehobelten Brettern bestehenden Kastengerinnes von $1,99 \mathrm{~m}$ Innenweite durchführte ${ }^{1}$ ) und ebenso die Reihen $9,10,11$, welche er in den gleichen Strecken vornahm, nachdem der Boden, der sich geworfen hatte, in der früheren Weise wiederhergestellt war ${ }^{2}$ ). Bei Auftragung von $\log R$ und $\log U$ als Abszissen und Ordinaten ordnen sich die Punkte in gerade Linien, aus deren Neigung $\mu$ folgt, mit dessen Kenntnis man dann weiter $\lambda$ und $\nu$ der Grundgleichung (7) ausrechnen

\begin{tabular}{|c|c|c|c|c|c|c|c|}
\hline $\begin{array}{c}\text { Bazins } \\
\text { Serie }\end{array}$ & Profil & $\begin{array}{l}\text { radi } \\
\mathrm{m}\end{array}$ & us $R$ & $\begin{array}{c}\text { Geschwindig- } \\
\text { keit } U \\
\mathrm{~m} / \mathrm{sec}\end{array}$ & Gefälle $J$ & $\mu$ & \\
\hline 6 & 0,073 & bis & 0,28 & 0,64 bis 1,59 & 0,00208 & 0,710 & \multirow{6}{*}{$\begin{array}{l}\text { Rechteckiger } \\
\text { Querschnitt } \\
1,98 \text { m } 1.99 \mathrm{~m} \\
\text { breit }\end{array}$} \\
\hline 7 & 0,057 & & 0,22 & $0,83 \quad . \quad 2,18$ & 0,0049 & 0,317 & \\
\hline 8 & 0,045 & & 0.19 & $1,07 \quad . \quad 2,61$ & 0,00824 & 0,610 & \\
\hline 9 & 0,084 & .. & 0,30 & $0,55 \quad, \quad, \quad 1,42$ & 0,0015 & 0,744 & \\
\hline 10 & 0,052 & & 0,21 & $0,91,2,35$ & 0,0059 & 0,685 & \\
\hline 11 & 0,045 & ", & 0,19 & $1,08,2,66$ & 0,00839 & 0,624 & \\
\hline
\end{tabular}
kann. Hier die cinzelnen Zahlen:

Die Gruppe $6,7,8$ gibt $U=134 R^{0,679} J^{0,582}$, die Gruppe $9,10,11$ gibt $U=140 R^{0,084} J^{0,587}$, so daß die 6 Serien zusammen für ungehobelte, aber gut aneinander schließende Bretter

I) a. a. O. 78, Taf. VII. ${ }^{2}$ ) a. a. O. S. 85,86 , Taf. V'II. 


$$
U=136 R^{0,68}, 70,58
$$

liefern $\left.{ }^{1}\right)$.

Für die nächsten Versuche ließ Bazin ${ }^{2}$ ) die Bretter des gleichen Kastengerinnes innen mit Latten von $27 \mathrm{~mm}$ Breite und $10 \mathrm{~mm}$ Dicke benageln, und zwar für die Reihen $12,13,14$ derart, daß zwischen benachbarten Latten Querfugen von $10 \mathrm{~mm}$ Weite, für 15, 16, 17 derart, daß Querfugen von $50 \mathrm{~mm}$ Weite freiblieben. Diese geregelte Rauhigkeit bewirkte ein gesetzmäßiges Wachstum von $U$ mit $R$, nämlich Einordnung in eine Gerade bei Auftragung von $\log U$ und $\log R$ gemä $\beta$ den beiden Gleichungen

(10a) $U=70 R^{0,7} J^{0,5}$ für Fugen von $10 \mathrm{~mm}$ Weite,

$$
U=46 R^{0,7} J^{0,5} \quad \text { " " " } 50 \text {, " , }
$$

denen wegen der Beschaffenheit der Oberfläche wohl besondere Bedeutung zukommt und deren Gültigkeit aus nachstehender Zusammenstellung erhellt:

\begin{tabular}{|c|c|c|c|c|c|c|c|c|}
\hline \multirow[t]{2}{*}{$\begin{array}{l}\text { Profil- } \\
\text { radius } \\
R \text { in } \mathrm{m}\end{array}$} & \multicolumn{2}{|c|}{$\begin{array}{c}\text { Mittlere } \\
\text { Geschwindigkeit } \\
U \text { in } \mathrm{m} / \mathrm{sec} \\
\\
\text { bегеchn.| gemess. }\end{array}$} & $\begin{array}{l}\text { Profil- } \\
\text { radius } \\
K \text { in } \mathrm{n}\end{array}$ & \multicolumn{2}{|c|}{$\begin{array}{c}\text { Mittlere } \\
\text { Geschwindigkeit } \\
U \text { in } \mathrm{m} / \mathrm{sec} \\
\text { berechn. gemess. }\end{array}$} & $\begin{array}{l}\text { Profil- } \\
\text { radius } \\
R \text { in } \mathrm{m}\end{array}$ & \multicolumn{2}{|c|}{$\begin{array}{c}\text { Mittlere } \\
\text { Geschwindigkeit } \\
U \text { in } \mathrm{m} / \mathrm{sec} \\
\text { berechn. gemess. }\end{array}$} \\
\hline & \multicolumn{2}{|c|}{ Serie 12} & & \multicolumn{2}{|c|}{ Serie 13} & & \multicolumn{2}{|c|}{ Serie 14} \\
\hline $\begin{array}{l}0,0921 \\
0,1346 \\
0,1932 \\
0,2361 \\
0.2710 \\
0,3004 \\
0,3281\end{array}$ & $\begin{array}{l}0,51 \\
0,67 \\
0,86 \\
0,99 \\
1,09 \\
1,17 \\
1,24\end{array}$ & $\begin{array}{l}0,50 \\
0,66 \\
0,87 \\
1,01 \\
1,13 \\
1,21 \\
1,28\end{array}$ & $\begin{array}{l}0,0626 \\
0,0922 \\
0,1347 \\
0,1684 \\
0,1959 \\
0,2182 \\
0,2409\end{array}$ & $\begin{array}{l}0,77 \\
1,01 \\
1,32 \\
1,55 \\
1,72 \\
1,85 \\
1,98\end{array}$ & $\begin{array}{l}0,76 \\
1,02 \\
1,34 \\
1,55 \\
1,72 \\
1,87 \\
1,97\end{array}$ & $\begin{array}{l}0,0556 \\
0,0831 \\
0,1227 \\
0,1520 \\
0,1775 \\
0,2005 \\
0,2214\end{array}$ & $\begin{array}{l}0,87 \\
1,15 \\
1,52 \\
1,76 \\
1,96 \\
2,14 \\
2,29\end{array}$ & $\begin{array}{l}0,87 \\
1,14 \\
1,50 \\
1,76 \\
1,95 \\
2,09 \\
2,21\end{array}$ \\
\hline 0,3281 & \multicolumn{2}{|c|}{ Serie 15} & & \multicolumn{2}{|c|}{ Serie 16} & & \multicolumn{2}{|c|}{ Serie 17} \\
\hline $\begin{array}{l}0,1153 \\
0,1675 \\
0,2367 \\
0,2870 \\
0,3270 \\
0,3649 \\
0,3960\end{array}$ & $\begin{array}{l}0,39 \\
0,51 \\
0,65 \\
0,74 \\
0,81 \\
0,88 \\
0,93\end{array}$ & $\begin{array}{l}0,39 \\
0,51 \\
0,67 \\
0,74 \\
0,81 \\
0,88 \\
0,93\end{array}$ & $\begin{array}{l}0,0805 \\
0,1170 \\
0,1687 \\
0,2092 \\
0,2410 \\
0,2688 \\
0,2942\end{array}$ & $\begin{array}{l}0,61 \\
0,79 \\
1,02 \\
1.18 \\
1,31 \\
1,41 \\
1,50\end{array}$ & $\begin{array}{l}0,58 \\
0,78 \\
1,03 \\
1,18 \\
1,31 \\
1,42 \\
1,50\end{array}$ & $\begin{array}{l}0,0706 \\
0,1076 \\
0,1551 \\
0,1913 \\
0,2210 \\
0,2476 \\
0,2699\end{array}$ & $\begin{array}{l}0,68 \\
0,91 \\
1,17 \\
1,36 \\
1,50 \\
1,63 \\
1,73\end{array}$ & $\begin{array}{l}0,67 \\
0,87 \\
1,14 \\
1,31 \\
1,48 \\
1,59 \\
1.70\end{array}$ \\
\hline
\end{tabular}

Rechteckiger Querschnitt. Mit Latten benagelte Bretter.

Die Gefälle $J$ waren bei Serie 12 und 150,0015 , bei Serie 13 und 16 0,0059 , bei Scrie 14 und 170,00886 .

1) Schoklitsch berechnet in einer ungedruckten Arbeit aus Bazins Recherches $U=130 R^{0,03} J^{0,5 T}$.

$\left.{ }^{2}\right)$ a. ล. O. S. 85,87 , Taf. VII. 
Dic Serien 32 und 33 fanden in 2 Strecken eines in Zementmörtel gemaucrten Bruchsteingerinnes ${ }^{1)}$ von flacher $1,8 \mathrm{~m}$ breiter Sohle und fast lotrechten, nämlich unter $1 / 10$ Anlage aufsteigenden Seitenmauern statt. Die Kopfflächen der Steine waren sorgfältig abgespitzt, die Sohle mit einer leichten Schlammdecke überzogen, die trotz der aufgetretenen Strömung haften blieb. Die Serien geben zwar $v=0,5 \mathrm{zu}$ erkennen, lassen sich aber nicht so gut vereinigen wie die vorhergehenden. Sic ergeben im Mittel

$$
U=66 R^{0,74} J^{0,5}
$$

und im einzelnen folgende Werte:

Gefälle $J=0,101$.

\begin{tabular}{c|c|c}
\hline $\begin{array}{c}\text { Profil- } \\
\text { radius } R \\
\text { in } \mathrm{m}\end{array}$ & $\begin{array}{r}\text { Mittlere Geschwindigkeit } \\
U \text { in } \mathrm{m} / \mathrm{sec}\end{array}$ \\
\hline & berechnet & gemessen \\
\hline 0,0989 & 3,75 & 3,01 \\
0,1424 & 4,93 & 4,96 \\
0,1767 & 5,69 & $\mathbf{5 , 8 2}$ \\
0,2017 & 6,43 & $\mathbf{6 , 4 2}$
\end{tabular}

Gefälle $J=0,037$.

\begin{tabular}{c|c|c}
\hline $\begin{array}{c}\text { Profil- } \\
\text { radius } R \\
\text { in m }\end{array}$ & $\begin{array}{c}\text { Mittlere Geschwindigkeit } \\
U \text { in } \mathrm{m} / \mathrm{sec}\end{array}$ \\
\hline & berechnet & gemessen \\
\hline 0,1294 & 2,76 & 2,80 \\
0,1889 & 3,49 & 3,70 \\
0,2272 & 4,13 & 4,24 \\
0,2597 & 4,60 & 4,68
\end{tabular}

Ebenso wie bei Röhren ist nach dem Alitgeteilten zu schließen, daß für Profilradien bis zu etwa $1 \mathrm{~m}$ bei glatter Wand der Exponent $v=$ ungefähr 0,57 ist und mit zunehmender Rauhigkcit rasch auf 0,50 sinkt.

Für größere Abmessungen bliebe v noch unsicher, wenn nicht glücklicherweise für eine Strecke großen Querschnittes M.essungen vorlïgen, welche bei ziemlich gleichbleibender Tiefe aber wechselndem Gefälle vorgenommen worden waren. Es war dies der betonverkleicete Werkgraben mit Trapezquerschnitt der Bayerischen Stickstoffwerke zwischen Trostberg und Tacherting an der Alz. Hier hatte der Erbauer Dr. Rümelin im Oktober 1910 nach Fertigstellung des Baues eingehende Abnahmeversuche vornchmen lassen, bei welchen der Wasserstand wenig geändert wurde, während man den Durchschnitt recht verschieden wählte.

Grundriß und Querschnittsskizzen des betreffenden Werkgrabens finden sich in der Schweizerischen Bauzcitung $\left.{ }^{2}\right)$. An das Trostberger Krafthaus, die Zentrale I, schlicßt sich eine etwas unregelmäßige, etwa $300 \mathrm{~m}$ lange Erdstrecke an, welche neben dem Wasser dieses Werkes noch 4,3 $\mathrm{m}^{3} / \mathrm{sec}$ einer älteren kleinen Anlage durch den sog. Riegerkanal bezicht. Dann folgen (s. Abb. 4) rund $600 \mathrm{~m}$ Betonschale mit flachgewölbter Sohle, senkrechten Seitenwänden und eigentümlichen Abtrep-

1) a, a, O. $\mathrm{S} .111, \mathrm{Pl}, \mathrm{XIII}$.

2) Bd. 68 (1916), Nr. 3, S. 21 im Aufsatz: Th. Rümelin, Die Fliebwirbel.

Forchhelmer, DurchifluB des Wassers. 
pungen zwischen der Sohle und den Seitenwänden, schließlich einige Kilometer des genannten gleichmäßigen Betongerinnes von Trapezquerschnitt bis zum Tachertinger Werk, der Zentrale II. Zwischen dem Einfang des Trostberger Obergrabens an der Alz und der Mündung des Tachertinger Untergrabens hatte Dr. Rümelin 20 Pegel aufstellen

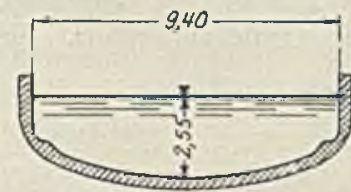

Abb. 4. Betongerinne bei Trostberg. lassen, an welchen während der Abnahmeversuche alle 5 Minuten abgelesen wurde ${ }^{1}$ ). Für die Betontrapezstrecke kommen hier die Pegel 12 und 13 in Betracht, weil sie bei genügendem gegenseitigen Abstand über eine von Störungen möglichst freie Strecke Aufschluß geben. Der Pegel 11 lag nämlich bei Kilometer 1,031 ungefähr an cler Übergangstelle der engeren Schale in die trapezförmige, der Pegel 12 von ihr $1172 \mathrm{~m}$ entfernt bei Kilometer 2,203, der Pegel 14 schon nahe bei der Tachertinger Stufe bei Kilometer 4,497. Die Erhebung der Durchflüsse geschah auf Grund der elektrischen Leistung. Sollte der Wirkungsgrad

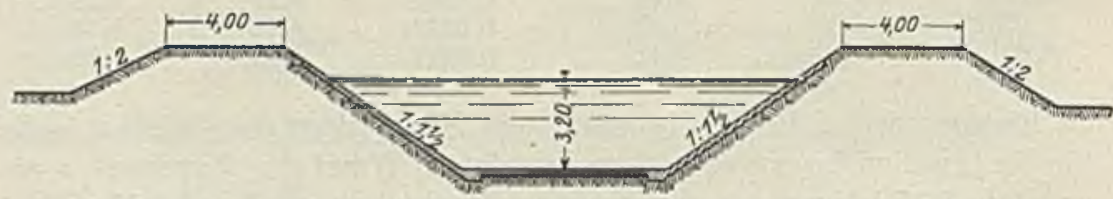

Abb. 5. Werkgrabenquerschnitt Trostberg-Tacherting. 1:300 w. Gr.

selbst ein etwas anderer als der damals angenommene gewesen sein, so würde die Schlußfolgerung auf das $\nu$ dennoch aufrecht bleiben. Zu den, den Akten des Dr. R ü mel in entnommenen Ziffern sei noch bemerkt, da $\beta$ am 21. Oktober der Durchfluß einmal mit Stillegung der Trostberger, das andere Mal mit Stillegung der Tachertinger Turbinen, also das eine Mal der Durchflu B im Tachertinger, das andere Nal der im Trostberger Werk gemessen wurde, und daß am 24. Oktober die Erhebung in Trostberg, am 22. Oktober in beiden Werken geschah. An diesem Tage führte der Riegerkanal wegen Bachauskehr kein Wasser, während sonst zum Triebwasser der Trostberger Turbinen, wie Flügelmessungen ergaben, noch $4,3 \mathrm{~m}^{3} / \mathrm{sec}$ aus dem Riegerkanal hinzuflossen. Zur einen Messung vom 2l. Olitober ist noch zu erwähnen, daß, wie die alle 5 IIinuten wiederholten Aufschreibungen zeigen, sich in der Zeit zwischen 4 Uhr 28 (Nachm.) und 4 Uhr 34, also in 360 Sekunden, eine 0,207 hohe Staustufe

1) Auf Grund der damaligen Aufschreibungen konnten auch Schlïsse auf die Wiedergewinnung von Geschwindigkeitshöhe gezogen werden. Sehweiz. Bauz. 75 (1920), S. 249. 
von Pegel 12 bis Pegel 11 auf eine Länge von $1172 \mathrm{~m}$ aufbaute. Das erforderte bei $16 \mathrm{~m}$ Spiegelbreite $(0,207.1172 .16): 360=10,8 \mathrm{~m}^{3} / \mathrm{sec}$. $\mathrm{Zu}$ den $35,4 \mathrm{~m}^{3} / \mathrm{sec}$, welche die Tachertinger Turbinen damals beaufschlagten, hat man daher noch $10,8 \mathrm{~m}^{3} / \mathrm{sec}$ hinzuzufügen, um den Grabendurchfluß zu erhalten. Das übrige besagen nachstehende Zahlenspalten:

\begin{tabular}{|c|c|c|c|c|}
\hline & Voll & vasservers & uche & $\begin{array}{l}\text { Kleinwasser- } \\
\text { versuch }\end{array}$ \\
\hline & 21. Okt. & 21. Okt. & 24. Okt. & 22. Okt. \\
\hline 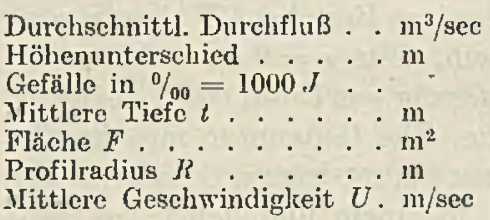 & $\begin{array}{l}46,2 \\
0,285 \\
0,1690 \\
3,25 \\
38,58 \\
2,061 \\
1,197\end{array}$ & $\begin{array}{l}41,27 \\
0,292 \\
0,1737 \\
2,95 \\
33,70 \\
1,893 \\
1,225\end{array}$ & $\begin{array}{c}43,0 \\
0,255 \\
0,1512 \\
2,95 \\
33,70 \\
1,893 \\
1,276\end{array}$ & $\begin{array}{l}17,21 \\
0,064 \\
0,03794 \\
2,752 \\
30,62 \\
1,810 \\
0,5620\end{array}$ \\
\hline
\end{tabular}

Aus diesen Spalten gehen nachstehende Reihen hervor:

\begin{tabular}{|c|c|c|c|c|c|}
\hline \multicolumn{4}{|c|}{ Vollwassermessung } & $\begin{array}{l}\text { Kleinwasser- } \\
\text { messung }\end{array}$ & $\begin{array}{l}\text { Yollwassermessung } \\
\text { im Mittel }\end{array}$ \\
\hline$R$ & $=2,061$ & 1,893 & 1,893 & 1,810 & $\therefore$ \\
\hline $1000 \mathrm{~J}$ & $=0,1690$ & 0,1737 & 0,1512 & 0,03794 & - \\
\hline$\frac{U}{R^{11,7} J^{1,1,0}}$ & $=66,0$ & 70,7 & 79,1 & 73,8 & 71,9 \\
\hline$\frac{U}{R^{0,3} J^{0,5}}$ & $=64,2$ & 67,5 & 75,4 & 67,8 & 69,0 \\
\hline$\frac{U}{R^{10,7}, J^{0,0}}$ & $=5 \overline{5}, \overline{5}$ & 59,4 & 66,4 & 60,2 & 60,4 \\
\hline
\end{tabular}

wonach für neuen Beton, dessen Sichtfläche nur mit der Latte abgestrichen worden ist ${ }^{1}$ ), in Gerinnen großer Abmessungen ein Exponent $v=0,5$ bis 0,52 am wahrscheinlichsten erscheint und für alten angegriffenen Beton $v=0,5 \mathrm{zu}$ erwarten ist. Auf dieselben $v$ hatten die Beobachtungen an Röhren geführt (s. oben S. 14).

\section{Der Exponent $\nu$ des Gefälles bei Fließen in Erdbetten.}

Für unveränderliche Erdbetten gilt offenbar ein ähnliches $v$ wie für alten Beton, auch ist für sie in den Formeln mit Rauhigkeitsziffer die Potenz $J^{0,5}$ gang und gäbe; für natürliche Flüsse und Bäche, die ihr

1) So nach mündlicher Nitteilung des damaligen Bauleiters Dr. Th. Rü melin. 
20 Der Exponent $\mu$ des Profilradius bei Fließen in festen offenen Gerinnen.

Geschiebe selbst aufbereiten, für die also in den einschlägigen mathematischen Ausdrücken die Rauhigkeitsziffern logischerweise entfallen, haben aber neuere Verfasser sich veranlaßt gesehen, den Exponenten zu verringern, und zwar hat sich Matalkiewicz für 0,48 bis 0,5 , Lindboe für 0,42 bis 0,47 und $O$. Gröger, wenn die Tiefe $2 \mathrm{~m}$ übersteigt, für 0,43 entschieden. Diese Abweichungen erklären sich dadurch, daß in ler Gesamtheit der Läufe mit beweglichem Bett die großen Gefälle mit den groben Geschieben, die geringen Neigungen mit den feinen Sanden und dem Schlamm örtlich zusammenfallen. Je größer $J$ ist, desto rauher ist daher im allgemeinen das Bett. Wäre ohne diesen Umstand $U$ der Potenz $J^{0,5}$ proportional, so muß infolge seines Bestehens $U$ einer niedrigeren Potenz annähernd proportional sein. Für $v=0,5$ bewirkt z. B. eine Verdoppelung des Gefälles eine Steigerung von $U$ auf das 1,414 fache, für $v=0,45$ aber nur auf das 1,366 fache. Die Genannten mußten also clurch ihre Zusammenfassung der Gewässer auf niedrigere Gefällpotenzen als $J^{0,5}$ kommen, wonn für Strömung in einem und demselben Bett $U$ proportional mit $J^{0,5}$ wächst. Auf noch einen Umstand, der aber von geringerer Bedeutung scin dürte, macht E. Beyerhaus ${ }^{\mathbf{1}}$ ) aufmerksam, nämlich darauf, daß die stärkeren Gefülle in der Regel in den Strecken, in denen sich das Wasser beschleunigt, und die schwächeren Gefälle in den Verzögerungsstrecken liegen. Die Änderung der Geschwindigkeitshöhe wirke also meist dem Spiegelgefälle entgegen und ermäßige scheinbar den Gefälleexponenten.

\section{Der Exponent $\mu$ des Profilradius bei Fließen in festen offenen Gerinnen.}

Zunächst werde zur Bewertung von $\mu$ für Gerinne mit unveränderlicher Wandung geschritten, für welche die Sachlage einfacher als für Betten ist, deren Oberfläche mit der Fließgeschwindigkeit wecl.selt. Gemäß den angeführten Gleichungen (4) (2) und (5) ist für Beton nach

$$
\begin{gathered}
\text { Bazin (ncuere Formel) } \\
U=\frac{87 R}{0,1+\sqrt{K}} \sqrt{J} \text { bis } \frac{87 R}{0,2+\sqrt{R}} \sqrt{J}
\end{gathered}
$$

$$
\begin{array}{l|l|c}
\multicolumn{1}{c}{\text { Ganguillet und Kutter, } n=0.013} & \text { Biel } \\
J=0.001 & J=0,0001 & \\
U=\frac{101,45 R}{0,3191+\sqrt{R}} \sqrt{J} & U=\frac{115.4 R}{0,5005+\sqrt{R}} \sqrt{J} & U=\frac{91,29 R^{x / 4}}{\sqrt{1+\sqrt{R}}} \sqrt{J}
\end{array}
$$

1) Bauing. 2 (1921), S. 486. 
Der Exponent $\mu$ des Profilradius bei Fließen in festen offenen Gerinnen. 21

In diesen Ausdrücken sind nur ein Teil der Faktoren von $R$ abhängig, und zwar nehmen sie folgende Werte an:

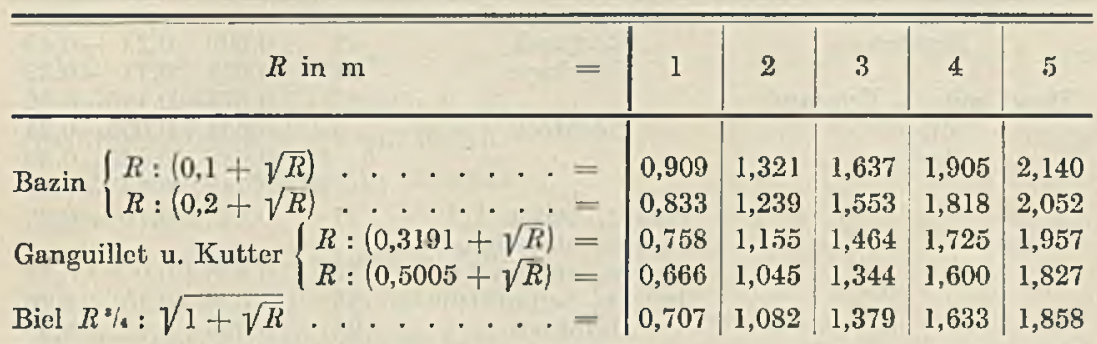

Die Zahlen einer Zeile stehen hicr in folgenden gegenseitigen Verhältnis :

\begin{tabular}{|c|c|c|c|c|c|c|}
\hline & $R=$ & 1 & 2 & 3 & 4 & 5 \\
\hline$R:(0,1+\sqrt{R})$ & $=$ & 1 & 1,45 & 1,80 & 2,10 & 2,35 \\
\hline$(R:(0,2+\sqrt{R})$ & $=$ & 1 & 1,49 & 1,86 & 2,18 & 2,46 \\
\hline Ganguillet u. Kutter $\left\{\begin{array}{l}J=0,001 \\
J=0,0001\end{array}\right.$ & $\therefore=$ & $\begin{array}{l}1 \\
1\end{array}$ & $\begin{array}{l}1,52 \\
1,57\end{array}$ & $\begin{array}{l}1,93 \\
2,02\end{array}$ & $\begin{array}{l}2,28 \\
2,40\end{array}$ & $\begin{array}{l}2,59 \\
2,74\end{array}$ \\
\hline ....... & $\therefore=$ & 1 & 1,53 & 1,95 & 2,31 & 2,63 \\
\hline
\end{tabular}

Andererseits ist für

\begin{tabular}{|c|c|c|c|c|c|c|}
\hline & $R=$ & l & 2 & 3 & 4 & 5 \\
\hline$F^{0,35 t}$ & . $=$ & 1 & 1,45 & 1.81 & 2,11 & 2,38 \\
\hline$R^{0,5}$ &.$=$ & 1 & 1,47 & 1,85 & 2,17 & 2.46 \\
\hline$R^{0,58}$ &.$=$ & 1 & 1,50 & 1,89 & 2,23 & 2,54 \\
\hline$R^{0,80}$ & $\cdot=$ & l & 1,52 & 1,93 & 2,30 & 2,63 \\
\hline$R^{0,02}$ &.$=$ & 1 & 1,54 & 1,98 & 2,36 & 2,71 \\
\hline$R^{0,04}$ & $\cdot=$ & 1 & 1,56 & 2,02 & 2,43 & 2,80 \\
\hline
\end{tabular}

Hiernach wächst bei zunehmendem Profilradius und gleichbleibendem Gefälle die Geschwindigkeit nach

$$
\begin{array}{ccc}
\text { Bazin } & \text { Ganguillet und Kutter } & \text { Biel } \\
\text { proportional mit } R^{0,54} \text { bis } R^{0,57} & R^{0,6} \text { bis } R^{0,63} & R^{0,60}
\end{array}
$$

Die Bazinschen Messungen selbst führon auf höhere Potenzen als die Formeln, seine eigene einbegriffen. Wenn man seine Angaben ausrechnet, die Rauhigkeit der Wandung schätzt und die Angaben nach dieser Rauhigkeit ordnet, erhält man nachstehende Zahlentafel: 


\begin{tabular}{|c|c|c|c|c|}
\hline $\begin{array}{r}\text { Wan } \\
\text { beschaff }\end{array}$ & $\begin{array}{l}\text { Quersel } \\
\text { for }\end{array}$ & $\begin{array}{c}\text { Bazins } \\
\text { Serie }\end{array}$ & $\mu$ & $\begin{array}{l}l \\
\mathrm{~m}\end{array}$ \\
\hline 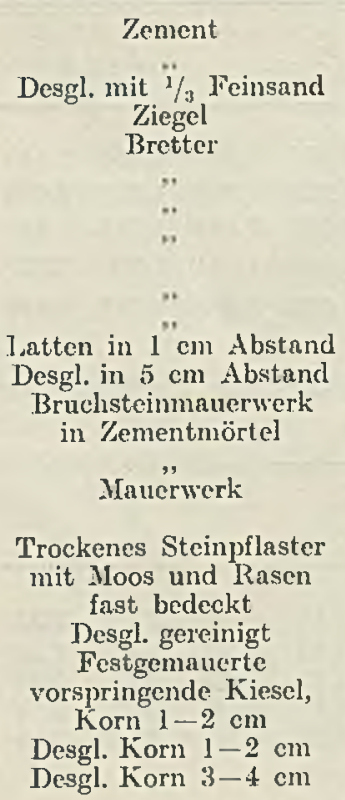 & $\begin{array}{c}\text { Rechteck } \\
\text { Halbkrcis } \\
\text { Rechteck } \\
\text {," } \\
\text { Trapez, Seiten } 1: 1 \\
\text { Trapez, eine Seite } \\
\text { lotrecht, andere } 1: 1 \\
\text { Dreieck, Seiten } 1: 1 \\
\text { Halbkreis } \\
\text { Rechteck } \\
\text { wagrechte Sohle } 1,8 \text { m } \\
\text { breit, Seiten } 1 / 10 \\
\text { Anlage } \\
\text { Sohle flache Kurve } \\
\text { Sciten lotrecht }\end{array}$ & $\begin{array}{c}2 \\
24 \\
25 \\
3 \\
6-11 \\
19-20 \\
21 \\
22 \\
23 \\
26 \\
12-14 \\
15-17 \\
32 \\
33 \\
45\end{array}$ & $\begin{array}{l}0.600 \\
0,678 \\
0.673 \\
0,638 \\
0,682 \\
0,748 \\
0,617 \\
0,675 \\
0,670 \\
0,696 \\
0,701 \\
0,714 \\
0.758 \\
0,733 \\
1,14\end{array}$ & $\begin{array}{l}0,23-0,45 \\
0,11-0,32 \\
0,115-0,32 \\
0.058-0,24 \\
0,045-0,30 \\
0,045-0,30 \\
0,10-0,33 \\
0,078-0,26 \\
0,10-0,26 \\
0,12-0,35 \\
0,056-0,33 \\
0,071-0,40 \\
0,099-0,20 \\
0,13-0,26 \\
0,30-0,49\end{array}$ \\
\hline
\end{tabular}

Nach diesen Zahlen war bei größter Glätte $\mu=0,6$ und stieg bei rauher Wand bis 0,7 und darüber, wobei freilich der Umstand mitwirkte, daß mit wachsendem $R$ die Querschnittsform günstiger wurde. Der

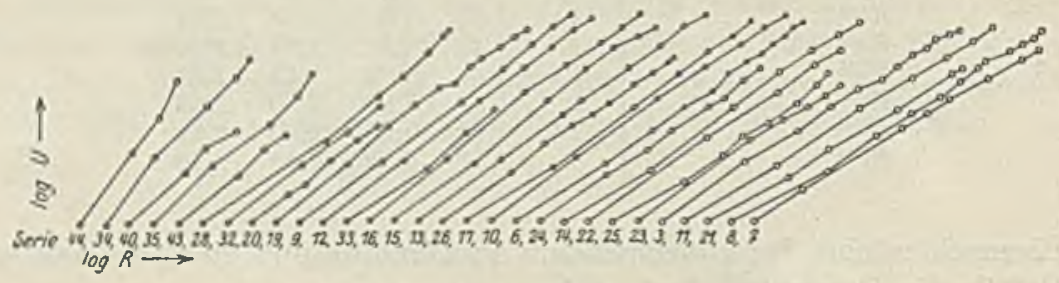

Abb. 6. Bazins regelmäßige Serien.

Zusammenhang zwischen Rauhigkeit und Exponent ist aber keineswegs ein einfacher, wie daraus erhellt, daß man bei Ordnung der Serien nach den Werten von $\mu$ eine ganz andere Reihenfolge der Serien erhält wie die in obiger Zahlentafel, und das, obgleich innerhalb derselben Serie $\mu$ sich nicht ändert. Dies bringt Abb. 6 zum Ausdruck, die ich Ingenieur Walter ron Sauer verdanke. Das Sprunghafte des Exponenten ist 
übrigens eine bei vielen hydraulischen Vorgängen wiederkehrende Erscheinung.

Anders wie offene Rinnsale scheinen sich Röhren zu verhalten, denn für vollkommene Glätte wies Blasius, für Gußeisenwandung Flamant nach, daß die Geschwindigkeit proportional mit $R^{0,714}$ wächst, von welcher Zahl 0,714 sich $\mu$ in

Röhren, soweit heute die Erfahrung reicht, nie weit zu entfermen scheint.

Uber einige Leitungen und Siele mit freiem Spiegel berich tet die englisch-amerikanische Literatur. Im Sudbury-Aquädukt von 0,000189 Sohlengefälle nahmen Fteley und Stearns ${ }^{1}$ ) Messungen vor, auf Grund deren

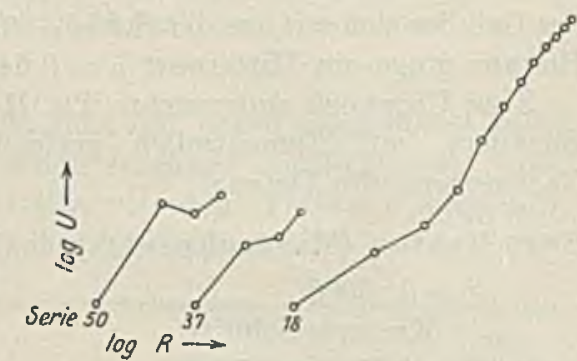

- Abb. 7. Unregelmäßige Serien Bazins. Hughes und Safford ${ }^{2}$ ) berechnen (in metrisches $M a ß$ umgerechnet), für Hufeisenquerschnitt von 2,74 m Lichtweite, 2,35 m Lichthöhe und sorgfültige Klinkerverkleidung

$$
U=82,1 R^{0,62} J^{0,5}
$$

für den gleichen Querschnitt und Zementverputz

$$
U=87,2 R^{0,02}, J 0,5
$$

für Betonsohle und zackige Stollenwände

$$
U=61,1 R^{0,62} J^{0,5} \text {. }
$$

Für den Croton-Aquädukt der Stadt New-York und Betonverkleidung war nach $\mathrm{Lea}^{3}$ ) in metrisches $\mathrm{MIaB}$ umgerechnet für

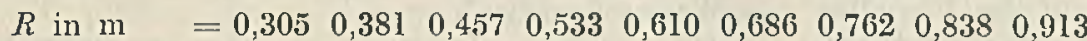

$$
\begin{aligned}
& 0,991 \quad 1,069 \quad 1,143 \quad 1,170 \\
& U \text { in } \mathrm{m} / \mathrm{sec}=0,417 \quad 0,485 \quad 0,546 \quad 0,594 \quad 0,643 \quad 0,692 \quad 0,735 \quad 0,768 \quad 0,808 \\
& 0,847 \quad 0,881 \quad 0,914 \quad 0,920 \text {, }
\end{aligned}
$$

woraus er nit 2 willkürlich $=0,532$

$$
U=100 R^{0,612} J^{0,532}
$$

ableitet. Für eine Klinkerverkleidung derselben Wasserleitung und die Sohlenneigung 0,00013257 berechnen Hughes und Safford (in Metermaß umgewandelt)

$$
U^{i}=73,1 R^{0,56} J^{0,5}
$$

1) Transactions of the American Society of Civil Ingineers (12) S. 114. S. 366 .

क) H. J. Hughes und A. T. Saf ford, A Treatise on Hydraulics. New-York 1911.

3) Aqueduct Commissioner's Report 1895. F. C. Lea, Hydraulies S. 203. 
Berichtet wird auch ${ }^{1}$ ) über Messungen im Felsstollen, welcher Wasser vom Loch (See) Katrine nach Glasgow bringt, welcher Stollen zwar eine durchgehende Betonsohle erhielt, aber an den Ulmen nur zu 0,53 seiner Länge mit Beton verkleidet wurde und zu 0,47 seiner Länge unverkleidet und $60 \mathrm{~cm}$ breiter blieb. Die Messungen erstreckten sich nur auf Profilradien zwischen 0,37 und $0,58 \mathrm{~m}$ und scheinen bezüglich des Gefälles sich auf das der Sohle - 0,0001818 - beschränlit zu haben. Hieraus ginge ein Mittelwert $\mu=0,646$ hervor.

Zwei Unratsiele untersuchte Th. Horton ${ }^{2}$ ); beide waren in Ziegeln gemauert, mit Zementmilch getüncht (cement-washed brickwork). Nachistehend die Daten:

East Boston (Massachusetts)

$$
\begin{gathered}
J=1: 3000 \\
\text { Kreisquerschnitt } \\
R=0,19 \text { bis } 0,70 \mathrm{~m} \\
U=0,43 \text { bis } 1,77 \mathrm{~m} / \mathrm{sec}
\end{gathered}
$$

Nach Lea bei Eröffnung:

$$
U=109,8 R^{0,612} J^{0,532}
$$

Nach 4 Betriebsjahren:

$$
U=95,3 R^{0,612} J^{0,532}
$$

Charlestown (Massachusetts)

$$
\begin{aligned}
& J=1: 2000 \\
& \text { Korbbogenquerschnitt } \\
& R=0,34 \text { bis } 0,65 \mathrm{~m} \\
& U=0,70 \text { bis } 1,01 \mathrm{~m} / \mathrm{sec}
\end{aligned}
$$

$$
U=92,8 R^{0,612} J^{0,532}
$$$$
U=80,6 R^{0,012} J^{0,532}
$$

oder nach Ersatz des willkürlichen $v=0,532$ durch $v=0,5$

(12e) bei Eröffnung $\quad U=85,0 R^{0,612} J^{0,5} \mathrm{bzw} .=72,7 R^{0,612} J^{0,5}$ (12f) nach 4 Betriebsjahren $U=73,7 R^{0,612} J^{0,5}$ bzw. $=63,2 R^{0,012} J^{0,5}$

Die Messung war mit Sorgfalt geschehen, da jedoch die Flüssigkeit aus Jauche bestand und die Beschaffenheit der Sielhaut daher von der Geschwindigkeit und der Spiegelschwankung abhing, ist eine Folgerung auf das Verhalten von Wasser unsicher ${ }^{3}$ ).

Auf den Wasserstollen, der von der Sitter unter $0,000555 \mathrm{Ge}$ fälle zum Elektrizitätswerk Kubel führt und durchweg mit geglättetem Beton verkleidet ist, wurde bereits oben hingewiesen. Die Annahme $\mu=0,7$ und $v=0,5$ führt auf nachstehende .

gemessen $\quad\left\{\begin{array}{lllll}U \text { in } \mathrm{m} / \mathrm{sec}=0,88 & 1,25 & 1,35 & 1,45 & 1,50 \\ R \text { in } \mathrm{m}=0,270 & 0,436 & 0,515 & 0,573 & 0,586\end{array}\right.$

Hieraus folgt ${ }^{4}$ ) in $\mathrm{m}^{0,3} / \mathrm{sec} \quad \lambda=93,41 \quad 91,07 \quad 91,18 \quad 90,89 \quad 92,56$

1) A. F. Bruce, Minutes of Proceedings of the Institution of Civil Engineers, 123 (1896), S. 414.

2) Transactions of the American Society of Civil Engineers 46 (1901), S. 78.

3) Ebenda S. 87 fülırt R. Hering das verschiedene Verhalten der beiden Siele auf ihre ungleiche Spiegelschwankung zuriick.

1) Für diese $U$ und $R$ findet sich

Chézys $c=83,1 \quad 81,3 \quad 79,8 \quad 77,3 \quad 71,8$

Ganguillet und Kutters $n=0,01130,01150,01150,01160,0115$. 
Die Übereinstimmung der errechneten $\lambda$, die als Mittel 91,82 liefern, bestätigt das Zutreffen der Annahne $\mu=0,7$. Als beste Lösung erscheint

$$
U=91,82 R^{0,7} J^{0,5},
$$

welche Gleichung als Summe der Fehlerquadrate nur ein 0,55 tel der Fehlerquadratsumme des Ansatzes

$$
U=92,06 R^{0,69} J^{0,5}
$$

gibt.

Zuverlässige Erhebungen an dem ganz mit Beton verkleideten Bette der Wien in Wien wurden, wie schon eingangs erwähnt, vom österreichischen hydrographischen Zentralbureau dem Verfasser mitgetcilt.

\begin{tabular}{|c|c|c|c|c|c|c|c|}
\hline \multirow{2}{*}{$\begin{array}{l}\text { MeBstelle } \\
\text { MeBtag }\end{array}$} & \multicolumn{3}{|c|}{ Ungarbrücke } & \multicolumn{3}{|c|}{ Rudolfbrücke } & \multirow{2}{*}{$\begin{array}{l}\text { Rein. } \\
\text { prechts- } \\
\text { brücke } \\
3 . V . \\
1910\end{array}$} \\
\hline & $\begin{array}{l}13 . V . \\
1910\end{array}$ & $\begin{array}{l}\text { 4. V. } \\
1910\end{array}$ & $\begin{array}{l}3 . V . \\
1910\end{array}$ & $\begin{array}{l}\text { 19. IV. } \\
1900\end{array}$ & $\begin{array}{c}\text { 7. VI. } \\
1906\end{array}$ & $\begin{array}{l}3 . \mathrm{V} . \\
1910\end{array}$ & \\
\hline$Q$ & 06 & 3 & 49 & 9,0 & 16,7 & 5,22 & 22,05 \\
\hline & & & & & & & \\
\hline there & 0 & 1 , & & 0.56 & & & 1,36 \\
\hline ? & & & & & & & 1,70 \\
\hline$H \mathrm{~m}$ & & 1,1 & 1,7 & 0,2 & & 1, & 1,259 \\
\hline $\begin{array}{l}\text { Gefälle in } \% \text { oo } \\
\text { Mittl. Geschwin- }\end{array}$ & 0,5746 & 05 & 0,5 & 3,2455 & 3, & 3,6 & 4,0 \\
\hline $\begin{array}{l}\text { digkeit } U \mathrm{~m} / \mathrm{sec} \\
\text { Größte Gesehwin- }\end{array}$ & 0,72 & 2,00 & 2,84 & 2,99 & 4,47 & 5,61 & 6,42 \\
\hline & & & & & & - & - \\
\hline DurchifluB $Q$ & 5,11 & 6,7 & 141 & 26,9 & 74,6 & 141,6 & 141,6 \\
\hline $\begin{array}{l}\mathrm{c}=U: \sqrt{X} J \\
\text { Ganguillet und }\end{array}$ & 56,78 & 80,78 & 93,84 & 70,26 & 79,20 & 83,43 & 90,51 \\
\hline Kut & 0,0148 & 0,0126 & 0,0113 & 0,0134 & 0,0126 & 0,0126 & 0,011 \\
\hline & & & & & & & \\
\hline$\lambda=U$ & & 9 & & & & & 96 \\
\hline$\lambda=U: R^{0,04} J^{0,52}$ & 80,5 & 93,4 & 96,2 & 87,5 & 89,4 & 87,9 & 96,9 \\
\hline
\end{tabular}
Die Ergebnisse erhellen aus nachstehender Zahlentafel:

Von diesen Erhebungen ist die erste mit nur 0,29 m Tiefe mit den übrigen offenbar nicht in Verbindung zu bringen, diese übrigen aber führen bei Auftragung der Logarithmen ebenfalls auf eine ähnliche Formel. Auch gibt die Gleichung $U=\lambda R^{0,7} J^{0,5}$ besser übereinstimmende Werte von $\lambda$ als $U=\lambda R^{0,7} J^{0,52}$ oder $U=\lambda R^{0,68} J^{0,52}$, wie man aus den letzten drei Tafelzeilen ersieht. Hiermit ist $\mu=0,7$ und für das Wienbett

$$
U=80,1 \quad R^{0,7} J^{0,5}
$$

gefunden. 
Eine Bestätigung dieses Ansatzes $\mu=0,7$ für große Gerinne liefern schließlich Xessungen, die bei verschiedener Füllung im Kanale GarchingNeukirchen und im Lechwerkkanale vorgenommen wurden, von denen weiter unten (s. S. 32 u. 46) die Rede sein wird.

\section{Der Koeffizient $\lambda$ für Gerinne mit fester Wandung.}

Wieder geben die Bazinschen Versuche Aufschluß, soweit es sich um geringe Abmessungen handelt, und zwar werden, da $\nu$ und $\mu$ jetzt mehr oder weniger bekannt sind, auch Einzelserien verwendbar, die bisher keinen Schluß auf $\lambda$ zuließen. Das übrige besagt nachstehende Tafel. Auf den in ihr vorkommenden Wert $y=0,58$ haben die Versuche mit Brettern geführt. Dahingestellt bleibt, ob nicht mit Rücksicht auf dic für glatte Rohre geltende Blasiussche Gleichung (8a) der Ansatz $v^{\prime}=0,5 \bar{\tau}$ den Vorzug verdienen würde.

\begin{tabular}{|c|c|c|c|}
\hline Wandbeschaffenheit & Querschnitt & Seric Bazins & $U$ ist $=$ \\
\hline $\begin{array}{l}\text { Zement } \\
\text { Desgl. mit } \ddot{1 / 3} \text { Feinsand } \\
\text { Bretter } \\
\text { Ziegel } \\
\text { Latten in } 1 \text { cm Abstand } \\
\text { Bruchstein in Zementmörtel } \\
\text { Kiesel } 1-2 \mathrm{~cm} \text { in Zement } \\
\text { " } 3-4,,, ", ",\end{array}$ & $\begin{array}{c}\text { Rechteck } \\
\text { Halbkreis } \\
\text { Rechteck, Trapez, } \\
\text { Dreieck' } \\
\text { Halblkreis } \\
\text { Rechteck } \\
\text {," } \\
\text { fast Rechteck } \\
\text { Rechteck } \\
\text { ", }\end{array}$ & $\begin{array}{c}2 \\
24 \\
25 \\
6-11,19-23 \\
26 \\
3 \\
12-14 \\
15-17 \\
32.33 \\
4 \\
5\end{array}$ & 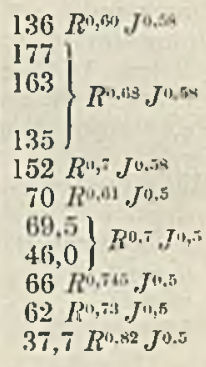 \\
\hline
\end{tabular}

Auf die weiteren in den Gleichungen (8) bis (14a) enthaltenen Werte von $\lambda$ wird später noch zurückgekommen werden. Hier aber werde zunächst auf die Beobachtungen eingegangen, die gegenwärtig an Werkgräben großer Abmessungen vorliegen.

Mit dem Canale Cavour befaßten sich P. Pasini und $\mathrm{C}$. Gioppi ${ }^{1}{ }^{1}$. Eine der untersuchten Strecken hatte eine $20 \mathrm{~m}$ breite ebene Betonsohle und seitlich Ziegelmauern von $1 / 20$ Anlage. Leider war die Strecke nur $133 \mathrm{~m}$ lang, so da $\beta$ bei den auftretenden Spiegelschwankungen erst wiederholte Messungen einen Schluß auf das Spiegelgefälle zuließen. welches die beiden Beobachter schließlich auf 0,00011 bewerten zu dürfen glaubten. Drei an rerschiedenen Tagen vorgenommene Aufnahmen gaben

1) Giornale del genio civile 31 (1893), S. 60 . 
Cavour-Kanal.

\begin{tabular}{|c|c|c|c|c|}
\hline 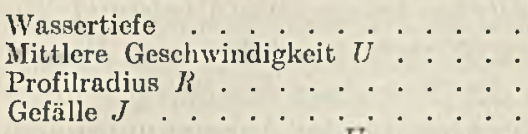 & $\stackrel{m}{m / s e c}_{-}^{m}$ & $\begin{array}{l}1,84 \\
1,074 \\
1,560 \\
0,00011\end{array}$ & $\begin{array}{l}2,12 \\
1,147 \\
1,757 \\
0,00011\end{array}$ & $\begin{array}{l}2,79 \\
1,337 \\
2.195 \\
0,00011\end{array}$ \\
\hline de Chézysche Zahl $c=\frac{U}{\sqrt{ } / R, J} \quad \cdots$ & $\mathrm{m}^{1} / 2 / \mathrm{sec}$ & 81,97 & 82,50 & 86,06 \\
\hline $\begin{array}{l}\text { Ganguillet-Kuttersche Rauhigkeit } n \\
\lambda=U: R^{0,7}, J^{n, 1} \ldots . .\end{array}$ & $\mathrm{m}^{\overline{0.3}} / \mathrm{sec}$ & $\begin{array}{l}0,0130 \\
75,10\end{array}$ & $\begin{array}{l}0,0130 \\
75,71\end{array}$ & $\begin{array}{l}0,0129 \\
73,52\end{array}$ \\
\hline
\end{tabular}

also im Mittel (für $\mu=0,7$ und $\gamma=0,5$ ) $\lambda_{0}=74,11$.

Unter der Voraussetzung, es sei $U=\lambda R^{0, \pi} J^{0,5}$, können die von Dr. Rümelin vor 12 Jahren veranlaßten Trostberger Aufnahmen einer Rechnung unterzogen werden. Dort war der Beton, wie schon erwähnt, nur mit der Latte abgestrichen-worden. Die Rechnung nimmt folgende Gestalt an:

Trostberg-Tacherting 1910.

\begin{tabular}{|c|c|c|c|c|c|c|}
\hline & & & Vollwasser & & Iittel & Klo \\
\hline$U$ & $\mathrm{~m} / \mathrm{sec}$ & 1,197 & & 1276 & & \\
\hline & $\mathrm{m}$ & & & & & \\
\hline 100 & - & & & & 0,1646 & \\
\hline & - & & & & & \\
\hline $\log J^{0,3}$ & - & $5-2$ & $0,11990-2$ & 0,0 & - & $55-3$ \\
\hline & - & 1, & 1,77423 & 1,8 & & 981 \\
\hline & $\mathrm{m}^{0.3} / \mathrm{ec}$ & 55,50 & 59,46 & 66,38 & $60,4 \tilde{5}$ & 60,2 \\
\hline $\begin{array}{l}c=U: \sqrt{K J} . \\
\text { Rauhigkeic } n\end{array}$ & $\mathrm{~m}^{2} / 2 / 3 \mathrm{sec}$ & - & - & - & $\begin{array}{l}66,94 \\
0,0167\end{array}$ & $\begin{array}{l}67,82 \\
0,0175\end{array}$ \\
\hline
\end{tabular}

Danach mußte $\lambda=$ ungefähr 60,3 gewesen sein. Es wirl sich später zeigen, da $\beta$ die sehr glatte neue Strecke Garching-Neukirchen nur $\lambda=59,0$ aufweist. Vermutlich ist in Trostberg-Tacherting der nur nach der elektrischen Leistung beurteilte Durchfluß seinerzeit etwas überschätzt worden und $\lambda$ nicht größer als 59,0 gewesen.

Seitdem hat sich der Zustand der Betonoberfläche dort wesentlich verschlechtert; es sind Löcher bis zu $20 \mathrm{~cm}$ Ausdehnung und bis zu 5 . ausnahmsweise auch wohl $10 \mathrm{~cm}$ Tiefe entstanden, so daß die Oberfläche der eines gewöhnlichen festgelagerten Kieses gleicht, dessen eiförmige Kiesel 1 bis $5 \mathrm{~cm}$ Länge besitzen. Hier wurde während der dasalbst vorgenommenen 3 Durchflußmessungen der Spiegel einer $4000 \mathrm{~m}$ langen Strecke alle $400 \mathrm{~m}$ beobachtet. Es waren also 11 Beobachter nötig, deren jeder den Auftrag hatte, den Wasserstand während einer vorher festgesetzten Zeit von 46 Minuten alle 2 Minuten aufzuschreiben. 


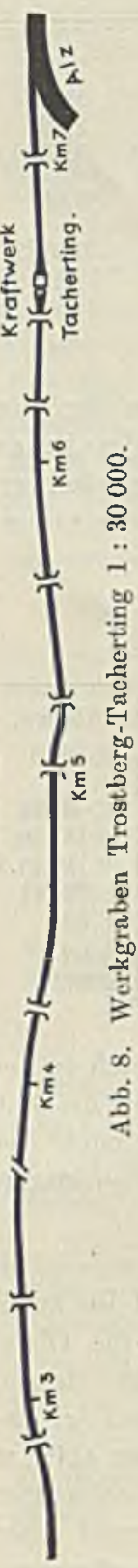

Dabei war angenommen worden, daß die Durchflußmessungen sicher nicht mehr als 46 Minuten $^{1}$ ) erfordern werden.

Die üblichen Pegelpflöcke haben den Übelstand, zu nahe am Ufer und seinen Wirbeln zu stehen, das Wasser aufzustauen und wegen der Tiefenlage des Spiegels unter dem Standplatz des Beobachters für das Ablesen unbequem zu sein. Diese UUbelstände wurden durch ein wesentlich von Bauführer (heute Oberbauverwalter) P. Thoma erdachtes Verfahren überwunden. Quer zur Uferlinie wurden auf der Uferfläche je 2 Pflöcke so eingeschlagen, daß die beiden

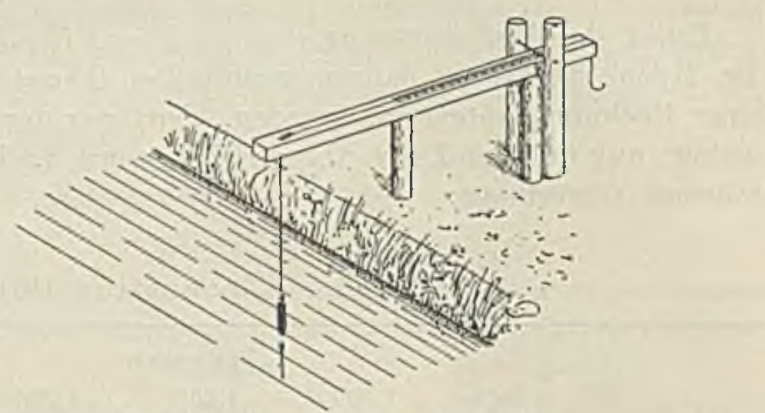

Abb. 9. Bestimmung der Spiegelhöhe.

Köpfe des Paares genau in gleiche Höhe kamen. Die Kopfflächen wurden dann in ein Nivellement einbezogen. Vor der Wassermessung legte man auf jedes Pflockpaar eine Latte, in deren Oberseite ein Zweimeterstock eingelassen war und keilte die Latte gegen den Verbindungsdrahtstift zweier weiterer Pflöcke fest, die zu diesem Zweck rechts und links von der späteren Latte eingeschlagen worden waren ${ }^{2}$ ). Der Nullpunkt des Meßstockes war der Landseite zugekehrt. Am wasserseitigen Ende trug die Latte ein Röllchen, über welches ein dünner Draht durch eine Bohrung der Latte hindurch lief; an ihm hing ein Eisenstück, welches schwer genug sein mußte, um den Draht zu spannen. Auf den Draht wurde eine Drahtranke geklemmt, die, wenn das Eisenstück z. B. $16 \mathrm{~cm}$ lang war und man es hinaufzog, bis seine obere Kante an die Unterseite der Latte anstieß,

1) Sie dauerten hier 28 bis 33 Minuten. Es ist kaum nötig, zu bemerken, daß alle Uhren vor der Messung auf gleiche Zoit gestellt wurden. Sämtliche Neuaufnahmen erliegen bei der Landesstelle für Gewässerkunde in Miünchen.

7) Die Verkeilung ist in der Abbildung fortgelassen. 
über dem Teilstrich 16 des Meßstockes lag. Beim Messen ließ nan das Eisenstück hinab, bis seine untere Spitze den Wasserspiegel traf. Dann gab der Teilstrich, über den die Ranke kam, unmittelbar die Tiefenlage des Spiegels unter den Pfahlköpfen an. Es war leicht, auf diese Weise die schwankende Spiegellage 3 bis $4 \mathrm{~mm}$ genau zu ermitteln, ja

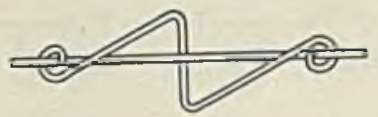

Abb. 10. Ranke. bei ruhigem Spiegel hätte sein Stand wohl mit I mm Genauigkeit festgestellt werden können.

Die Meßergebnisse sind nachstehend zusammengestellt, wobei bei Aufsuchung der Gesamtmittel die für die 3 inneren Beobachtungspunkte gefundenen Daten mit doppeltem Gewicht eingeführt wurden.

Trostberg-Tacherting 1920.

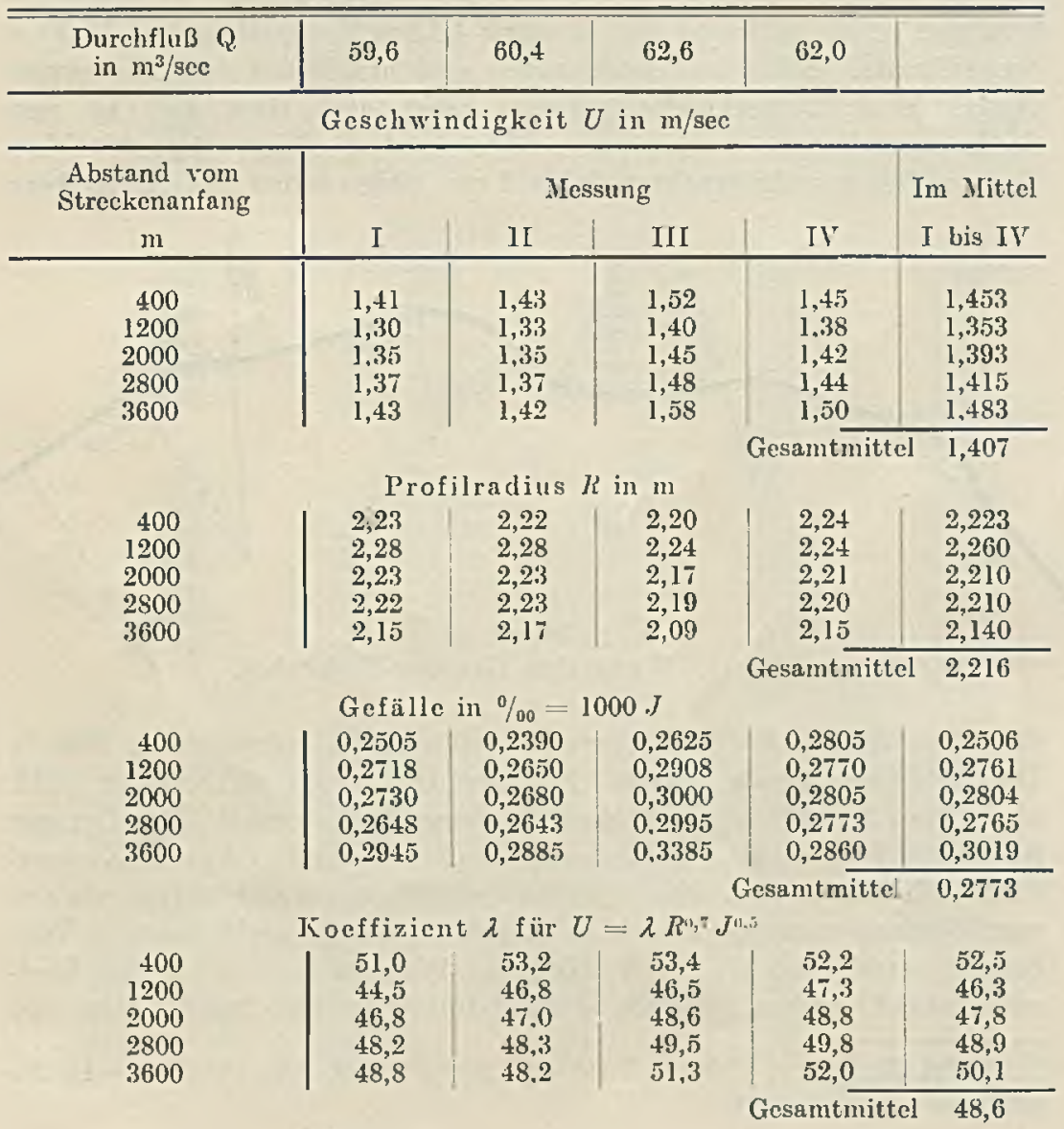


Den Gesamtmitteln $U=1,407, R=2,216, J=0,0002773$ entspricht de Chézys Zahl $c=56,72 \mathrm{~m} / \mathrm{sec}$ und Ganguillett-Kutters Rauhigkeit $u=0,020$.

Das durch den Untergraben von Tacherting in die $\mathrm{Alz}$ zurückgekehrte Wasser wird gegenwärtig in einem zweiten Graben der Bayerischen

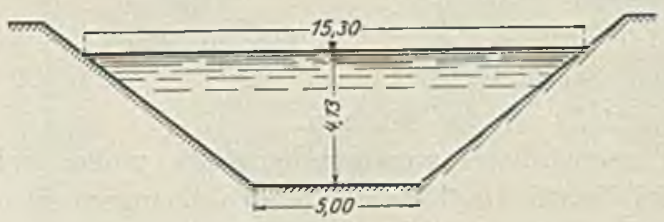

$1: 300$ w. Gis. Stickstoffwerke abermals gefaßt, welcher Graben zwischen Garching und Neukirchen gute Meßgelegenheit bot. $\mathrm{Er}$ hat Trapezquerschnitt mit wagrechter Sohle von $5 \mathrm{~m}$

Abb. 11. Werkgraben Garching-Neukirehen. fast lage und zeigte während der Hessung $4,13 \mathrm{~m}$ Wasserticfe und $15,30 \mathrm{~m}$ Spiegelbreite. Sohle und Böschungen sind mit Beton vom Mischungsverhältnis 1:12 verkleidet, dessen Sand und Kies an Ort und Stelle ausgehoben worden war. Die letzten gleichzeitig mit dem ïbrigen Beton aufgebrachten 2 bis $3 \mathrm{~cm}$ bilden einen mit Holzreibern

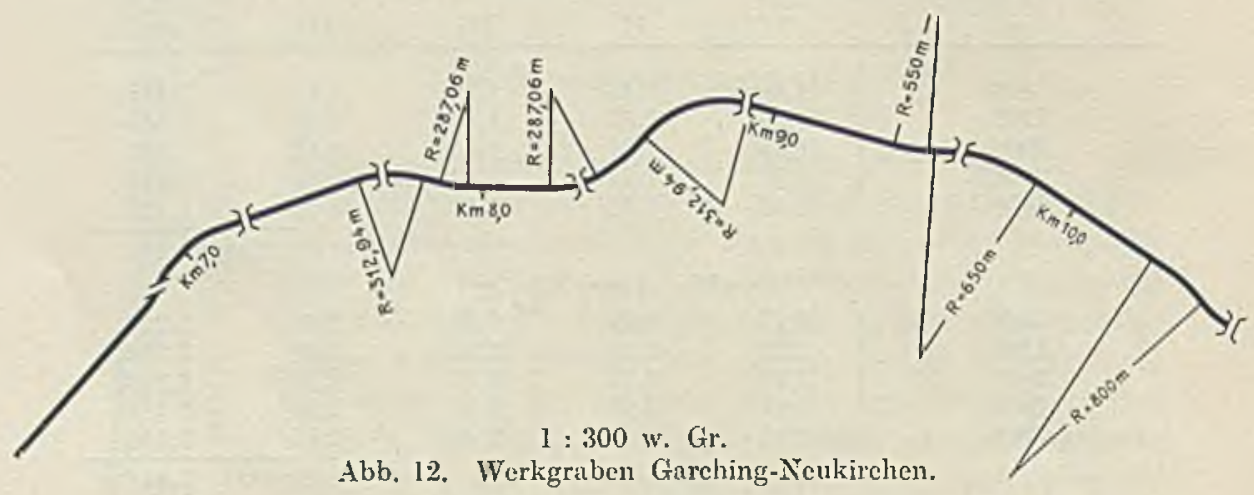

Abb, 12. Werkgraben Garching-Neukirchen.

von etwa 20 auf $30 \mathrm{~cm}$ Fläche oder mit der Kelle geglätteten Putz ${ }^{1}$ ). Die Betonierung war teils im Sommer 1917, teils im Sommer 1918, also I und 2 Jahre vor der Messung, hergestellt worden. Das Gerinne zeichnet sich durch Regelmäßigkeit, Gleichförmigkeit und guten Zustand seiner Oberfläche aus. Die Spiegelschwankungen waren gering, da das vom Gerinne versorgte Werk in Margarethenberg noch nicht in Vollbetrieb stand, also ein großer Teil des Wassers hier durch den Leerschuß ablief. Diese Umstände und die dreimalige Durchflußbestimmung

1) Vgl. H. Dietz, Z. V. d. I. Bd. 64 (1920), S. 723. Der Putz hatte die Mischung $1: 3$. 
bei gleichzeitiger Spiegelbeobachtung an 10 Punkten längs einer Streckc von $3600 \mathrm{~m}$, die wenige und nur flache Kurven enthielt, machen die Aufnahme zu einer besonders zuverlässigen. Sie liefert folgende Daten, wenn wieder bei der Gesamtmittelbildung dic zweite bis vierte Reihe mit dem doppelten Gewicht der ersten und letzten bewertet wird.

Garching-Nenkirchen 1920.

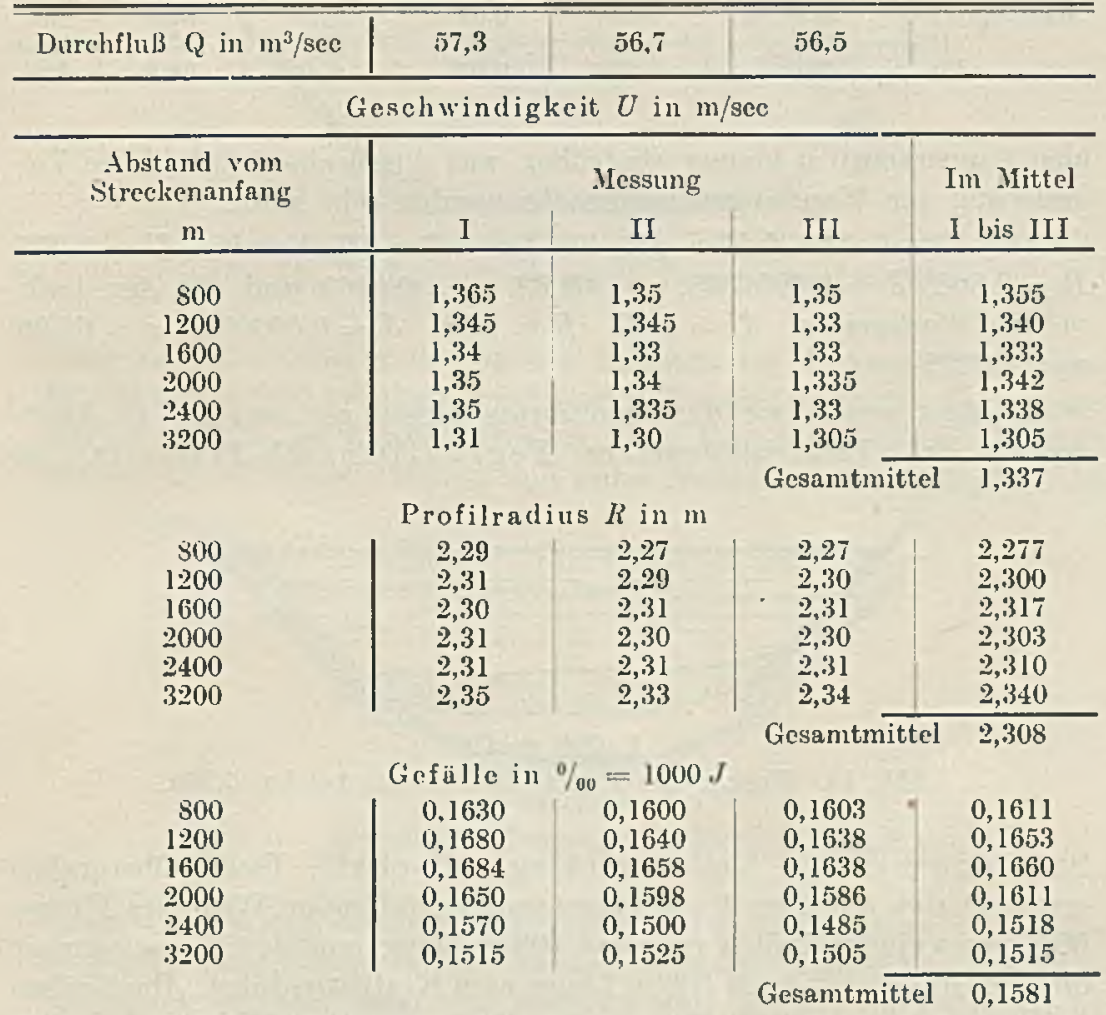

Aus obigen Zahlen geht durch Zusammenstellung der Nittel hervor:

\begin{tabular}{|c|c|c|c|c|}
\hline $\begin{array}{c}\text { Abstand vom } \\
\text { Streckenanfang } \\
\mathrm{m}\end{array}$ & $\begin{array}{c}\text { Profilradius } \\
\qquad R \\
\mathrm{~m}\end{array}$ & $\begin{array}{l}\text { Gefülle } \\
\text { in U/on } \\
1000 \%\end{array}$ & $\begin{array}{c}\text { Geschwindig- } \\
\text { keit } U \\
\text { m/sec }\end{array}$ & $\begin{array}{c}\text { Koeffizient } \\
\lambda \text { in } \\
U==\hat{\lambda} K^{U, *} J^{0, \mathrm{~s}}\end{array}$ \\
\hline $\begin{array}{r}800 \\
1200 \\
1600 \\
2000 \\
2400 \\
3200\end{array}$ & $\begin{array}{l}2,277 \\
2,3 \\
2,317 \\
2,303 \\
2.310 \\
2,340\end{array}$ & $\begin{array}{l}0,1611 \\
0,1653 \\
0,1660 \\
0,1611 \\
0,1518 \\
0,1515\end{array}$ & $\begin{array}{l}1,355 \\
1,340 \\
1,333 \\
1,342 \\
1,338 \\
1,305\end{array}$ & $\begin{array}{l}60,01 \\
58,18 \\
57,46 \\
58,96 \\
60,43 \\
58,47\end{array}$ \\
\hline & & & G'esamt & 58,92 \\
\hline
\end{tabular}


Von besonderem Belang ist es, daß ${ }^{5} / 4$ Jahre später neue Messungen bei halbvollem Kanal vorgenommen wurden. Es zeigte sich:

\begin{tabular}{|c|c|c|c|c|c|}
\hline & $\begin{array}{c}\text { DurehfluB } \\
Q \\
\mathrm{~m}^{3} / \mathrm{sec} \\
\end{array}$ & $\begin{array}{c}\text { Profilradius } \\
\qquad R \\
\mathrm{~m}\end{array}$ & $\begin{array}{c}\text { Gefälle } \\
\text { in \%o } \\
=1000 \mathrm{~J}\end{array}$ & $\begin{array}{l}\text { Gescliwin- } \\
\text { digkeit } U \\
\mathrm{~m} / \mathrm{sec}\end{array}$ & $U=\lambda R^{\prime, \pi}, J^{0 . \pi}$ \\
\hline $\begin{array}{cr}\text { MIessung } & \text { I } \\
, " & \text { II } \\
., & \text { III }\end{array}$ & $\begin{array}{l}22,6 \\
22,2 \\
22,9\end{array}$ & $\begin{array}{l}1.88 \\
1,88 \\
1,88\end{array}$ & $\begin{array}{l}0,077 \\
0,077 \\
0,077\end{array}$ & $\begin{array}{l}0,79 \\
0,78 \\
0,80\end{array}$ & $\left\{\begin{array}{c}\operatorname{im}_{11} \\
\text { Mittel } \\
58,5\end{array}\right.$ \\
\hline
\end{tabular}

also $\hbar$ unwesentlich kleiner als früher, was durch eine tatsächliche Veränderung der Wandungen verursacht worden sein kann.

Das Mittel aller Zahlen gibt für den vollen Werkgraben $U=1,335$, $R=2,308, J=0,0001595, c=69,63, n=0,0163$ und für den halkvollen Werligraben $U=0.79, \quad R=1,88, \quad J=0,000077, \quad c=65,66$. $n=0,0172$.

Weniger genau wie die angeführten Messungen war die im Obergraben des Elektrizitätswerkes Peggau-Deutsch-Feistritz der

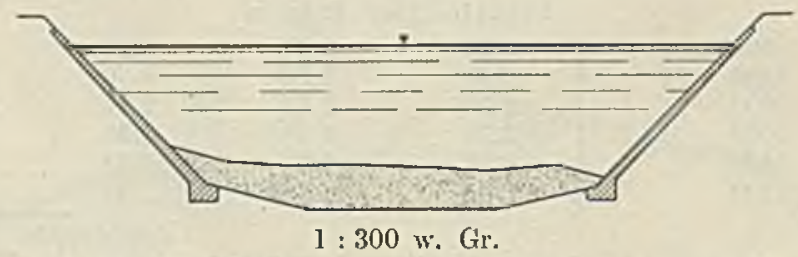

Abb. 13. Werkgraben Peggau-D. Feistritz bei km 0,300.

Steiermärkischen Elektrizitätsgesellschaft. Dieser Obergraben erstreclit sich auf über $1 \mathrm{~km}$ Lünge vom betreffenden Wehr des Flusses ILur bis zu einem Stollen von rund $400 \mathrm{~m}$ Lünge, von dem aus wieder ein offener Graben von rund $600 \mathrm{~m}$ Länge zum Krafthaus führt. Die Gräben haben eine wagrechte Sohle von $6 \mathrm{~m}$ Breite zwischen Wehr und Stollen und von $5 \mathrm{~m}$ zwischen Stollen und Krafthaus, an welche Sohle beidseitig flachgeneigte Streifen von je $3 \mathrm{~m}$ Grundrißbreite anschließen. die den Ubergang zu den Böschungen bilden. Die Neigung der Übergangsstreifen betrïgt 1:4 zwischen Wehr und Stollen, $1: 2$ zwischen Stollen und Krafthaus, die der Böschungen durchwegs 1:1. Durch die Utbergangsflächen erscheinen, besonders zwischen Stollen und Krafthaus, die toten Ecken in günstiger Weise sehr eingeschrïnkt. Oberhalb des Stollens sind die Böschungen mit Beton versichert und war die Sohle ïberall mit Schlamm und Kies bedeckt. Gemessen wurde von Profil 100 bis 600 (vom Wehr aus bezeichnet) und von 700 bis 1049,5 , und zwar 
weil diese Teile gerade sind, während zwischen ihnen ein Bogen liegt. Auch vom Stollen abwärts, wo der ganze Umfang betoniert ist, wurde gemessen. Die Messungen begannen am 9. April 1920 zwischen Wehr und Stollen, und die Untersuchung zeigte Sohle und Ubergangsstreifen - wie schon angedeutet - von einem Gemenge von Schlamm und Ur. gebirgschotter bedeckt, welch letzterer aus Sand und Kies mit abge-

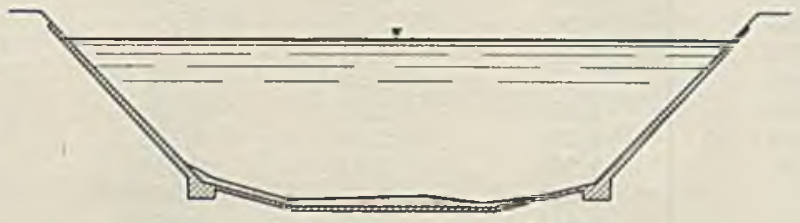

1 : 300 w. Gr.

Abb. 14. Werkgraben Peggau-D. Feistritz boi $\mathrm{km} 0,900$.

rundeten (also nicht ganz runden) Körnern bis Ganseigröße bestand. Der Beton ist gut erhalten, zeigt in der Kiessohlenstrecke Algenansatz, keinen solchen im übrigen Graben. Dic Gefälsermittlung litt unter der Kürze der Einzelstrecken und unter fortwährenden Spiegelschwan-

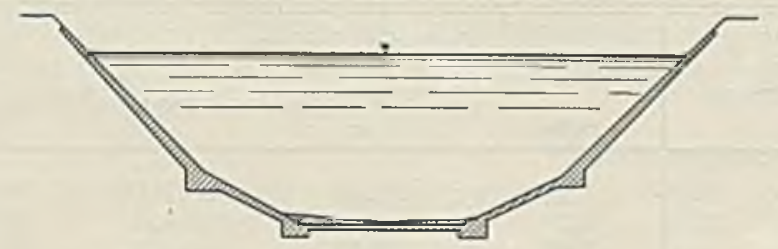

$1: 30000$ w. Gr.

Abb. 15. Werkg1aben Peggan-D. Feistrit\% bei km 2,450.

kungen, zeigte sich doch das Gefälle auf $100 \mathrm{~m}$ Länge bisweilen negativ, so daß nur der Wittelwert des Spiegelgefälles auf brauchbare Lösungen führt. Am 10. April fand eine Spülung statt, bei der die Geschwindigkeit aber nicht über $2 \mathrm{~m}$ sticg, da man der Kiessohle wegen nicht wagte, kräftiger vorzugehen, so da $B$ dic Deckschichte an den Meßstellen zwar verändert und etwas vermindert, aber nicht fortgeschafft wurde. Die Meßergebnisse sind die folgenden, wobei für jeden Punkt, soweit angängig, sowohl das jeweilige örtliche wie auch das ausgeglichene Gefälle eingesetzt wurde. 
Peggau-Deutsch Feistritz 1920.

\begin{tabular}{|c|c|c|c|c|}
\hline $\begin{array}{c}\text { Entfernung } \\
\text { rom } \\
\text { Grabenanfang } \\
\text { km }\end{array}$ & $\begin{array}{c}U \\
\mathrm{~m} / \mathrm{sec} \\
\end{array}$ & $\begin{array}{l}\text { er Spi } \\
R \\
m \\
\end{array}$ & $1000 \mathrm{~J}$ & $\begin{array}{l}\text { 2. in } U= \\
\lambda R^{0,7} J^{10,8} \\
\mathrm{~m}^{0,3} / \mathrm{sec}\end{array}$ \\
\hline $\begin{array}{l}0,100 \\
0,100 \\
0,100 \\
0,100 \\
0,300 \\
0,300 \\
0,300 \\
0,300 \\
0,500 \\
0,500 \\
0,500 \\
0,700 \\
0,900 \\
0,900 \\
1,0495 \\
1,0495\end{array}$ & $\begin{array}{l}1,21 \\
1,21 \\
1,26 \\
1,26 \\
1,15 \\
1,15 \\
1,20 \\
1,20 \\
0,947 \\
0,947 \\
1,09 \\
1,00 \\
0,925 \\
0,925 \\
0,91 \\
0,91\end{array}$ & $\begin{array}{l}2,48 \\
2,48 \\
2,51 \\
2,51 \\
2,55 \\
2,55 \\
2,62 \\
2,62 \\
3,07 \\
3,07 \\
2,85 \\
3,01 \\
3,23 \\
3,23 \\
3,20 \\
3,20\end{array}$ & $\begin{array}{l}0,0904 \\
0,130 \\
0,178 \\
0,210 \\
0,0904 \\
0,130 \\
0,178 \\
0,210 \\
0,0465 \\
0,0503 \\
0,146 \\
0,096 \\
0,0874 \\
0,096 \\
0,0874 \\
0,096\end{array}$ & $\begin{array}{l}64,0 \\
53,3 \\
49,7 \\
45,7 \\
63,0 \\
52,3 \\
46,0 \\
42,3 \\
63,5 \\
60,7 \\
43,3 \\
47,2 \\
43,7 \\
40,6 \\
43,1 \\
41,1\end{array}$ \\
\hline
\end{tabular}

Der Durchfluß $Q$ betrug bei den 3 vorgenommenen Durchflußmessungen $70,2,70,2$ und $75,2 \mathrm{~m}^{3} / \mathrm{sec}$.

\begin{tabular}{|c|c|c|c|c|}
\hline $\begin{array}{c}\text { Entfernung } \\
\text { vom } \\
\text { Grabenanfang } \\
\text { km }\end{array}$ & $\begin{array}{c}U \\
\mathrm{~m} / \mathrm{sec}\end{array}$ & $\begin{array}{c}\text { der } \mathrm{S}_{1} \\
R \\
\mathrm{~m} \\
\end{array}$ & $1000 \mathrm{~J}$ & $\begin{array}{l}\lambda \operatorname{in} U= \\
\lambda R^{0,7}, J^{1,3} \\
\mathrm{~m}^{0,3} / \mathrm{sec}\end{array}$ \\
\hline $\begin{array}{l}0,100 \\
0,100 \\
0,100 \\
0,100 \\
0,300 \\
0,300 \\
0,300 \\
0,300 \\
0,500 \\
0,500 \\
0,500 \\
0,500 \\
0,500 \\
0,700 \\
0,700 \\
0,900 \\
0,900 \\
0,900 \\
0,900 \\
1,0495 \\
1,0495 \\
1,0495 \\
1,0495\end{array}$ & $\begin{array}{l}1,22 \\
1,28 \\
1,26 \\
1,21 \\
1,18 \\
1,13 \\
1,14 \\
1,18 \\
1,10 \\
1,06 \\
1,10 \\
1,055 \\
1,10 \\
1,01 \\
0,965 \\
0,925 \\
0,89 \\
0,90 \\
0,954 \\
0,94 \\
0,91 \\
0,91 \\
0,945\end{array}$ & $\begin{array}{l}2,51 \\
2,46 \\
2,53 \\
2,53 \\
2,05 \\
2,70 \\
2,68 \\
2,68 \\
2,81 \\
2,82 \\
2,79 \\
2,84 \\
2,81 \\
2,85 \\
3,00 \\
3,24 \\
3,21 \\
3,22 \\
3,11 \\
3,22 \\
3,21 \\
3,22 \\
3,17\end{array}$ & $\begin{array}{l}0,146 \\
0,150 \\
0,186 \\
0,186 \\
0,1195 \\
0,124 \\
0,133 \\
0,133 \\
0,0804 \\
0,0804 \\
0,089 \\
0,103 \\
0,133 \\
0,0635 \\
0,086 \\
0,0369 \\
0,0369 \\
0,0497 \\
0,0635 \\
0,0369 \\
0,0369 \\
0,0497 \\
0,0635\end{array}$ & $\begin{array}{l}53,0 \\
55,7 \\
48,5 \\
46,5 \\
54,7 \\
51,0 \\
49,8 \\
51,7 \\
59,2 \\
57,0 \\
57,0 \\
49,3 \\
46,5 \\
59,8 \\
48,0 \\
68,0 \\
66,0 \\
56,0 \\
56,4 \\
69,0 \\
67,3 \\
57,0 \\
56,0\end{array}$ \\
\hline
\end{tabular}

Zwei Durchflußmessungen ergaben $Q=74,6$ und $72,6 \mathrm{~m}^{3} / \mathrm{sec}$. 


\begin{tabular}{|c|c|c|c|c|}
\hline $\begin{array}{l}\text { Entfeinung } \\
\text { rom } \\
\text { Grabenanfang } \\
\text { km }\end{array}$ & $\begin{array}{c}U \\
\mathrm{~m} / \mathrm{sec}\end{array}$ & $\begin{array}{c}\text { der } \mathrm{S} \\
\mathrm{n} \\
\mathrm{m}\end{array}$ & $1000 . J$ & $\begin{array}{l}\lambda \text { in } v= \\
\lambda R^{k, 7}, J^{\prime \prime, i+} \\
\mathrm{m}^{0,8} / \mathrm{sec}\end{array}$ \\
\hline $\begin{array}{l}2,450 \\
2,450 \\
2,450 \\
2,650 \\
2,650 \\
2,650 \\
2,850 \\
2,850 \\
2,850\end{array}$ & $\begin{array}{l}1,06 \\
1,04 \\
1,06 \\
1,07 \\
1,05 \\
1,07 \\
1,02 \\
1,00 \\
1,02\end{array}$ & $\begin{array}{l}3,08 \\
3,10 \\
3,08 \\
3,07 \\
3,07 \\
3,07 \\
3,17 \\
3,17 \\
3,17\end{array}$ & $\begin{array}{l}0,0612 \\
0,0612 \\
0,0632 \\
0,0612 \\
0,0612 \\
0,0632 \\
0,0612 \\
0,0612 \\
0,0612\end{array}$ & $\begin{array}{l}62,0 \\
60,5 \\
60,6 \\
62,6 \\
61,4 \\
61,5 \\
58,3 \\
57,2 \\
57,4\end{array}$ \\
\hline
\end{tabular}

Zwei Durchflußmessungen ergaben $Q=74,0$ bzw. 75,5.

Diese 3 Zahlentafeln liefern als Mittel für den Graben: vom Wehr zum Stollen vor der Spülung $\ldots \ldots \lambda=50,0 m m^{0.3} / \mathrm{sec}$ " " , " nacls " " ... vom Stollen zum Krafthaus nach der Spülung . . $\lambda=60,2$ ",

Hiernach hat dje Spülung zwischen Wehr und Stollen eine Glättung der Sohle bewirkt. Zwischen Stollen und Krafthaus, wo der Spülstrom kräftiger wurde, tat sie das vermutlich in höherem Grade. Die wesentliche Ursache, da $B$ hier $\%$ größer war als weiter stromauf, bestand aber wohl im günstigeren Verhältnis der Betonböschungen zur versandeten Sohle. Es waren nämlich die Anteile von Beton einerseits, Schlamm und Kies andererseits am benetzten Umfang

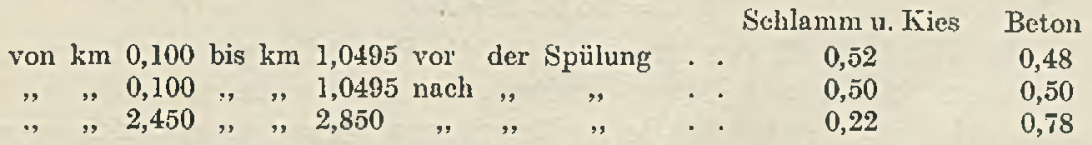

Man sieht, daß eine schmale Sohle, die man schon wegen der hydrat1lisch günstigeren Umrißform heute gerne wählt, auch durch die Einschränkung der Schlamm- oder Kiesdecke wesentlichen Vorteil bietet.

Vorstchende Daten ergeben ferner

\begin{tabular}{c|c|c|c|c|c}
\hline \multirow{2}{*}{$\begin{array}{c}\text { Entfernung } \\
\text { vomı } \\
\text { Grabenanfang } \\
\mathrm{km}\end{array}$} & \multicolumn{3}{|c|}{ Vor der Splilung } & de Chézy's $c$ & $\begin{array}{c}\text { Ganguillet- } \\
\text { Kutters } n\end{array}$ \\
& $\begin{array}{c}U \\
\mathrm{~m} / \mathrm{sec}\end{array}$ & $\begin{array}{c}R \\
\mathrm{~m}\end{array}$ & $1000 \mathrm{~J}$ & $\mathrm{~m}^{2 / / / s e c}$ & \\
\hline \multirow{2}{*}{0,100} & 1.235 & 2,495 & 0,1521 & 67,15 & 0,0172 \\
0,300 & 1,175 & 2,585 & 0,1521 & 59,26 & 0,0199 \\
0,500 & 0,961 & 2,993 & 0,0809 & 63,94 & 0,0193 \\
0.700 & 1,000 & 3,01 & 0,096 & 58,83 & 0,0210 \\
0,300 & 0,925 & 3,23 & 0,0917 & 53.75 & 0,0237 \\
1,0495 & 0,910 & 3,20 & 0,0917 & 53,12 & 0,0240 \\
& & & & & $3 *$
\end{tabular}




\begin{tabular}{c|c|c|c|c|c}
\hline \hline $\begin{array}{c}\text { Entfernung } \\
\text { vom } \\
\text { Grabenanfang }\end{array}$ & \multicolumn{3}{|c|}{$\begin{array}{c}\text { Nach der Spülung } \\
\text { Im Inittel }\end{array}$} & de Chézys $c$ & Ganguillet- \\
Km & $U$ & $R$ & $1000 J$ & $\mathrm{~m}^{2 / 2} / \mathrm{sec}$ & \\
\hline & $\mathrm{m}$ & $\mathrm{m}$ & & & \\
\hline & & & & & \\
0,100 & 1,243 & 2,508 & 0,1670 & 04,72 & 0,0192 \\
0,300 & 1,158 & 2,528 & 0,1274 & 64,56 & 0,0182 \\
0,500 & 1,083 & 2,814 & 0,0972 & 65,48 & 0,0184 \\
0,700 & 0,988 & 2,925 & 0,07475 & 66,82 & 0,0184 \\
0,900 & 0,917 & 3,195 & 0,04675 & 75,20 & 0,0169 \\
1,0495 & 0,926 & 3,205 & 0,04675 & 75,65 & 0,0168 \\
2,450 & 1,053 & 3,087 & 0,06187 & 76,19 & 0,0162 \\
2,650 & 1,063 & 3,070 & 0,06187 & 77,13 & 0,0159 \\
2,850 & 1,013 & 3,170 & 0,06187 & 72,33 & 0,0173 \\
& & & & &
\end{tabular}

oder im Gesamtmittel

ron $\mathrm{km} 0,1$ bis 1,0495 vor der Spülung . . . . c $c=59,3 \quad n=0,0209$ " , $0,1 \quad$ " 1,0495 nach . " ... . . . c $=68,1 \quad n=0,0180$

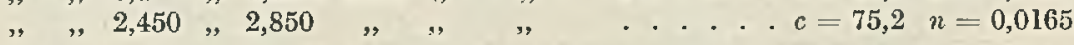

Ähnlichkcit mit dem Peggauer Kanal besitzt der des Elektrizitìts werkes zu Aarau, von dem Eppor ${ }^{1}$ ) folgende Daten angibt:

$U=1,014 \mathrm{~m} / \mathrm{sec}, R=2,016 \mathrm{~m}, J=0,000120$, Sohle aus feinem Kies, linke Wandung Betonmauer mit Neigung 1,1 wagrecht auf 1 lotrecht, rechte Wandung 1,2 wagrecht auf 1 lotrecht, also Anteil des Kieses am Umfang 0,74, Anteil des Betons am Umfang 0,26, $c=65,19 \mathrm{~m}^{1} / 2 / \mathrm{sec}, n=0,0173$. Das ergibt $\lambda=56,66$ oder

$$
U=56,66 R^{0,7} J^{0,5}
$$

Der Versuchstoff, der nummehr für die Beurteilung fester Geriume, besonders solcher aus Beton, vorliegt, ist nicht unbeträchtlich, und zwar sei vorerst der folgende in Erinnerung gebracht, in welchem $\mu$ oder $\nu$ oder beide Exponenten von den Werten 0,7 bzw. 0,5 abweichen.

\begin{tabular}{|c|c|c|}
\hline & $\underset{\text { im }}{R \text { inittel }} \mathrm{m}$ & $\begin{array}{l}U \text { in } \mathrm{m} / \mathrm{sec} \\
\text { ist }=\end{array}$ \\
\hline Ganz glattes Rohr Gl. (8) & - & $20 \mathrm{I} R^{0, \pi 1} J^{0, \pi, \pi}$ \\
\hline Brettergerinne Gl. (10) & 0,20 & $136 R^{1,00}, J^{0,56}$ \\
\hline Sudbury-Aquädukt in Klinker G1. (12) & 0,43 & $82,1 R^{0, r 2} J^{0,3}$ \\
\hline ", "Zementputz Gl. (12a). & 0,43 & $87,2 R^{0,68} J^{0,5}$ \\
\hline 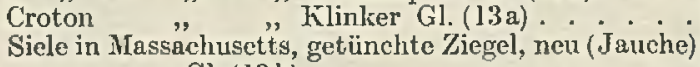 & 0,75 & $73.1 R^{0,50} J^{0,5}$ \\
\hline Gl. $(13 \mathrm{~b})$. & 0,47 & $72,7 R^{0,61^{2}} J^{0,5}$ \\
\hline Desgl. nach 4 Betriebsjahren (Jauche) Gl. $(13 \mathrm{c}$ ) & 0,47 & $63,2 R^{40,312}, J^{0,5}$ \\
\hline
\end{tabular}

Tut man den Ausdrücken den Zwang an, nur die Baumeise $U=$ 7. $R^{0,7} J^{0,5}$ zuzulassen und schließt man ihmen jetzt die Fälle an, in

1) Entwicklung der Hydrometrie in der Schweiz, Pl. 83, 84. 
denen $\mu=0,7, \nu=0,5$ gefunden oder vorausgesetzt wurde, so erhält man als Zahlenspaite für $\%$ :

Ganz glattes Rohr für $J=0,0001$. . . . . . . . . . . . 104,4

Glattes Holzgerinne für $J=0,005$. . . . . . . . . . . . 90,5

Sudbury-Aquädukt in Klinker . . . . . . . . . . . . . . . 87,8

" " "Zementputz .............. . 93,3

Croton " "Klinker ................ 75,4

Sittertunnel in Beton . . . . . . . . . . . . . . . . 91,8

Wienbett in Beton .................. . . 80,1

Werkgraben Garching-Neukirchen, 1 bis 2 Jahre alter Beton . . . . . . 59,0

" Trostberg-Tacherting, neuer Schalenbeton . . . . . . . . . . . 50,3

" " " nach 10 Betriebsjahren . . . . . . . 48,6

" Peggau zu 0,78 Beton, zu 0,22 Schlamm und Kies . . . 60,2

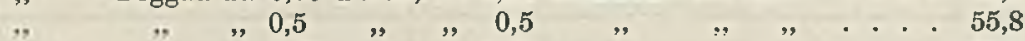

" $\quad$ " "

, Aarau zu 0,26 Beton, zu 0,74 Feinkies . . . . . . . . 56,6

Die Unterschiede der Glättezahlen $\lambda$ erklären sich nicht nur durch clie Herstellungsweise, von deren Einfluß bereits oben auf Seite 14 die Rede war, sondern auch durch den Erhaltungszustand und die Reinheit der Wandungen. So bleiben geschlossene Leitungen freier ron pflanzlichem Ansatz als offene Rinnsale. Die Glätte des Wienbettes kommt, wenigstens zum Teil daher, daß vor jeder Messung, die man hei höherem Wasserstande vornahm, das Hochwasser das Bett rein gespült hatte. Vergleichsweise ungünstiger verhalten sich die meisten Werkgräben, besonders solche mit breiter flacher Sohle.

Hiernach gilt für ablagerungsfreien Beton im allgemeinen

$$
U=59 R^{0,7} J^{0,5}
$$

für alten angegriffenen Beton

$$
U=50 R^{0,7} J^{0,5}
$$

\section{Der Exponent $\mu$ des Profilradius bei Fließen in Erd- und Kiesbetten.}

Es ist bereits S. 21 mitgeteilt worden, auf welche Potenzen des Profilradius drei der üblichsten Formeln führen. Für Erd-und Kiesbetten nimmt die entsprechende Ableitung nachstehende Form an:

\begin{tabular}{c|c|c}
\hline $\begin{array}{c}\text { Geschwindig- } \\
\text { keit } \mathrm{m} / \mathrm{sec}\end{array}$ & $\begin{array}{c}\text { BagelmäBige } \\
\text { Frdbetten }\end{array}$ & $\begin{array}{c}\text { Kanäle } \\
\text { üblichen 7ustandes }\end{array}$ \\
\hline & $\frac{87 R}{0,85 \div \sqrt{R}} \sqrt{J}$ & $\frac{87 R}{1,3+\sqrt{R}} \sqrt{J}$
\end{tabular}




\begin{tabular}{|c|c|c|c|}
\hline $\begin{array}{l}\text { Geschwindig- } \\
\text { keit } \mathrm{m} / \mathrm{sec}\end{array}$ & $\begin{array}{c}\text { Ganguille } \\
n= \\
J=0,001\end{array}$ & $\begin{array}{l}\text { ind Kutter } \\
.025 \\
J=0,0001\end{array}$ & $\stackrel{\text { Biel }}{\text { mit seinem } f=0,45}$ \\
\hline$U=$ & $\frac{63,16 R}{0,5789+\sqrt{R}} \sqrt{J}$ & $\frac{64,55 R}{0,6138+\sqrt{R}} \mid J$ & $\frac{91,29 R^{3}}{\sqrt{3,75+\sqrt{R}}} \sqrt{J}$ \\
\hline
\end{tabular}

Die von $R$ abhängigen Teile stehen in nachstehendem Verhältnis zueinander :

\begin{tabular}{|c|c|c|c|c|c|c|}
\hline $\begin{array}{c}\text { Yon } R \text { abhängig } \\
R \text { in } \mathrm{m}\end{array}$ & $R=$ & I & 2 & 3 & 4 & $\overline{3}$ \\
\hline$R:(0,85+\sqrt{R})$ & $=$ & 1 & 1,62 & 2,11 & 2,54 & 2,93 \\
\hline$R:(1,3+\sqrt{R})$ & $=$ & l & 1,69 & 2,27 & 2,78 & 3,25 \\
\hline$R:(0,5789 \div \sqrt{R})$ & $=$ & 1 & 1,58 & 2,05 & 2,45 & 2,80 \\
\hline$R:(0,6138+\sqrt{R})$ & $=$ & 1 & 1,59 & 2,06 & 2,47 & $2,8: 3$ \\
\hline$R^{2}, \sqrt{3.75}+\sqrt{R} \ldots$ & $=$ & 1 & 1,61 & 2,12 & 2,57 & 2,98 \\
\hline
\end{tabular}

Andererseits ist für obige $R$

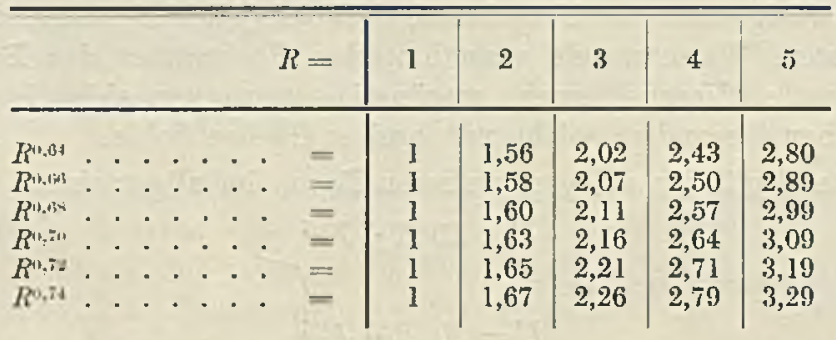

Hiernach soll bei zunehmendem Profilradius die Geschwindigkeit nach Bazin Ganguillet und Kutter Biel proportional mit $R^{0,70}$ bis $R^{0,74} \quad R^{0,65}$ bis $R^{0,66} \quad R^{0,68}$ wachsen, wobei besonders die Bielsche Gleichung mit dem Exponential. ausdruck gut übereinstimmt.

Versuche, die Bazin mit einem rechteckigen Gerinne von $1,8 \mathrm{~m}$ Weite machte, dessen Innenfläche mit vortretenden Kieseln von 1 bis $2 \mathrm{~cm}$ Korn rerkleidet war (Serie 4 ), ergaben bei $R=0,076$ bis $0,25 \mathrm{~m}$, $J=0,0049$

$$
U=62 R^{0,733} J^{0,5}
$$

während bei gleicher Auskleidung aber Halbkreisquerschnitt ron 1,22 m Durchmesser und $R=0,14$ bis $0,31 \mathrm{~m}, J=0,0015$ (Serie 27)

$$
U=74 R^{0,743} J^{0,5}
$$


und bei rechteckigem Gerinne von 1,8 $\mathrm{m}$ Weite und dem Kieselkorn von 3 bis $4 \mathrm{~cm}, R=0,09$ bis $0,26 \mathrm{~m}, J=0,0049$ (Serie 5 )

$$
U=38 R^{0,823} J^{0,5}
$$

war. Die hohen Werte von $\mu$ sind überraschend und jedenfalls nicht, wie sich zeigen wirl, auf Gräben von großen Abmessungen übertragbar.

Für solche lassen sich Aufnahmen verwenden, welche das österreichische hydrographische Zentralbureau im Donaukanal ${ }^{1}$ ) vorgenommen hat. Sie empfehlen sich ganz besonders, weil sie in der Ermittelung von nicht weniger als 14 Staukurven im selben ziemlich regelmäßigen Bett bestehen, welche Staukurven den Vorteil bieten, daß sie das Gefälle mit Sicherheit erkennen lassen. Erzeugt wurde der Stau dadurch, daß man - wie dort üblich - bei Hochwasser im Hauptstrom, der „Großen Donau“ nur einen Teil des Wassers an der Abzweigstelle durch das dortige Schützenwehr in den Kanal treten ließ. Dann bewirkte der hohe Donauspiegel von der Kanalmündung hinauf einen Rückstau in den Kanal. In diesem befindet sich, nebenbei gesagt, ebenfalls ein Stauwehr, welches aber zur Zeit der Aufnahmen inmer vollständig niedergelegt war.

Die Bearbeiter der Aufnahmen ${ }^{2}$ ) Ehrenberger und Kovarik fanden es zweckmäßig, den Donaukanal in clie 4 Strecken

$$
\begin{aligned}
& \text { Jubiläumsbrücke - Brigittabrücke . . . . . ron } \mathrm{km} 0,75 \text { bis } 4,85 \\
& \text { Kaiserbadschlcuse - Ferdinandsbrücke . . . . " , " , } \quad 4,85 \quad, \quad 6,80 \\
& \text { Franzensbrücke - Gasrohrsteg :. . . . . . " " " } 6,80 \text {, } 11,00 \\
& \text { Simmering - Donauuferbahnbrücke . . . . . . " "11,00 , 16,65 }
\end{aligned}
$$

zu zerlegen. Von diesen Strecken scheidet bei der Besprechung, die jetzt folgen soll, die zweite aus, weil sie ein Wehr mit Kammerschlense sowie den Mittelpfeiler der Ferdinandsbrücke enthält. Die Beobachtungen in den drei anderen Strecken lassen sich zu nachstehender Tabelle (s. S. 40) vereinigen:

In diesen Zahlenreihen kommt die mittlere Tiefe $T$, die im Donaukanale rom Profilradius nur wenig verschieden ist, und die de Chézysche Zahl $c=U: \sqrt{R J}$ vor. Soll die Exponentialgleichung (7) gelten, so müssen bei Auftragung ron $\log T$ und $\log c$ als Abszissen und Ordinaten die Punkte in eine Gerade fallen. Das taten sie nicht genau, doch ordneten sie sich in 3 von links nach rechts ansteigende Scharen an. Dic Aufsuchung der Geraden, welche die Fehlerquadrate der Logarithmen (also nicht, wie allerdings richtiger wäre, die der Beobachtungen selbst) zu cinem Minimum machten, ergaben nach Ersatz der

1) Es ist eigentlich cin alter Donauarm, führt aber den Namen Donaukanal.

2) Ost. Wochenschr. f. d. öffentl. Baudienst 18 (1912), S. 746. 
Donaukanal.

\begin{tabular}{|c|c|c|c|c|c|c|c|c|c|c|c|}
\hline - & 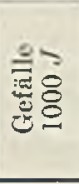 & 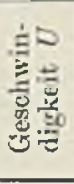 & $\begin{array}{l}\frac{3}{5} \\
\text { s. } \\
0 \\
0 \\
3 \\
3\end{array}$ & 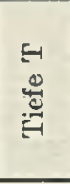 & 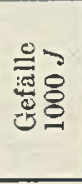 & 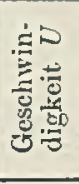 & $\begin{array}{l}\text { है } \\
\text { s. } \\
0 \\
0 \\
0\end{array}$ & $\begin{array}{l}E \\
0 \\
0 \\
E \\
E\end{array}$ & 总号 & 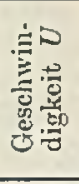 & 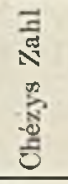 \\
\hline 1,67 & 285 & 1,23 & 56,4 & 2,20 & 0,284 & 0.96 & 38,3 & 2,68 & 0,190 & $0,8 \mathrm{~J}$ & 35,9 \\
\hline 1,72 & 299 & 1,13 & 50,4 & 2,37 & 0,211 & 0,00 & 40,2 & 3,03 & 0,193 & 0,91 & 37,8 \\
\hline 1,72 & 0,299 & 1,15 & 50,5 & 2,51 & 0,161 & 0,87 & 43,4 & 3,42 & 0,082 & 0,62 & 36,7 \\
\hline 2,07 & 0.289 & 1,24 & 50,7 & 2,51 & 0,278 & 1.09 & 41,2 & 3,43 & 0,160 & 0,86 & 36,9 \\
\hline 2,19 & 0,324 & 1,28 & 48,0 & 2,75 & 0,243 & 1,07 & 41,4 & 3,77 & 0,145 & 0,93 & 39,9 \\
\hline 2,22 & 0,255 & 1,14 & 47,9 & 3,00 & 0,231 & 1,16 & 44,5 & 3,83 & 0,052 & 0,57 & 40,5 \\
\hline 2,43 & 0,314 & 1,3 & 49 & 3,39 & 0,170 & 1,0 & 43,6 & 4,61 & 0,085 & 0,75 & 38,0 \\
\hline 2,4 & 0,290 & 1,4 & 52,6 & 3,44 & 0,1 & 1, & 46,4 & 4,66 & 0,070 & 0,83 & 46.0 \\
\hline 2,5 & 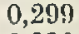 & 1,50 & 48,4 & 3,45 & 0,0 & 0 & $4:$ & 4,72 & 0,077 & 0 , & 38,3 \\
\hline 2,5 & 0,290 & 1,3 & 55 & 3,50 & 0,170 & 1,1 & 46,1 & 4,89 & 0,035 & 0,53 & 40,8 \\
\hline 2,57 & 0,245 & 1,30 & 51 & 3,61 & 0,132 & 0,97 & 44,5 & 4,96 & 0,055 & 0,65 & 39,6 \\
\hline 2,6 & $0, \mathbf{2 3 5}$ & 1,2 & 50 & 3,85 & 0,1 & 1, & 46,9 & 5,04 & 0,099 & 0,99 & 47,1 \\
\hline 3,00 & 0,245 & 1,64 & 60 & 4,04 & 0,0 & 0,8 & 46,5 & 5,34 & 0,075 & 0,92 & 46,0 \\
\hline 3,05 & 0,235 & 1,58 & 59,1 & 4,04 & 0,164 & 1,21 & 47,1 & 5,57 & 0,032 & 0,61 & 44,8 \\
\hline \multicolumn{4}{|c|}{ im Mittcl } & \multicolumn{4}{|c|}{ im Mittel } & \multicolumn{4}{|c|}{ im Mitte } \\
\hline 2,35 & 0,279 & 1,333 & 52,3 & 3,19 & 0,183 & $1,(3$ & $+3,8$ & 4,28 & 0,097 & $0,7 \bar{\imath}$ & 40,6 \\
\hline
\end{tabular}

Tiefen $T^{\prime}$ durch die Profilradien $R$, weil hier $T=$ ungefähr $1,04 R$ ist, die Beziehungen

Bezeichnung in der $\mathrm{Abl}$.

(17) für Jubiläumsbrücke-Brigittabłücke . . $c=43,3 \quad R^{0,21} \quad$

(17a) , Franzensbrücke-Gasrohrsteg . . $c=31,6 R R^{0,20} \otimes$

(17b) "Simmering-Donauuferbahnbrückc . $c=26,3 \quad R^{0,30}$

Messungen (mit + in der Abb. 16 bezcichnet), die von der Jubiläumsbrücke aus mit in üblicher Weise vollzogener Gefällsernittelung vorgenommen waren $^{1}$ ), 16 an der Zahl, ordneten sich zwischen den Scharen der Strecke Franzensbrücke-Gasrohrsteg und denen der Strecke Simmering-Donauuferbahmbrücke ebenfalls mit schrigem Ansticg an, während 15 Messungen im großen Strom (mit $\times$ in der Abb. 16 bezeichnet), die man ron der dortigen Kaiser Franz Joseph-Brücke aus bewerkstelligt hatte, ein von der Tiefe scheinbar unabhängiges c rom Mittelwert 50,3 im nicht ausufernden und von Mittelwert 46,7 in ausufernden Strom lieferten. Dies erkennt man zweifellos trotz der Streuung der Punkte, die sich durch die mit dem Wasserstande wechselnden Ufereinflüsse, Strömungen, Veränderungen der Sohle und Messungsfehler erklärt. Daß die „Große Donau“" der Strömung im künstlichen, regelmäßigen Durchstich trotz einiger

1) Beiträge zur Hydrographic Österreichs (E. La uda) 3. Die hydrometrischen Erhebungen an der Donau nüchst Wien im Jahre 1897. Wien 1899, S. 60, 61. 
tiefliegender Einbauten weniger Widerstand leistet als der größte Teil des Donaukanals, entspricht dem technischen Gefühle jener clort tätigen Ingenieure, mit denen hierüber gesprochen werden konnte. Die geringe Abnahme der Reibung im Bette der ,Großen Donau" mit deren Austreten über die Ufer ist un so eher begreiflich, als die Überschwemmungsfläche ganz eben, nur mit Gras bewachsen und gleichförmig breit ist.

Für den Wechsel der Rauheit im Donaukanal lassen sich verschiedene Ursachen angeben. Daß das Gefälle Tranzensbrücke-Gasrohrsteg jenes bei Simmering übertrifft, mag daher kommen, daß erstere Strecke natürlichen Ursprungs ist und einen geschlängelten Lauf besitzt, während die zweite (wie eine Stromlarte aus dem Jahre 1819 zeigt) durch eine gerade Grabung entstanden ist und daher ein größeres Gefälle erhielt, welches

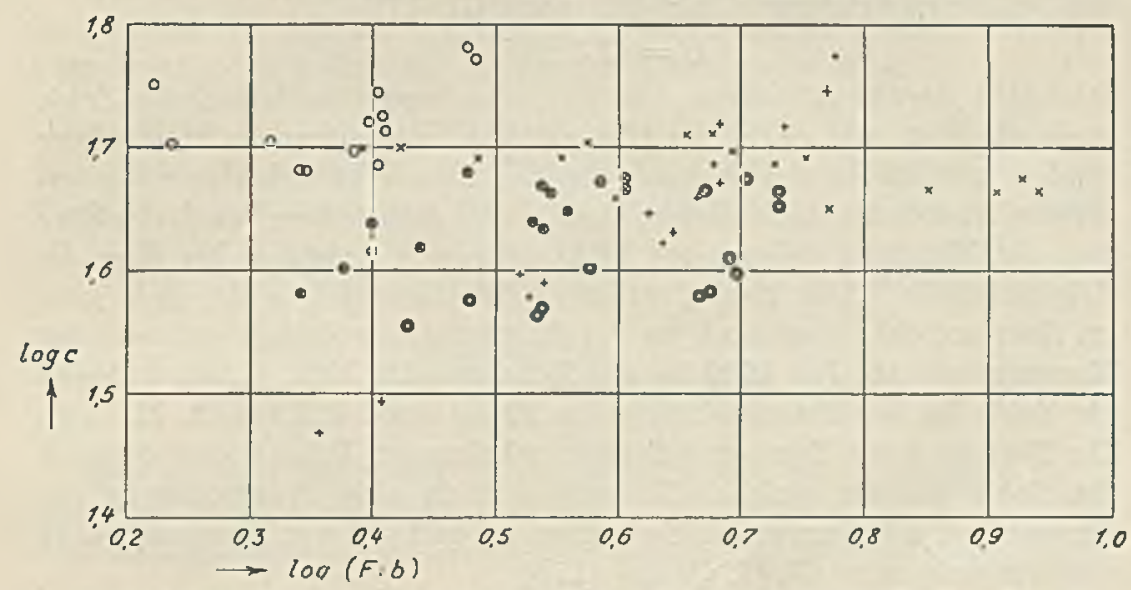

Abb. 16. De Chézysche Zahlen im Donaukanal und in der Großen Donau.

heute allerdings fast verschwunden ist. Erheblicher und auffallender ist dio glattere Beschaffenheit zwischen der Jubiläums. und der Brigittabrücke. $D a B$ von der Brigittabrücke abwärts der FluB im alten Stadtgebiete liegt, wo von Ufersicherungen herrührende Steine vielleicht selbst Pfahlreste den Abfluß behindern, kann nicht der Grund der verschiedenen Rauhiglieiten sein, weil diese Steine und etwaigen Pfahlreste sicher nicht in hierfür genügender Zahl vorhanden sind. Der Krottenbach, der ab und zu Schotter bringt, die Wien und die Sammelkanäle, dic bloß Schlamm führen, könnten nur das Entgegengesetzte bewirken von dem, was der Fall ist. Eine Vertiefung der Sohle um 50 bis $60 \mathrm{~cm}$ auf $3,2 \mathrm{~m}$ unter Null im Sommer $1902 \mathrm{kann}$ wohl kaum die Flußteile ungleich becinflußt haben. Auch der nach Beobachtungen des Wiener Stadtbauamtes vor sich gehenden Aufhöhung der Donaukanalsohle ist dic in Rede stehende Erscheinung schwerlich zuzuschreiben. 
So bleibt als einzige Ursache die Dampfschiffahrt übrig. Die beiden unteren Strecken wurden bis zur Wienmündung von Schleppern der Süddeutschen Donau-Dampfschiffahrt-Gesellschaft sowie der Sandbagger-Gesellschaft befahren, das ist von Raddampfern von höchstens 1 bis 1,2 m Tauchung; auch fuhr ebensoweit ein paarmal in Jahr der Schraubendampfer der Donauregulierungskommission, dessen Heck während der Fahrt 1,5 m tief taucht. Die obere Strecke wurde aber nie von cinem Dampfer aufgesucht. Die Dampfer sind es also, die die Sohle aufrauhen.

Sehr erklärlich sind die Veränderungen, welche die Rauhigkeit an ein und derselben Stelle bei wachsender Tiefe aufweist. Auf der oberen Kanalstrecke herrscht ein Gesetz mit ähnlichen Exponenten wie bei Betonwandungen, nämlich nach Gl. (17)

$$
U=43,3 R^{0,71} J^{0,5}
$$

Dies läßt darauf schließen, daß hier eine wenig veründerliche Sohle vorhanden ist, wie es in der Tat zutrifft. Bedeutendere Hochwässer werden nämlich an der Abzweigung des Kanales durch das schon erwähnte Nadelwehr mehr oder weniger zurückgehalten und auch der Stau von der Mündung gelangt gar nicht oder sehr ermäßigt bis über dic Brigittabrücke. Die beiden unteren Strecken stehen dagegen ganz im Staubereiche, stieg doch an der Mündung der Spiegel während der Messung vom 16. Juli 1909 bis zur Höhe von 156,10 ü. M. an, während die Sohle an cler Franzensbrücke im Mittel etwa 153,9 $\mathrm{m}$ ü. M. liegt. Der Stau muß nun Sand- und Schlammabsätze zur Folge haben, dadurch die Sohle glätten, welcher Vorgang sich in einer Vergrößerung des Exponenten $\mu$ äußern muß. So kommt es, daß von der Franzensbrücke abwärts sich nach Gl. (17a) und (17b)

$$
U=31,6 R^{0,79} J^{0,5} \text { bzw. } 26,3 R^{0,8} J^{0,5}
$$

ergab. Ist im unteren Donaukanal bei wachsender Tiefe die Sohle glatter, so geschieht in der Großen Donau das Gegenteil. Hier hindert kein Sperrwerk den Wassereintritt und es geht das gleiche bei Hochwasser vor sich, wie in anderen Strömen: Die Sohle wird aufgewühlt und durch das Fortspülen des feineren Sandes rauher. Der Exponent $\mu$ im Ausdruck für die Geschwindigkeit muß hierdurch eine Verringerung erfahren ${ }^{1}$ ) und wirklich zeigte sich, wie oben berichtet, im offenen Strom $c$ konstant oder sinkt hier $\mu$ auf 0,5 hinab. Somit liegen die Erscheinungen klar: es gilt für die Geschwindigkeit bei unveränderlicher Bettfläche

$$
U=\lambda \cdot R^{0,7} J^{0,5} \text {, }
$$

in Geschiebebetten, wenn das Gefälle starker Aufwirbelung unterliegt,

$$
U=\lambda \cdot R^{0,5}, J^{0,5}=c \sqrt{R \cdot},
$$

in welcher Gleichung $\lambda=c$ von der Rauhigkeit abhängt.

1) Vgl. die ähnliche Betrachtung bezüglich v auf S. 20. 
Diese Abhängigkeit des Exponenten $\mu$ von der Beweglichleit der Sohle erfährt eine Bestätigung dadurch, daß nach Messungen, die Harlacher ${ }^{1}$ ) seinerzeit in der Elbe bei Herrnkretschen vornahm, wo die Sohle aus Fels und Geschiebe zusammengesetzt ist, sich mit $v=0,5$ sehr genau

$$
U=396 R^{0,642} J^{0,5}
$$

zeigte, also ein $\mu$ zwischen dem des beweglichen Grundes und dem des festen Bettes.

\section{Der Koeffizient $\lambda$ für Erd- und Kiesbetten.}

Auf welche Koeffizienten $\lambda$ die älteren Messungen bei Profilradien bis zu etwa $1 \mathrm{~m}$ führen, wird durch die auf ihnen beruhenden Formeln ausgedrückt. So haben bei geeigneter Schreibweise nach

$$
\text { Bazin Ganguillet und Kutter Biel }
$$

Erdkanäle üblichen Kanäle in Erde, Bäche u. Flüsse Regelmäßige Erd. Zustandes $\gamma=1,30 \quad n=0,025$ für $J=0,0001 \quad$ Betten, $f=0,45$

$$
\begin{gathered}
U=\frac{87 R^{0,3}}{1,3+R^{0,5}} R^{\cup, 7} J^{0,5} \quad U=\frac{78,5 R^{0,3}}{0,9625+R^{0,5}} R^{0,7} J^{0,5} \\
U=\frac{\sqrt{8333} R^{0,05}}{\sqrt{3,75+\sqrt{R}}} R^{0,7} J^{0,5}
\end{gathered}
$$

Man erkennt bei dieser Schreibweise sofort die Ausdrücke für $\lambda$ und kann leicht ausrechnen, daß für

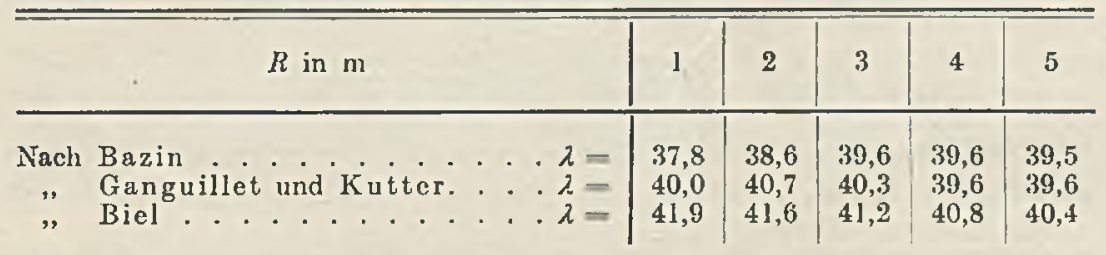

sein soll.

Besondere Erwähnung verdienen die Erhebungen, die Pasini und Gioppi an 3 Strecken des Cavour-Kanales vornahmen, von denen die erste längs $600 \mathrm{~m}$, die zweite stromauf und stromab über je einen Kilometer, die dritte längs eines beträchtlichen Stückes (per buon tratto) gerade und mit ungeändertem Querschnitt ohne störenden Einbau verläuft. In jedcr Strecke fanden 3 Messungen an verschiedenen Tagen statt, die das folgende Bild geben ${ }^{2}$ ).

1) Beiträge zur Hydragraphie des Königreiches Böhımen, 3. Lieferung, 1875.

2) Giornale del genio cirile 31 (1893), S. 62. 
Der Koeffizient $\lambda$ für Erd- und Kiesbetten.

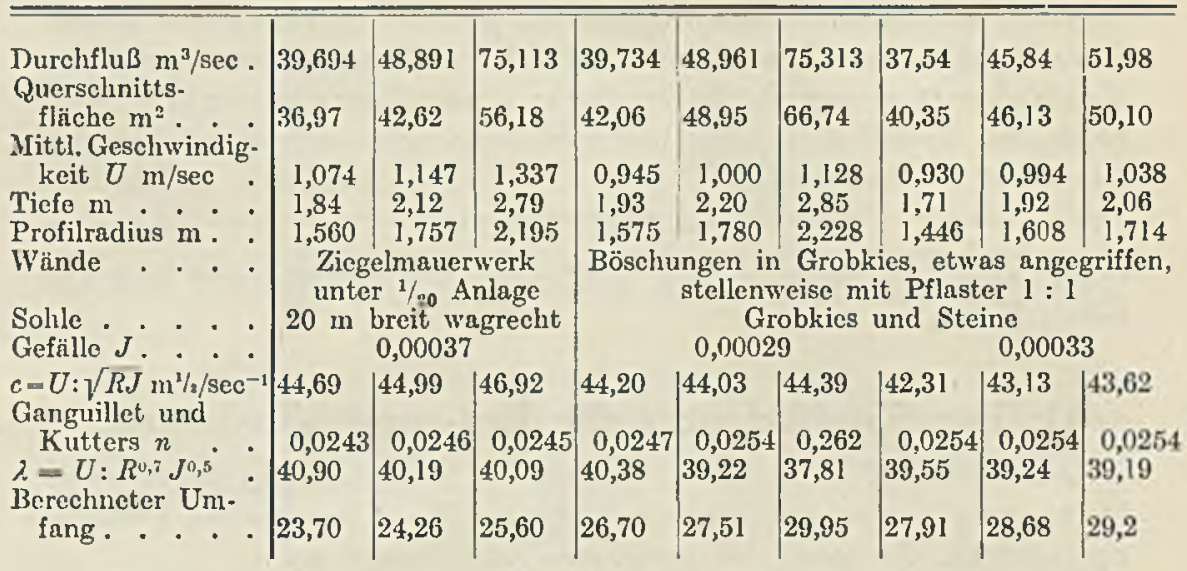

Ersetzt man die Ziegelwände der ersten Strecke schätzungsweise durch Kiesböschungen, welche die gleichen Widerstände hervorrufen, so kann man den benetzten Umfang hier zu 23,4 bzw. 23,9 bzw. $25,1 \mathrm{~m}$ bewerten und hat $R=1,58$ bzw. 1,78 bzw. $2,24 \mathrm{~m}$ und $\lambda=40,7 \mathrm{bzw}$. 39,8 bzw. 39,5, also im Mittel $=40,0$. Für die 3 Strecken ist dann

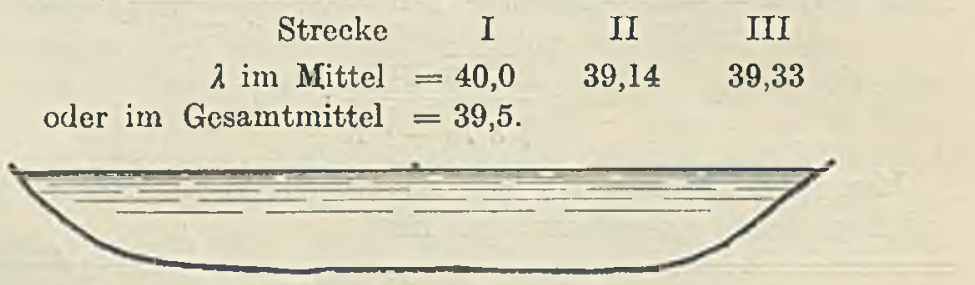

\section{$1: 300 \mathrm{w}$. Gr.}

Abb. 17. Obergraben des Uppenbornwerkes.

Die Messungen, die der Verfassis an nicht betonierten noch sonstwie gesicherten Kanälen großer Abmessungen vornahm, ergaben zumeist etwas kleinere Werte von $\lambda$.

Am wenigsten rauh stellte sich der geradlinige Oberwassergraben des Uppenbornwerkes ${ }^{2}$ ) dar. Dieser bezicht sein Wasser aus der Isar bei Mnosburg ungefälır $50 \mathrm{~km}$ nördlich von München. Sein Bett besteht wesentlich aus Kalksteinsshotter, dessen Stücke zwar gut abgerundet, aber nicht immer eiförmig sind und bis zu $5 \mathrm{~cm}$ länge besitzen und dessen Zwischenräume durch 'Sand und Schlanm ausgeglichen sind. Nachstehend sind die Ergebnisse zusammengestellt, wobei für einige Punkte sowohl das Gefälle der Teilstrecke von $660 \mathrm{~m}$ als auch das der Gesamtstrecke von $1320 \mathrm{~m}$ Länge als $J$ eingetragen ist, wclche Punkte

1) Eine Beschreibung der Anlage durch den Bauleiter, den jetzigen Professor K, Dantscher, findet sich in Beton und Fisen, 6 (1907), S. 276, 317. 
durch doppelte Fintragung mit doppeltem Gewicht auf das Mittel wirken.

Uppenbornwerk 1920.

\begin{tabular}{c|c|c|c|c}
\hline $\begin{array}{c}\text { Entfermung } \\
\text { voun } \\
\text { Grabcrnanfang } \\
\mathrm{m}\end{array}$ & $\begin{array}{c}\text { Gescliwindigkeit } \\
U\end{array}$ & $\begin{array}{c}\text { Profilradius } \\
K\end{array}$ & $\begin{array}{c}\text { Gefialle in } \% \\
1000 \mathrm{~J}\end{array}$ & $\lambda$ \\
\hline & $\mathrm{m} / \mathrm{sec}$ & $\mathrm{m}$ & & $\mathrm{m}^{0,3} / \mathrm{sec}$ \\
\hline 330 & 1,28 & 2,16 & 0,321 & 41,7 \\
330 & 1,335 & 2,15 & 0,320 & 43,7 \\
660 & 1,245 & 2,16 & 0,290 & 41,9 \\
660 & 1,245 & 2,16 & 0,298 & 41,9 \\
660 & 1,29 & 2,17 & 0,301 & 43,2 \\
660 & 1,29 & 2,17 & 0,292 & 43,9 \\
900 & 1,138 & 2,36 & 0,274 & 37,8 \\
990 & 1,19 & 2,35 & 0,265 & 40,3 \\
IIttel & 1,25 & 2,21 & 0,29625 & 41,80
\end{tabular}

Für den Obergraben des Uppenbornwerkes gilt also

$$
U=41,80 R^{0,7} J^{0,5}
$$

ferner im Mittel $c=48,91, \sqrt{R}=1,487, n=0,0231$.

Ein geringeres $\lambda_{\text {, }}$ also größere Rauhigkeit, zeigt der Untergraben des Uppenbornwerkes, dessen Böschungen unregelmäßig geworden

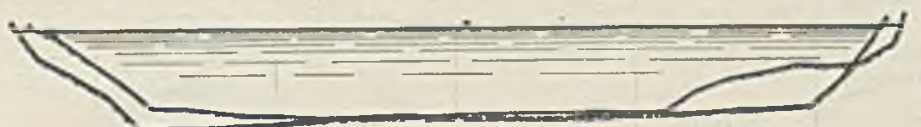

I : 300 w. Gr.

Abb. 18. Querschnitte des Untergrabens des Uppenbornwerkes.

sind, so daß stellenweise auf der rechten Seite ein Streifen von einigen Metern Breite nur schwach durchflossen wird. Auch ist das Verhältnis cler Spiegelbreite von etwa $27 \mathrm{~m}$ zur mittleren Tiefe von etwa $2,2 \mathrm{~m}$ ungünstiger als beim Obergraben. Er verläuft geradlinig. Es ergaben sich folgende Zahlen:

Uppenbornwerk 1920.

\begin{tabular}{c|c|c|c|c}
\hline $\begin{array}{c}\text { Entfermung } \\
\text { vom } \\
\text { Grabenanfang } \\
\mathrm{m}\end{array}$ & $\begin{array}{c}\text { Geschwindigkeit } \\
\mathrm{m} / \mathrm{sec}\end{array}$ & $\begin{array}{c}\text { Profilradius } \\
R\end{array}$ & $\begin{array}{c}\text { Gefälle in } \% \\
1000 \mathrm{~J}\end{array}$ & $\lambda$ \\
\hline & $\mathrm{m}$ & & $\mathrm{m}^{0.3 / \mathrm{sec}}$ \\
\hline 300 & 1,145 & 2,14 & 0,407 & 33,4 \\
300 & 1,19 & 2,16 & 0,415 & 34,0 \\
600 & 1,16 & 2.07 & 0,412 & 34,3 \\
600 & 1,16 & 2,07 & 0,412 & 34,3 \\
600 & 1.18 & 2,10 & 0,417 & 34,4 \\
600 & 1,18 & 2,10 & 0,417 & 34,4 \\
900 & 1,125 & 2,08 & 0.417 & 33,0 \\
900 & 1,17 & 2,10 & 0,418 & 34,2 \\
Mitte & 1,164 & 2,10 & 0,41438 & 34,075
\end{tabular}


Für den Untergraben des Uppenbornwerkes gilt also (21 a)

$$
U=34,08 R^{0,7} J^{0,5}
$$

und auch

$$
c=39,36 \quad \sqrt{R}=1,449, n=0,0294 .
$$

So wie für das große Betongerinne von Garching-Neukirchen liegen für einen großen Erdgraben, nämlich den der Lech werke bei Stettenhofen Messungen bei 2 verschiedenen Füllungen vor, die im Mittel auf

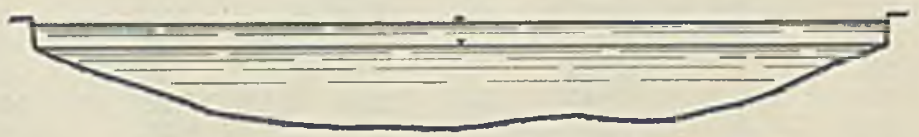

1: 300 w. Gr.

Abb. 19. Lechwerk bei Stettenhofen.

dasselbe $i=40,6$ führten. Die Sohle besteht daselbst aus Sand und Kies in allen Größen bis zu Ganseigrößc, d. i. bis zu etwa $6 \mathrm{~cm}$ Länge. Die Böschungen sind zum Teil schlammig. Die Messungen ergaben:

\begin{tabular}{|c|c|c|c|c|c|}
\hline $\begin{array}{l}\text { Entfernung } \\
\text { vom MeB- } \\
\text { strecken- } \\
\text { anfang } \\
\text { m }\end{array}$ & $\begin{array}{c}\text { DurchfluB } \\
Q \\
\mathrm{n}^{3} / \mathrm{sec}\end{array}$ & $\begin{array}{c}\text { Geschwin- } \\
\text { digkeit } U \\
\mathrm{~m} / \mathrm{sec}\end{array}$ & $\begin{array}{c}\text { Profilradius } \\
\qquad R \\
\mathrm{~m} \\
\end{array}$ & $\begin{array}{l}\text { Gefälle } \\
\text { in } \% \% \\
=1000 \mathrm{~J}\end{array}$ & $\begin{array}{l}\lambda \text { in } U= \\
\lambda R^{20, \pi} J^{0,3}\end{array}$ \\
\hline 420 & $\begin{array}{l}38,1 \\
38,0 \\
38,1 \\
37,6\end{array}$ & $\begin{array}{l}0,905 \\
0,910 \\
0,920 \\
0,895\end{array}$ & $\begin{array}{l}1,68 \\
1,67 \\
1,65 \\
1,67\end{array}$ & $\begin{array}{l}0,200 \\
0,206 \\
0,213 \\
0,202\end{array}$ & $\begin{array}{l}44, \overline{5} \\
44,4 \\
44.4 \\
43, \overline{5}\end{array}$ \\
\hline 840 & $\begin{array}{l}38,1 \\
38,0 \\
38,1 \\
37,6\end{array}$ & $\begin{array}{l}0,855 \\
0,864 \\
0,873 \\
0,850\end{array}$ & $\begin{array}{l}1,68 \\
1,66 \\
1,65 \\
1,67\end{array}$ & $\begin{array}{l}0,219 \\
0,233 \\
0,241 \\
0,234\end{array}$ & $\begin{array}{l}40,1 \\
39,5 \\
39.7 \\
39,2\end{array}$ \\
\hline 1200 & $\begin{array}{l}38,1 \\
38,0 \\
38.1 \\
37,6\end{array}$ & $\begin{array}{l}0,862 \\
0,870 \\
0,882 \\
0,858\end{array}$ & $\begin{array}{l}1,73 \\
1,71 \\
1,70 \\
1,72\end{array}$ & $\begin{array}{l}0,211 \\
0,223 \\
0.226 \\
0,216\end{array}$ & $\begin{array}{l}40.5 \\
40.1 \\
40.4 \\
40,0\end{array}$ \\
\hline 1220 & $\begin{array}{l}38,1 \\
38,0 \\
38,1 \\
37,6\end{array}$ & $\begin{array}{l}0,862 \\
0,870 \\
0,882 \\
0,858\end{array}$ & $\begin{array}{l}1,73 \\
1,71 \\
1,70 \\
1,72\end{array}$ & $\begin{array}{l}0,210 \\
0,223 \\
0,228 \\
0.214\end{array}$ & $\begin{array}{l}40,4 \\
40,0 \\
40.2 \\
40,2\end{array}$ \\
\hline 1600 & $\begin{array}{l}38,1 \\
38,0 \\
38,1 \\
37,6\end{array}$ & $\begin{array}{l}0,810 \\
0,825 \\
0,835 \\
0,807\end{array}$ & $\begin{array}{l}1.76 \\
1,73 \\
1,72 \\
1,74\end{array}$ & $\begin{array}{l}0,203 \\
0,214 \\
0,212 \\
0,198\end{array}$ & $\begin{array}{l}38,3 \\
38,4 \\
39,2 \\
38,7\end{array}$ \\
\hline
\end{tabular}

Stettenhofen bei niedrigem Wasserstand 192l: 
Stettenhofen bei hohem Wasserstand 1921:

\begin{tabular}{|c|c|c|c|c|c|}
\hline $\begin{array}{c}\text { Entfernung } \\
\text { rom Me } \\
\text { strecken- } \\
\text { anfang } \\
\text { m }\end{array}$ & $\begin{array}{c}\text { Durchfluß } \\
Q \\
\mathrm{~m}^{3} / \mathrm{sec}\end{array}$ & $\begin{array}{c}\text { Geschwin- } \\
\text { digkeit } U \\
\mathrm{~m} / \mathrm{sec}\end{array}$ & $\begin{array}{c}\text { Profilradius } \\
k \\
\mathrm{~m}\end{array}$ & $\begin{array}{l}\text { Gefälle } \\
\text { in } \% / 00 \\
=1000 \mathrm{~J}\end{array}$ & 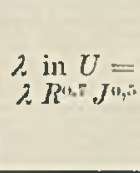 \\
\hline $420^{\circ}$ & $\begin{array}{l}65,0 \\
65,6\end{array}$ & $\begin{array}{l}1,1,5 \\
1,15\end{array}$ & $\begin{array}{l}2,07 \\
2,08\end{array}$ & $\begin{array}{l}0,277 \\
0,273\end{array}$ & $\begin{array}{l}41,7 \\
41,7\end{array}$ \\
\hline 820 & $\begin{array}{l}65,0 \\
65,6\end{array}$ & $\begin{array}{l}1,12 \\
1,10\end{array}$ & $\begin{array}{l}2,09 \\
2,13\end{array}$ & $\begin{array}{l}0,280 \\
0,284\end{array}$ & $\begin{array}{l}39,9 \\
39,1\end{array}$ \\
\hline 1220 & $\begin{array}{l}65,0 \\
65,6\end{array}$ & $\begin{array}{l}1,10 \\
1,10\end{array}$ & $\begin{array}{l}2,06 \\
2,08\end{array}$ & $\begin{array}{l}0,250 \\
0,241\end{array}$ & $\begin{array}{l}42,0 \\
42.5\end{array}$ \\
\hline 1220 & $\begin{array}{l}65,0 \\
65,6\end{array}$ & $\begin{array}{l}1,10 \\
1,10\end{array}$ & $\begin{array}{l}2,06 \\
2,08\end{array}$ & $\begin{array}{l}0,292 \\
0,285\end{array}$ & $\begin{array}{l}38, \overline{5} \\
39,1\end{array}$ \\
\hline 1600 & $\begin{array}{l}65,0 \\
65,6\end{array}$ & $\begin{array}{l}1,08 \\
1,02\end{array}$ & $\begin{array}{l}2,16 \\
2,19\end{array}$ & $\begin{array}{l}0,308 \\
0,302\end{array}$ & $\begin{array}{l}(36,2) \\
(35,6) \\
\end{array}$ \\
\hline
\end{tabular}

Im Mittel fand sich also sowohl für niedrigen als auch für hohen Wasserstand in Stettenhofen

$$
U=40,6 R^{11,7} J^{(1.5}
$$

ferner für niedrigen Stand

$$
U=0,865 . R=1,70, J=0,2163 \%, c=45.11, n=0,0246,
$$

ferner für hohen Stand

$$
U=1,115, R=2,08, J=0,2727 \%: c=46,82, n=0,0244 .
$$

Hierzu ist zu bemerken, daß bei höherem Wasserstande das Profil 1600 unter dem Einfluß der $40 \mathrm{~m}$ unterhalb liegenden Brücke stehen dürfte, aus welchem Grunde bei der Bildung des Mittelwertes von $\lambda$, dieses Profil nicht in Betracht gezogen wurde.

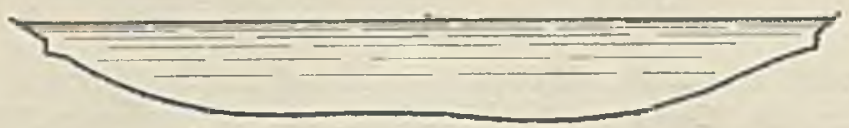

$$
1: 300 \text { w. Gr. }
$$

Abb. 20. Untergraben bei Tacherting.

Am rauhesten stellte sich der Un tergra ben von Tacher ting heraus. dessen Sohle aus eirunden Kalksteinen von etwa 1 bis $7 \mathrm{~cm}$ Länge des größten der drei Durchmesser besteht. Sie geht heute mit Abrundung in die beidseitigen $1^{1} / 2$ füßigen Böschungen über, deren jede zu oberst, nämlich zwischen 0,5 und ungefähr 0,9 $\mathrm{m}$ Wassertiefe durch eine Bohlen- 
wand begrenzt ist. Dic Wände werden alle $1,5 \mathrm{~m}$ durch wasserseitig vorgerammte Pfähle von 8 bis $10 \mathrm{~cm}$ Dicke gehalten. Die Strecke ist gerade (vgl. Abb. 8 und 30). Je nach Einführung des mittleren Gefälles der Strecke 0 bis $560 \mathrm{~m}$ oder 280 bis $560 \mathrm{~m}$ als $J$ reigte sich

\begin{tabular}{|c|c|c|c|c|c|c|}
\hline \multirow{2}{*}{$\begin{array}{l}\text { Entfernung } \\
\text { v. Graben- } \\
\text { anfang } \\
\mathrm{m} \\
\end{array}$} & \multirow{2}{*}{$\begin{array}{c}\text { Gesehwin- } \\
\text { digkeit } U \\
\mathrm{~m} / \mathrm{sec}\end{array}$} & \multirow{2}{*}{$\begin{array}{l}\text { Profil- } \\
\text { radius } R \\
\mathrm{~m}\end{array}$} & \multicolumn{2}{|c|}{ Gefülle in $\%=1000 \mathrm{~J}$} & \multicolumn{2}{|c|}{2} \\
\hline & & & $\begin{array}{c}\text { Strecke } \\
0-560 \mathrm{~m}\end{array}$ & $\begin{array}{c}\text { Strceke } \\
280-560 \mathrm{~m}\end{array}$ & $\begin{array}{c}\text { Strecke } \\
0-560 \mathrm{~m} \\
\end{array}$ & $\begin{array}{c}\text { Strecke } \\
280-560 \mathrm{~m} \\
\end{array}$ \\
\hline $\begin{array}{c}0 \\
280 \\
560\end{array}$ & $\begin{array}{l}1,03 \\
1,11 \\
1,15\end{array}$ & $\begin{array}{l}2,14 \\
2,16 \\
2,14\end{array}$ & $\begin{array}{l}0,488 \\
0,400 \\
0,436\end{array}$ & $\begin{array}{l}0,532 \\
0,487 \\
0,462\end{array}$ & $\begin{array}{l}27,4 \\
30,9 \\
32,3\end{array}$ & $\begin{array}{l}26,2 \\
30,8 \\
31,5\end{array}$ \\
\hline Mittel & 1,097 & 2,147 & 0,441 & 0,494 & 30,2 & 29,5 \\
\hline
\end{tabular}

Da den Gefällen der ganzen Strecke mehr Gewicht zukommt als denen der Unterstrecke, erscheint $\lambda_{0}=30,0$ am wahrscheinlichsten, und somit (23)

$$
U=30,0 R^{0,7} J^{0,5}
$$

Mit $U=1,097, R=2,147, \quad J=0,000459$, erhäl man ferner de Chézys $c=34,95$, Ganguillet-Kutters $n=0,0337$.

Die künstlich hergestellten Erdgräben ergaben also

Obergraben des Uppenbornwerkes . . . $\lambda=41,8 \quad c=49,0 \quad n=0,0231$

Graben der Lechwerke bei Stettenhofen . $\lambda=40,6$ / $c=45,1 \quad n=0.0246$

Graben der Lechwerke bei Stettenhofen $\cdot \lambda=40,6$, $c=46,8 \quad n=0,0244$

Cavour Kanal (wesentlich Grobkies) . . . $\lambda=39,2 \quad c=43,6 \quad n=0,0254$

Untergraben des Upperbornwerkes . . . . $\lambda=34,1 \quad c=39,5 \quad n=0,0293$

" bei Tacherting . . . . . $\lambda=30,0 \quad c=35,0 \quad n=0,0337$

Diese Zahlenreihe findet durch Beobachtungen an natürlichen Flüssen ihre Ergänzung, so licferte der Donaukanal genannte Donauarm

$$
U=43,3 \text { bis etwa } 31,6 R^{0,7} \mathrm{J0,5}
$$

und kam E. Beyerhaus ${ }^{1}$ ) für 25 Gruppen von Messungen, die an natürlichen Flüssen vorgenommen worden waren, zu derselben Grundformel wie die vorliegende Abhandlung, und zwar im Mittel zu

$$
U=26,35 R^{0,7}, J^{0,5} \text {. }
$$

Dabei steigt sein 2. von 23,9 (für die Memel bei Pagulbinnen) bis zu 30,63 (für den Mississippi bei Vicksburg) an. Beyerlhaus läßt es in Zwweifel, ob nicht dic Einführung von $J^{0,46}$ vor der von $J^{0,5}$ den Vorzug verdiene. Diesbezüglich sei auf das auf S. 20 Gesagte hingeviesen und hiermit die Betrachtung abgeschlossen, dic von mehr als $90 R^{0,7} J^{0,5}$ bis zu jenen kleinen Werten von $\lambda$ geleitet hat, ohne daß sich bei offenem Spiegel cine Abweichung von der Formel $U=\lambda . R^{0,7} J^{0,5}$ oder eine Inderung von $\lambda$ mit der Rinnsalgröße ergeben hätte.

1) Bauing. 2 (1921), S. 486,523 f. 


\section{Die Beziehung zwischen $\lambda$ und $n$.}

Im vorstehonden wurde für dic Berechnung der Wasserbewegung die Formel (18) oder $U=\lambda, R^{1,7} J^{0,5}$ empfohlen. Sie bildet das Ergebnis einer Bestimmung von $\lambda, \mu$ und $\nu$ für Werkgräben großer Abmessungen im Ausdrucke $U=\lambda R^{\mu} J^{\prime}$. Es reigte sich dann, daß mit einer für praktische Zwecke genïgenden Genauigkeit bei unveründerlichen Rohroder Bettwandungen allgemein $\mu=0,7$ und $\gamma=0,5$ gesetzt werden darf und dabei $\lambda$ innerhalb weiter Grenzen nur von der Wandbeschaffenheit, also der Rauhigkeit abhängt. Ähnliches hat im Jahre 1890 bereits Manning gesagt ${ }^{1}$ ), dessen Formel aber in England und Amerika nur wenig, in den übrigen Ländern so viel wie gar keine Beachtung fand. Mannings Ansatz, wie er nach Scobey heute in englischen Fußmaß gewöhnlich geschrieben wird, lautet

$$
U=\frac{1,486}{n} R^{0,4 i \pi} J 0,5
$$

enthält also neben ähnlichen Txponenten wie G1. (18) noch die Angabe, daß der Koeffizient der rechten Seite der Gangujllet-Kutterschen Rauhigkeit $n$ verkelirt proportional ist. Die Umrechnung auf metrisches Maß verwandelt (25) fast genan in ${ }^{2}$ ) die Form, die der Verfasser dieser Schrift angeführt hat.

$$
U=\frac{1,00}{n} R^{3 / 2}, J, 5,
$$

wonach in der empfohlenen Gleichung (18)

$$
\lambda \text { ungefähr }=\frac{1}{n}
$$

sein müßte, genal und immer kamn wogen des verschiedenen Baues der cmpfohlenen Gleichung und jener von $\mathrm{G}$ ang $\mathrm{n}$ illet-Kutter $\lambda$ überhaupt nicht $=1: n$ sein. Inwieweit nun $\lambda$. mit I $: n$ vertauscht werden darf, müssen bereits dic ausgerechneten Sonderfïlle erkennen lassen. Es war bei den Betonröhren

$$
\begin{aligned}
& \lambda=\begin{array}{llllllllllll}
84 & 76 & 80 & 68 & 70 & 77 & 89 & 95 & 69 & 80 & - & -
\end{array} \\
& 10000 n=123134128147146138120113138128 \quad- \\
& \begin{array}{llllllllllll}
1: n= & 81 & 75 & 78 & 68 & 68 & 72 & 83 & 88 & 72 & 78 & -
\end{array}
\end{aligned}
$$

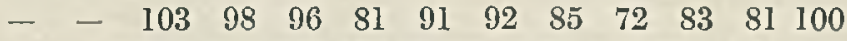

$$
\begin{aligned}
& \text { — }-\begin{array}{llllllllll}
103105 & 112 & 137 & 118 & 108 & 120 & 139 & 124 & 124 & 102
\end{array} \\
& \begin{array}{lllllllllllll}
- & - & 97 & 95 & 89 & 73 & 85 & 93 & 83 & 72 & 81 & 81 & 98
\end{array}
\end{aligned}
$$

1) Transactions of the Institution of Civil Engineers of Trcland 12 (1890), S. 68.

2) Ph. Forch heimer, Hydraulik 1914, S. 70 und Grundriß der Hydraulik 1920, S. 47. Genau umgerechnet wïrde G]. (25) $1,004 R^{0,67}$ statt $1,00 R \%$ ergeben.

For ch heimer, Durchilub des Wasaers. 
ferner bei den untersuchten offenen Läufen

\begin{tabular}{|c|c|c|c|c|c|c|c|}
\hline & \multirow{2}{*}{ Wienfluß } & \multirow{2}{*}{$\begin{array}{l}\text { Cavour- } \\
\text { Kanal }\end{array}$} & \multicolumn{3}{|c|}{$\begin{array}{l}\text { Trostberg- } \\
\text { Tacherting }\end{array}$} & \multicolumn{2}{|c|}{ Garching-Neukirchen } \\
\hline & & & 1910 & 1910 & 1920 & nlt & später \\
\hline $\begin{array}{r}\lambda= \\
10000 x= \\
1: n=\end{array}$ & 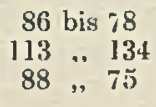 & $\begin{array}{rll}74 & \text { bis } & 75 \\
129 & . " & 130 \\
78 & \# & 77\end{array}$ & $\begin{array}{r}60 \\
167 \\
60\end{array}$ & $\begin{array}{r}60 \\
175 \\
57\end{array}$ & $\begin{array}{r}49 \\
200 \\
50\end{array}$ & $\begin{array}{r}59 \\
163 \\
6 \mathrm{I}\end{array}$ & $\begin{array}{r}58 \\
172 \\
58\end{array}$ \\
\hline
\end{tabular}

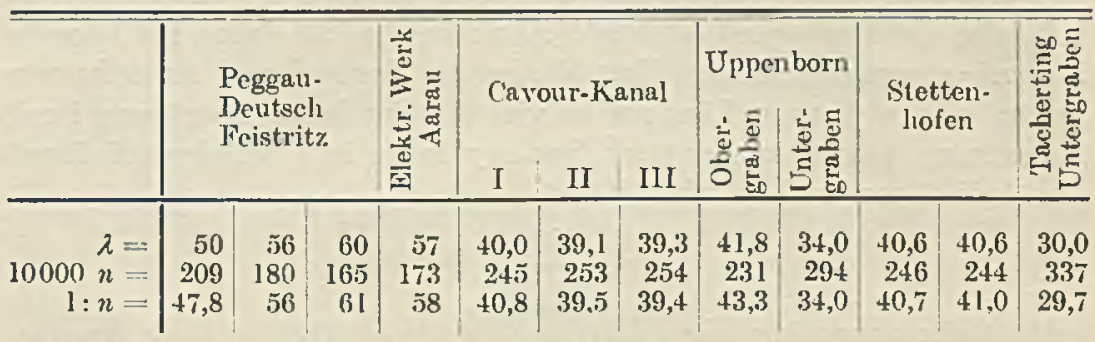

Die Ubereinstimmung der Glättezahl $\lambda$ mit dem reziproken Wert der Rauhigkeitszahl $n$ ist offenbar eine solche, daß die Abweichung im Verlaufe beider Formeln geringer als der Fehler ist, der im allgemeinen durch die unvermeidliche Ungenauigkeit in der Schätzung cler Rauhigkeit entsteht. Ist der Profilradius $R=1 \mathrm{~m}$, so ergeben die Formeln, wie man sich überzeugen kann, für beliebiges Gefälle $J$, daß $\lambda$ mit $I: n$ gleichbedeutend ist. Für andere $R$ und $J$ ist dies noch der Fall, wenn

$$
\left(23+\frac{0.00155}{J}\right) n=\frac{R^{0,3}\left(1-R^{0,2}\right)}{1-R^{0,3}}
$$

oder z. B. für

$$
\begin{aligned}
& R \text { in } \mathrm{m}=\begin{array}{lllllll}
0,1 & 0,3 & 0,5 & \text { fast } 1 & 1 & 1,5 & 2,0
\end{array} \\
& \left(23+\frac{0,00155}{J}\right) n=0,371 \quad 0,492 \quad 0,560 \quad 0,667 \quad \begin{array}{lllll}
\text { big } & 0,738 & 0,791
\end{array}
\end{aligned}
$$

ist. Insoweit Ganguillet-Kutters Gleichung zutrifft, kann man, wenn, wie dies vielfach heute der Fall ist, man durch eine Messung $n$ bercits bestimmt hat, für veränderte Gefälle oder Wasserstände den Durchfluß unter Benutzung des einfachen Exponential-Ausdruckes

$$
U=\frac{1}{n} R^{1,7} J^{0,5}
$$

berechnen. 
Zur Bestimmung strömender Flüssigkeitsmengen im offenen Gerinne. Ein neues Verfahren von Dipl.-Ing. Oskar Poebing, Betriebsleiter des Hydraulischen Institutos der Technischen Hochschule Mfinchen Mit 23 Textabbildungen und 1 Trfel. 1922.

GZ. 1,7

Betrachtungen über Abflub, Stau und Walzenbildung bei tliebenden Gewïssern und ihre Verwertung fur die Ausbildung des Utberfalles bei der Untertunnelung der Sihl durch die linksufrige Seebahn in der Stadt Zurich. Untersuchungen nus dem Flußbaulaboratorium der Tech. nischen Hochschule in Kiarlsruhe. Von Th. Rehbock, Oberbaurat, Professor an der Technischen Hochschule "Fridericiana" in Karlsruhe. Mit 28 Textabhildungen, 13 Plinen und 23 Tafoln mit 66 Photographien in Autotypie. 1917.

GL. 28

Berechnung der Wasserspiegellage beim Wechsel des Fließzustandes. Von Dr.-Ing. Paul Böß, Assistent am Flußbaulaboratorium der Technischen Hochschule zu Karlsruhe. Mit 13 Abbildungen und 7 Planen. 1919.

GZ. 2,4

Strömungsenergie und mechanische Arbeit. Boitrüge zur abstrakten Dymamik und ihre Anwendung auf Schiffspropeller, schnellaufende Pumpen und Tarbinen, Schiffswiderstand, Schiffssegel, Windturbinen, Tragund Schlagfügel und Luftwiderstand von Geschossen. Von I'aul Wagner. Oberingenieur in Berlin. Mit 151 Textfiguren. 1914. Gebunden GZ. 10

Allgemeine Theorie über die veränderliche Bewegung des Wassers in Leitungen. I. Teil: Rohrleitungen. Von Lorenzo Alliévi. Deutsche, erlauterte Ausgabe von Robert Dubs und V. Bataillard. II. Teil: Stollen and Vasserschlob. Von Robert Dabs. Mit 35 Textfiguren. 1909.

GZ. 10

Energieumwandlungen in Flüssigkeiten. Von Dónát Bánki, Maschineningenieur, o. ö. Professor an der Technischen Hochschule, Mitglied der Akademio der Wissenscbaften zu Budapest.

Erster Band: Eimleitung in die Konstruktionslehre der Wasserkraftmaschinen. Kompressoren, Dampfturbinen und Aeroplane. Mit 591 Textabbildangen und 9 Tafeln. 1921.

Gebunden GZ. 15

Handbuch der Hydrologie. Wesen, Nachweis, Untersuchung und Gewinuung unterirdischer Wasser: Quellen, Gruadwasser, unterirdische Wasser. lihufe, Grundwasserfassungen. Von Zivilingenieur E. Prinz. Mit 331 Textabbildungen. 1919.

GZ. 12

Technische Hydrodynamik. Von Dr. Franz Prísil, Professor an der Eidgenosischen Technischen Hochschule in Zurich. Z wo ite Auflage.

In Vorberoitung

Dic Grundzahlen (GZ.) entsprechen den ungefihren Vorkricospreisen und croeben mit dem

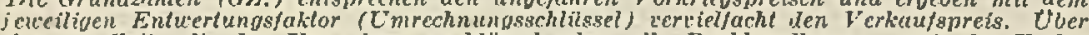
den zur Zeit veltenden Umrechnungsschlussel geben alle Buchhandlungen soute der Verluy bereitwilligst A Askinfl. 


\title{
Handbibliothek für Bauingenieure
}

Ein Hand- und Nachschlagebuch für Studium und Praxis

Herausgegeben von

\section{Robert Otzen}

Geheimer Regierungsrat,
Professor an der Technischen Hochschule zu Hannover

Enthaltend:

Teil I. Hilfswissenschaften .. . . . . . 5 Bunde

Teil II. Eisenbahnwesen und Stadtebau . . . 9 Bunde

Teil III. Wasserbau . . . . . . . . . . S Bunde

Teil IV. Brïcken- und Ingenieur-Hochbau . . . 4 Bände

\author{
III. Teil: Wasserbau. 2. Band,
}

See- und Seehafenbau. Von H. Proetel, Regierungs- und Baurat in Magdeburg. Mit 292 'Textabbildungen. 1921. Gobunden GZ. $\bar{\tau}, \overline{\bar{c}}$

III. Teil: Wasserban. 4. Band.

Kanal- und Schleusenbau. Von Friedrich Engelhard, Regierungsund Baurat an der Regierung zu Oppeln. Mit 303 Textabbildungen und einer farbigen Ubersichtskarto. 1921. Gebunden GZ. 8,5

III. Toil: IVasserbau. 7. Band.

Kulturtechnischer Wasserbau. Vou E. Krïger. Geh. Regierungsrat ordentlicher Professor der Kulturtechnik an der Landwirtschaftlichen Hochschule zu Berlin. Mit 197 Textabbildungen. 1921. Gebunden GZ. 9,5

Der Teichbau. Anloitung zur Anlage und zum Bau von Teichen fur Kulturingenieure, Studierende und praktischo Teichwirte. Von Oberingenieur F. A. Yink. Mit 133 Textfiguren und 3 Tafoln. 1914.

GZ.9

Wahl, Projektierung und Betrieb von Kraftanlagen. Ein Hilrsbuch für Ingenieure, Betriobsleiter, Fabrikbesitzor. Von Friedrich Barth, Oberingenieur an der Bayrischen Landesgewerbeanstalt in Nürnberg. D ritte, umgearbeitete und erweiterte Anflage. Mit 176 Figuren im Text und auf 3 Tafeln. 1922.

Gebunden GZ. 15

Die Wasserkräfte, ihr Ausbau und ihro wirtschaftliche Ausnutzung. Ein technisch-wirtschaftliches Lehr- und Handbuch. Von Bauinspektor Dr.-Ing. Arolf Ludin. 2 Binde. Mit 1087 Abbildungen im Text und auf 11 Tafeln.

- Proisgokrünt von der Akademie des Bauwesens in Berlin. Unverinderter Neudruck. 1922.

Gebunden GZ. 7i)

Über Wertberechnung von Wasserkrijften. Von Dr.-Ing. Adolf Indin, und Dr.-Ing. Dr. rer. pol. Wr. G. Waffenschmidt, Karlsruhe i. B. (Sonderdruck aus, Dur Bauingenieur" 1921, H. 4.) 1921.

GZ. 0,45

Die Grundzahlen (GZ.) enlsprechen den ungefähren Vorkriegsprcisen und ergeben mil dem jeweiligen Entuertungsfaktor (Umrechnungsschlussel) tervielfacht den Derkaufspreis. Uber den zur Zeit geltenden Umurechnungsschlilssel geben alle Buchhandlungen sowic der Verlag bereitwilligst $A$ uskunft. 
BG Politechniki Sląskiej

$n r$ inw.: $102-127780$

Verlag von Julir

Handbiblio thel

Ein Hand- und Nachsah

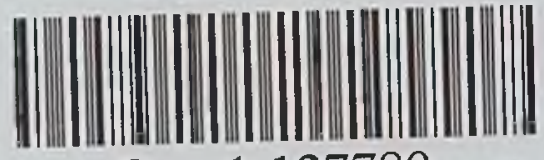

Dyr.1 127780

Her

\section{Robert otzen}

Professor an der Technischen Hochschule zu Hannover

Enthaltend:

Teil I. Hilfswissenschaften ...... . . 5 Bünde

Teil II, Eisenbahnwesen und Strdtebail. . . 9 Bande

Teil III. Wasserbau . . . . . . . 8 Binde

Teil IV. Brỉcken- und Ingenieur-Hochban . . 4 Bănde

III. Teil: IVasscrbau. 2. Band.

See- und Seehafenbau. Von H. Proetcl, Regierungs- und Baurat in Magdeburg. Mit 292 'Textubbildungen. 1921. Gobunden GZ, 7,5

\section{IIr. Teil: Wasserban. 4. Band.}

Kanal- und Schleusenbau. Von Friedrich Engelhard, Regierungsund Baurat an der Regierung zu Oppeln. Mit 303 Textabbildungen und einer farbigen Ubersichtakarte. 1921. Gebunden GZ. 8,5

\section{Toil: Wasserbau. 7. Band.}

Kulturtechnischer Wasserbau. Von E. Krïger, Geh. Regierungsrat ordentlicher Professor der Kulturtechnik an der Landwirtschaftlichen Hochschule zlt Berlin. Mit 197 Textabbildungen. 1921. Gebunden GZ. 9,5

Del' Teichban. Anleitung zur Anlage und zam Bau von Teichen fur Kulturingenieure, Stadierende und praktische Teichwirte. Von Oberingenieur F. A. Zink. Mit 133 Textfiguren und 3 Tafoln. 1914.

GZ.

Wahl, Projektierung und Betrieb von Kraftanlagen. Ein Hilfsbuch far Ingenieure, Betriebsleiter, Fabrikbesitzer. Von Frirdrich Barth. Oberingenieur an der Bayrischen Landeggewerbeanstalt in Nirnberg. Dritte, umgearbeitete und erweiterte Auflage. Mit 176 Figaren im Text und anf 3 Tafeln. 1922.

Gebunden (XZ. 15

Die Wasserkriffte, ihr Ausbau und ihre wirtschaftliche Ausnutznng. Ein technisch-wirtschaftliches Lehr- und Handbuch. Von Bauinspektor Dr.-Ing. Allolf Ludin. 2 Binde. Mit 1087 Abbildungen im Text und naf 11 Tafeln. Preisgekront yon der Akrdemie des Bauwesens in Berlin. Unverunderter Noudruck. 1922.

Gebunden GZ. 7\%s

Über Wertberechnung von Wasserkrüften. Von Dr.-Ing. Adolf Iudin, und Dr.Ing. Dr. rer. pol. W. G. Waffenschmidt, Karlsruho i. B. (Sonderdruck aus .Der Bauingenieur"s 1921, H. 4.) 1921.

GZ. 0,45

Die Grundzahlen (GZ.) exlsprechen den unjelahren Vorkriegsprcisen und ergeben mit dem jewelligen Entwertungsfaktor (Umrechnungsschlthsel) vervilifacht den Verkaufopreis. Uber den sur Zeif oellenden Umrechnungsschlissel geben alle Buchhandlungen souie der Verlus beteitwilligst Auskunfl. 